\title{
AIDS Acquired by Drug Consumption and Other Noncontagious Risk Factors
}

\author{
Pharmacology \& Therapentics55: 201-277, 1992
}

\section{A bstract}

The hypothesis that human immunodeficiency virus (HIV) is a new, sexually transmitted virus that causes AIDS has been entirely unproductive in terms of public health benefits. M oreover, it fails to predict the epidemi ology of AIDS, the annual AIDS risk and the very heterogeneous AIDS diseases of infected persons. The correct hypothesis must explain why: (1) AIDS indudes 25 previously known diseases and two clinically and epi demiologically very different epidemics, one in A merica and Europe, the other in A frica; (2) almost all American (90\%) and European (86\%) AIDS patients are males over the age of 20 , while A frican AIDS affects both sexes equally; (3) the annual AIDS risks of infected babies, intravenous drug users, homosexuals who use aphrodisiacs, hemophiliacs and A fricans vary over 100-fold; (4) many AIDS patients have diseases that do not depend on immunodeficiency, such as Kaposi's sarcoma, lymphoma, dementia and wasting; (5) the AIDS diseases of Americans (97\%) and Europeans (87\%) are predetermined by prior health risks, including long-term consumption of illicit recreational drugs, the antiviral drug AZT and congenital deficiencies like hemophilia, and those of A fricans are A frica-specific. Both negative and positive evidence shows that AIDS is not infectious: (1) the virus hypothesis fails all conventional criteria of causation; (2) over 100-fold different AIDS risks in different risk groups show that HIV is not sufficient for AIDS; ( 3 ) AIDS is only "acquired," if at all, years after HIV 
is neutralized by antibodies; (4) AIDS is new but HIV is a long-established, perinatally transmitted retrovirus; (5) alternative explanations disprove all assumptions and anecdotal cases cited in support of the virus hypothesis; (6) all AIDS-defining diseases occur in matched risk groups, at the same rate, in the absence of HIV; (7) there is no common, active microbe in all AIDS patients; (8) AIDS manifests in unpredictable and unrelated diseases; and (9) it does not spread randomly between the sexes in A merica and Europe Based on numerous data documenting that drugs are necessary for HIV-positives and sufficient for HIV-negatives to develop AIDS diseases, it is proposed that all American/ European AIDS diseases, that exceed their normal background, result from recreational and anti-HIV drugs. A frican AIDS is proposed to result from protein malnutrition, poor sanitation and subsequent parasitic infections. This hypothesis resolves all paradoxes of the virusAIDS hypothesis. It is epidemiologically and experimentally testable and provides a rational basis for AIDS control.

\section{Contents}

1. Virus-AIDS Hypothesis Fails to Predict Epidemiology and Pathology of AIDS

2. Definition of AIDS

2.1. AIDS: 2 epidemics, sub-epidemics and 25 epidemic-specific diseases

2.1.1. The epidemics by case numbers, gender and age

2.1.2. AIDS diseases

2.1.3. AIDS risk groups and risk-group specific AIDS diseases

2.2. The HIV-AIDS hypothesis, or the definition of AIDS

2.3. Alternative infectious theories of AIDS

3. Discrepancies Between AIDS and I nfectious Disease

3.1. Criteria of infectious and noninfectious disease

3.2. AIDS not compatible with infectious disease

3.3. No proof for the virus-AIDS hypothesis

3.3.1. Virus hypothesis fails to meet Koch's postulates

3.3.2. Anti-HIV immunity does not protect against AIDS 
3.3.3. Antiviral drugs do not protect against AIDS

3.3.4. All AIDS-defining diseases occur in the absence of HIV

3.4. N oncorrelations between HIV and AIDS

3.4. 1. Only about half of A merican AIDS is confirmed HIV-antibody positive

3.4.2. A ntibody-positive, but virus-negative AIDS

3.4.3. HIV: just one of many harmless microbial markers of behavioral and clinical AIDS risks

3.4.4. A nnual AIDS risks of different HIV-infected risk groups, induding babies, homosexuals, drug addicts, hemophiliacs and A fricans, differ over 100-fold

3.4.5. Specific AIDS di seases predetermined by prior health risks

3.5. A ssumptions and anecdotal cases that appear to support the virus-AIDS hypothesis

3.5.1. HIV is presumed new because AIDS is new

3.5.2. HIV - assumed to be sexually transmitteddepends on perinatal transmission for survival

3.5.3. AIDS assumed to be proportional to HIV infection

3.5.4. AIDS assumed to be homosexually transmitted in the U.S. and Europe

3.5.5. AIDS assumed to be heterosexually transmitted by A frican "lifestyle"

3.5.6. HIV claimed to be abundant in AIDS cases

3.5.7. HIV to depend on cofactors for AIDS

3.5.8. All AIDS diseases to result from immunodeficiency

3.5.9. HIV to induce AIDS via autoimmunity and apoptosis

3.5.10. HIV assumed to kill T-cells

3.5.11. A ntibodies assumed not to neutralize HIV

3.5.12. HIV claimed to cause AIDS in $50 \%$ within 10 years

3.5.13. HIV said to derive pathogenicity from constant mutation

3.5.14. HIV assumed to cause AIDS with genes unique among retroviruses

3.5.15. Simian retroviruses to prove that HIV causes AIDS 
3.5.16. A necdotal AIDS cases from the general population

3.6. Consequences of the virus-AIDS hypothesis

4. The Drug-AIDS Hypothesis

4.1. Chronological coincidence between the drug and AIDS epidemics

4.2. Overlap between drug-use and AIDS statistics

4.3. Drug use in AIDS risk groups

4.3.1. Intravenous drug users generate a third of all AIDS patients

4.3.2. Homosexual users of aphrodisiac drugs generate about $60 \%$ of AIDS patients

4.3.3. A symptomatic $A Z T$ users generate an unknown percentage of AIDS patients

4.4. Drug use necessary for AIDS in HIV-positives

4.4.1. AIDS from recreational drugs

4.4.2. AIDS from $A Z T$ and $A Z T$ plus confounding recreational drug use

4.5. Drug use sufficient for AIDS indicator diseases in the absence of HIV

4.5.1. Drugs used for sexual activities sufficient for AIDS diseases

4.5.2. Long-term intravenous drug use sufficient for AIDSdefining diseases

4.6. Toxic effects of drugs used by AIDS patients

4.6.1. Toxicity of recreational drugs

4.6.2. Toxicity of AZT

4.7. Drug-AIDS hypothesis correctly predicts the epidemiology and heterogeneous pathology of AIDS

4.8. Consequences of the drug-AIDS hypothesis: Risk-specific preventions and therapies, but resentment by the virus-

AIDS establishment

5. Drugs and Other N oncontagious Risk Factors Resolve all Paradoxes of the Virus-AIDS Hypothesis

6. Why did AIDS Science go Wrong?

6.1. The legacy of the successful germ theory: a bias against noninfectious pathogens 
6.2. Big funding and limited expertise paralyze AIDS research Note Added in Proof

Acknowledgements

References

"It's too late to correct," said the Red Queen. "When you've once said a thing, that fixes it, and you must take the consequences"

— Lewis Carroll, Through the Looking Glass

\section{Virus-AIDS Hypothesis Fails to Predict Epidemiology and Pathology of AIDS}

At a press conference in A pril 1984, the A merican Secretary of Health and Human Services announced that the Acquired I mmunodeficiency Syndrome (AIDS) was an infectious disease, caused by a sexually and parenterally transmitted retrovirus, now termed human immunodeficiency virus (HIV). The announcement predicted an antiviral vaccine within two years (Connor 1987; Adams, 1989; Farber, 1992; Hodgkinson, 1992).

However, the hypothesis has been a complete failure in terms of public health benefits. Despite unprecedented efforts in research and health care, the hypothesis has failed to generate the promi sed vaccine, and it has failed to develop a cure (Thompson, 1990; Savit, 1991; Dues berg, 1992b; Waldholz, 1992). The U.S. Government alone spends annually about \$1 billion for AIDS research and about \$3 billion for AIDS-related health care (N ational Center for Health Statistics, 1992). The situation has become so desperate that the director for AIDS research at the $\mathrm{N}$ ational Institutes of Health $(\mathrm{NIH})$ promotes via press release, eight years after HIV was declared the cause of AIDS, an as yet unedited paper, which has no more to offer than a renewed effort at causing AIDS in monkeys: "The best possible situation would be to have a human virus [HIV] that infects monkeys" (Steinbrook, 1992). This is said nine years after the NIH first started infecting chimpanzees with HIV - over 150 so far at a cost of \$40,000-50,000 apiece-all of which arestill healthy Hilts, 1992; Steinbrook, 1992) (Section 3.3 and J org Eichberg, personal communication). 
Moreover, the virus-AIDS hypothesis has failed completely to predict the course of the epidemic I Institute of M edicine, 1988; Duesberg, 1989C, 1991a; Duesberg and Ellison, 1990; Thompson, 1990; Savitz, 1991). For example, the NIH and others have predicted that AIDS would "explode" into the general population (Shorter, 1987; Anderson and M ay, 1992) and the G lobal AIDS Policy Coalition from Harvard's I nternational AIDS Center declared in J une 1992, “The pandemic is dynamic, volatile and unstable... A n explosion of HIV has recently occurred in Southeast A sia, in Thailand ..." (Mann and the G lobal AIDS Policy Coalition, 1992). But despite widespread alarm the "general population" has been spared from AIDS, although there is a general increase in unwanted pregnancies and conventional venereal diseases (Institute of M edicine, 1988; A ral and Holmes, 1991). Instead, A merican and European AIDS has spread, during the last 10 years, steadily but al most exclusively among intravenous drug users and male homosexuals who were heavy users of sexual stimulants and had hundreds of sexual partners (Sections 2.1.3, 3.3.4 and 4.3.2).

The hypothesis even fails to predict the AIDS diseases an infected person may develop and whether and when an HIV-infected person is to develop either diarrhea or dementia, Kaposi's sarcoma or pneumonia (Grimshaw 1987; A lbonico, 1991a b). In addition the hypothesis fails to explain why the annual AIDS risks differ over 100-fold between different HIV-infected risk groups, i.e recipients of transfusions, babies born to drug-addicted mothers, A merican/ European homosexuals, intravenous drug users, hemophiliacs and Africans (Section 3.4.4).

Clearly a correct medical hypothesis might not produce a cure or the prevention of a disease, as for exampletheories on cancer or sicklecell anemia. However, a correct medical hypothesis must be able to (1) identify those at risk for a disease, (2) predict the kind of disease a person infected or affected by its putative cause will get, (3) predict how soon disease will follow its putative cause and (4) lead to a determination of how the putative agent causes the disease Since this is not true for the virus-AIDS hypothesis, this hypothesis must be fundamentally flawed. Further, it seems particularly odd that an AIDS vaccine cannot be developed, sinceHIV induces highly effective virus-neutralizing 
antibodies within weeks after infection Clark $\notin$ al., 1991; Daar \& al., 1991). These are the same antibodies that are detected by the widely used “AIDS-test" (Institute of M edicine, 1986; Duesberg, 1989;; Rubinstein, 1990).

In view of this, AIDS is subjected here to a critical analysis aimed at identifying a causethat can correctly predict its epidemiology, pathology and progression.

\section{Definition of AIDS}

\section{AIDS: 2 Epidemics, Sub-Epidemics and 25 Epidemic-Specific Diseases}

AIDS includes 25 previously known diseases and two clinically and epidemiologically very different AIDS epidemics, one in A merica and Europe, theother in A frica (Table 1) (Centers for Disease Control, 1987; Institute of M edicine, 1988; World Health Organization, 1992a). The A merican/ European epidemic falls into four sub-epidemics: the male homosexual, the intravenous drug user, the hemophilia and the transfusion recipient epi demics (Table 1).

\subsection{TheE pidernics by CaseNumbers, Gender and Age}

The A merican/ European AIDS epidemics of homosexuals and intravenous drug users are new, starting with drug-using homosexual AIDS patients in Los Angeles and N ew York in 1981 (Centers for Disease Control, 1981; Gottlieb « al., 1981; Jaffe đal., 1983a). By December 1991, 206,392 AIDS cases had been recorded in the U.S. and 65, 979 in Europe (Table 1) (World Health Organization, 1992a; Centers for D is ease Control, 1992b). The U.S. has reported about 30,000-40,000 new cases annually since 1987, and Europe reports about 12,000-16,000 cases annually (World Health Organization, 1992a; Centers for Disease Control, 1992b).

Remarkably for a presumably infectious disease, $90 \%$ of all A merican and $86 \%$ of all European AIDS patients are males Nearly all American (98\%) and European (96\%) AIDS patients are over 20 years old; the remaining $2 \%$ and $4 \%$, respectively, are mostly infants (Table 1 ) (World Health Organization, 1992a; Centers for Disease Control, 1992b). 


\section{Table 1. AIDS Statistics*}

\section{Epidemics}

AIDS total 1985-1991

AIDS annual since 1990

HIV carriers since 1985

Annual AIDS per

HIV carrier

AIDS by sex

AIDS by age, over 20 years

AIDS by risk group male homosexual intravenous drugs transfusions hemophiliacs general population
American

\section{European}

$$
66,000
$$$$
129,000
$$

$30-40,000$

$12-16,000$

$\sim 20,000$

1 million

500,000

6 million

$$
3-4 \%
$$

90\% male

$3 \%$

about $0.3 \%$

$98 \%$

$86 \%$ male

$50 \%$ male

$96 \%$ $?$

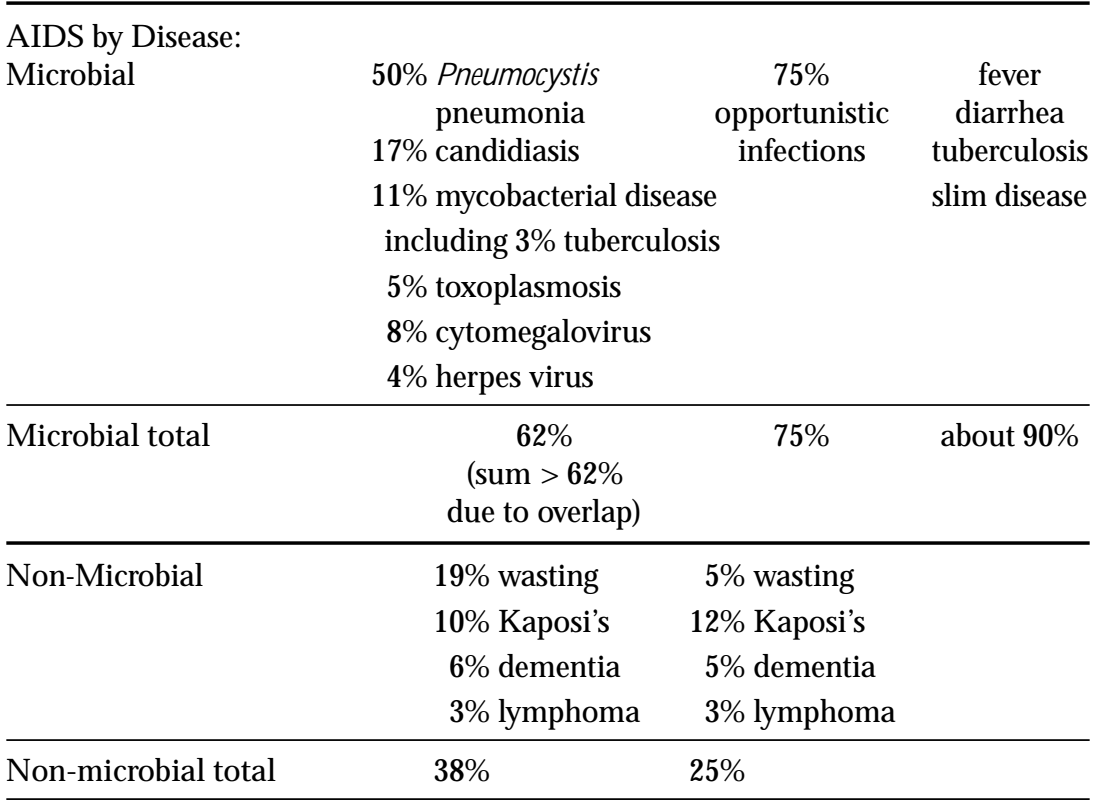

*Data from references cited in Section 2 . There are small ( $\pm 1 \%$ ) discrepancies between some numbers cited here and the most recent surveys cited in the text, because some calculations are based on previous surveys. 
There is very little AIDS among teenagers, as only 789 A merican teenagers have developed AIDS over the last 10 years, induding 160 in 1991 and 170 in 1990 (Centers for Disease Control, 1992b).

Since 1985, 129,066 AIDS cases have been recorded in A frica (World Health Organization, 1992b), mainly from the people of Central Africa (Blattner 1991). Unlikethe American and European cases, the A frican cases are distributed equally between the sexes Quinn $\notin$ al., 1986; Blatther \& al., 1988; Institute of Medicine, 1988; Piot \& al., 1988; Goodgame, 1990) and range “in age from 8 to 85 years” (Widy-Wirski $\notin$ al., 1988).

An AIDS crisis that was reported to "Ioom" in Thailand as of 1990 (Anderson, 1990; Smith, 1990) and that was predicted to "explode" now (M ann and the Global AIDS Policy Coalition, 1992) has generated only 123 A IDS patients from 1984 until J une 1991 (Weniger \& al., 1991).

\subsubsection{AIDS Diseases}

The majority of A merican (62\%) and European (75\%) AIDS patients have microbial diseases or opportunistic infections that result from a previously acquired immunodeficiency (World Health Organization, 1992a; Centers for Disease Control, 1992b). In A merica these include Pneumocystis pneumonia ( $50 \%)$, candidiasis ( $17 \%)$ and mycobacterial infections such as tuberculosis (11\%), toxoplasmosis ( $5 \%$ ), cytomegalovirus ( $8 \%$ ) and herpes virus disease (4\%) (Table 1 ) (Centers for D isease Control, 1992b). Pneumocystis pneumonia is often described and perceived as an AIDS-specific pneumonia. However, Pneumocystis carinii is a ubiquitous fungal parasite that is present in all humans and may become active upon immune deficiency like many others (F reeman, 1979; Pifer 1984; Williford Pifer \& al., 1988; Root-Bernstein, 1990a). Since bacterial opportunists of immune deficiency, like tuberculosis bacillus or pneumococcus, are readily defeated with antibiotics, fungal and viral pneumonias predominate in countries where antibiotics are readily available This is particularly true for risk groups that use antibiotics chronically as AIDS prophylaxis (Callen, 1990; Bardach, 1992). Indeed, young rats treated for several weeks simultaneously with antibiotics and immunosuppressive cortisoneall developed Pneumocystis pneumonia spontaneously (Weller, 1955). 
Contrary to its name, AIDS of many American (38\%) and European $(25 \%)$ patients does not result from immunodeficiency and microbes (Section 3.5.8). Instead, these patients suffer dementia ( $6 \% / 5 \%)$, wasting disease (19\%/5\%), K aposi's sarcoma (10\%/ 12\%) and lymphoma ( $3 \% / 3 \%$ ) (Table 1) (World Health Organization, 1992a; Centers for Disease Control, 1992b).

The A frican epi demic includes diseases that have been long established in Africa, such as fever, diarrhea, tubercul osis and "slim disease" (Tablel) (Colebunders \& al., 1987; Konotey-A hulu, 1987; Pallangyo \& al., 1987; Berkley \& al., 1989; Evans, 1989a; Goodgame, 1990; DeCock \&al., 1991; Gilks 1991). Only about 1\% are Kaposi's sarcomas (WidyWirski $\notin$ al., 1988). The A frican AIDS definition is based primarily on these A frica-specific diseases (Widy-Wirski \& al., 1988) “because of limited facilities for diagnosing HIV infection” (DeCock $\notin$ al., 1991).

\section{1. 3. AIDS Risk Groups and Risk-group Speeific AIDS Dises}

A Imost all A merican (97\%) and European (87\%) AIDS patients come from abnormal health risk groups whose health had been severely compromised prior to the onset of AIDS: $62 \%$ of A merican ( $47 \%$ of European) AIDS patients are male homosexuals who have frequently used oral aphrodisiac drugs (Section 4), 32\% (33\%) are intravenous drug users, $2 \%(3 \%)$ are critically ill recipients of transfusions and $1 \%$ (3\%) are hemophiliacs (Institute of Medicine, 1988; Brenner \&al., 1990; Centers for Disease Control, 1992b; World Health Organization, 1992a). A bout $38 \%$ of the A merican teenage AIDS cases are hemophiliacs and recipients of transfusions, $25 \%$ are intravenous drug users or sexual partners of intravenous drug users and $25 \%$ are malehomosexuals (Centers for D isease Control, 1992b). A pproximately $70 \%$ of the A merican babies with AIDS are born to drug-addicted mothers ("crack babies") and $13 \%$ are born with congenital deficiencies like hemophilia (Centers for Disease Control, 1992b). Only 3\% of the A merican and $13 \%$ of the European AIDS patients are from "undetermi ned exposure categories," i.e from the general population (Table 1) (World Health Organization, 1992a; Centers for Disease Control, 1992b). Some of the differences between European and American statistics may reflect dif- 
ferences in national AIDS standards between different European countries and the U.S. and differences in reporting between the World Health Organization (WHO) and the American Centers for Disease Control (CDC) (World Health Organization, 1992a). By contrast to the American and European AIDS epidemics, African AIDS does not claim its victims from sexual, behavioral or clinical risk groups.

The AIDS epidemics of different risk groups present highly characteristic, country-specific and sub-epidemic-specific AIDS diseases (Table 1 and Table 2):

1. A bout $90 \%$ of the AIDS diseases from A frica are old A frican diseases that are very different from those of the A merican/ European epi demic (Section 2.1.2, Table 1). The A frican diseases do not includePneumocystis pneumonia and candidiasis Goodgame 1990), although Pneumocystis and Candida are ubiquitous microbes in all humans including A fricans (Freeman, 1979; Pifer, 1984).

2. The A merican/ European epidemic falls into several sub-epidemics based on sub-epidemic-specific diseases:

a) A merican homosexuals have Kaposi's sarcoma 20 times more often than all other A merican A IDS patients Selik et al., 1987; Beral $\notin$ al., 1990).

b) Intravenous drug users have a proclivity for tuberculosis (Sections 4.5 and 4.6).

c) "Crack" (cocaine) smokers exhi bit pneumonia and tuberculosis (Sections 3.4.5 and 4.6).

d) Ninety-nine percent of all hemophiliacs with AIDS have opportunistic infections, of which about $70 \%$ arefungal and viral pneumonias, but less than 1\% have Kaposi's sarcoma (Evatt \& al., 1984; Centers for Disease Control, 1986; Selik \& al., 1987; Koerper. 1989).

e) Nearly all recipients of transfusions have pneumonia (Curran \&al., 1984; Selik \&al., 1987). 
f) HIV-positive wives of hemophiliacs exhibit only pneumonia and a few other AIDS-defining opportunistic infections (Section 3.4.4.5).

g) A merican babies exclusively have bacterial diseases (18\%) and a high rate of dementia (14\%) compared to adults (6\%) (Table 1) (Centers for Disease Control, 1992b).

h) U sers of the cytotoxic DNA chain termi nator AZT, prescribed to inhibit HIV, develop anemia, leukopenia and nausea (Section 4.6.2).

3. The Thai mini-epidemic of 123 is made up of intravenous drug users (20\%), heterosexual maleand female "sex workers" ( $50 \%$ ) and male homosexuals (30\%) (Weniger \& al., 1991). A mong the Thais $24 \%$ have tuberculosis, $22 \%$ have pneumonia and other opportunistic infections common in Thailand and $10 \%$ have had septicemia, which is indicative of intravenous drug consumption (Weniger e al., 1991).

\section{The HIV-AIDS Hypothesis, or the Definition of AIDS}

Based on epidemiological data collected between 1981 and 1983, AIDS researchers from the CDC (Centers for Disease Control, 1986) "found in gay culture- particularly in its perceived "extreme" and "non-normative" aspects (that is "promiscuity" and recreational drugs) - the crucial due to the cause of the new syndrome" (Oppenheimer, 1992). Accordingly the CDC had initially favored a "Iifestyle" hypothesis for AIDS.

However, by 1983 immunodeficiency was also recorded in hemophi liacs, some women and intravenous drug users. Therefore, the CDC adopted the "hepatitis B analogy" (Oppenheimer, 1992) and re-interpreted AIDS as a new viral disease, transmitted sexually and parenterally by blood products and needles shared for the injection of intravenous drugs (Francis \& al., 1983; Jaffe e al., 1983b; Centers for Disease Control, 1986; Oppenheimer, 1992). In A pril 1984 the A merican Secretary of Health and Human Services and the virus researcher Robert Gallo announced at a press conference that the new AIDS virus was found. 
Theannouncement was made, and a test for antibody against the virustermed the "AIDS test" - was registered for a patent, before even one A merican study had been published on this virus (Connor) 1987; Adams, 1989; Crewdson, 1989; Culliton, 1990; Rubinstein, 1990). Since then most medical scientists have believed that AIDS is infectious, spread by the transmission of HIV.

According to the virus-A IDS hypothesis the 25 different AIDS diseases and the very different AIDS epidemics and sub-epidemics are all held together by a single common cause, HIV. There are two strains of HIV that are $50 \%$ related, HIV-1 and HIV-2. But as yet only one A merican-born AIDS patient has been infected by HIV-2 (O'Brien \& al., 1992). Since nearly all HIV-positive AIDS cases recorded to date are infected by HIV-1, this strain will be referred to as HIV in this article The HIV-AIDS hypothesis proposes: (a) that HIV is a sexually, parenterally and perinatally transmitted virus, (b) that it causes immunodeficiency by killing T-cells, but on average only 10years after infection in adults and two years after infection in infants-a period that is described as the "Iatent period of HIV" because the virus is assumed to become reactivated in AIDS- and (c) that all AIDS diseases are consequences of this immunodeficiency Coffin $\notin$ al., 1986; I nstitute of Medicine, 1986, 1988; Gallo, 1987; Blattner Æ al., 1988; Gallo and M ontagnier, 1988; Lemp et al., 1990; Weiss and J affe, 1990; Blattner, 1991; Goudsmit, 1992).

Because of this belief, 25 previously known, and in part entirely unrelated diseases have been redefined as AIDS, provided they occur in the presence of HIV. HIV is in practice only detectable indirectly via antiviral antibodies, because of its chronic inactivity even in AIDS patients (Section 3.3). These antibodies are identified with disrupted HIV, a procedure that is termed the "AIDS test" (Institute of M edicine, 1986; Rubinstein, 1990). Virus isolation is a very inefficient and expensive procedure designed to activate dormant virus from leukocytes. It depends on the activation of a single, latent HIV from about 5 million leukocytes from an antibody-positive person. For this purpose the cells must be propagated in vitro away from the virus-suppressing immune system of the host. Virus may then be detected weeks later in the culture medium (Weiss $\notin$ al., 1988; D uesberg 1989c). 
A ntibodies against HIV were originally claimed to be present in most (88\%) AIDS patients (Sarngadharan \&al., 1984), but have since been confirmed in no more than about $50 \%$ of the A merican AIDS patients (Institute of Medicine, 1988; Selik et al., 1990). The rest are pre sumptively diagnosed based on disease criteria outlined by the CDC (Centers for Disease Control, 1987; Institute of M edicine, 1988). Because of confidentiality laws more tests are probably done than are reported to the CDC.

Since the "AIDS test" became available in 1985, over 20 million tests have been performed annually in the U.S. alone on blood donors, servicemen and applicants to the A rmy, AIDS patients and many others, and millions more are performed in Europe, Russia, A frica and other countries (Section 3.6). On the basis of such widespread testing, clearly the most comprehensive in the history of virology, about 1 million, or $0.4 \%$ of mostly healthy A mericans (Curran \& al., 1985; Institute of M edicine, 1988; Duesberg, 1991a; Vermund. 1991; Centers for Disease Control, 1992a), 0.5 million, or $0.2 \%$ of Western Europeans (M ann \& al., 1988; Blattner, 1991; World Health Organization, 1992a), 6 million, or $10 \%$ of mostly healthy Central Africans (Curran \& al., 1985; Institute of M edicine, 1988; Piot \& al., 1988; Goodgame 1990; Blattner, 1991; Anderson and May, 1992) and 300,000 or 0.5\% of healthy Thais (Weniger \& al., 1991) are estimated to carry antibodies to HIV (Table 1). According to the CDC the incidence of HIV-2 is "relatively high" in Western A frica with a record of $9 \%$ in one community, but "exceedingly low" in the U.S. where not even one infection was detected among 31,630 blood donors (O’Brien đal., 1992).

\section{Alternative Infectious Theories of AIDS}

In view of the heterogeneity of the AIDS diseases and the difficulties in reducing them to a common, active microbe, several investigators have proposed that AIDS is caused by a multiplicity of infectious agents such as viruses and microbes, or combinations of HIV with other microbes (Sonnabend \& al., 1983; Konotey-A hulu, 1987, 1989; Stew. art, 1989; Cotton, 1990; Goldsmith, 1990; Lemaitre \& al., 1990; RootBernstein, 1990a, Balter, 1991; Lo \& al., 1991).

However, the proponents of infectious AIDS who reject HIV as the 
sole cause or see it as one of several causes of AIDS have failed to establish a consistent alternative to or cofactor for HIV. Instead, they typically blame AIDS on viruses and microbes that are widespread and either harmless or not life-threatening to a normal immune system, such as Pneumocystis, cytomegalovirus, herpes virus, hepatitis virus, tubercul osis bacillus, Candida, mycoplasma, treponema, gonococci, toxoplasma and cryptosporidiae (Section 3.5.7) (Freeman, 1979; M ims and W hite, 1984; Pifer, 1984; Evans, 1989c; Mills and M asur, 1990; Bardach, 1992). Since such microbes are more commonly active in AIDS patients than in others, they argue that either chronic or repeated infections by such microbes would generate fatal AIDS Sonnabend et al., 1983; Stewart, 1989; Mills and M asur, 1990; Root-Bernstein, 1990a, C).

Yet all of these microbes also infect people with normal immune systems either chronical ly or repeatedly without causing AIDS (F reeman, 1979; Mims and White, 1984; Evans, 1989c; Mills and M asur, 1990). It follows that pathogenicity by these mi crobes in AIDS patients is a consequence of immunodeficiency acquired by other causes (Duesberg, 1990c, 1991a). This is why most of these infections are termed opportunistic.

\section{Discrepancies Between AIDS and I nfectious D isease}

\subsection{Criteria of Infectious and Noninfectious Disease}

The correct hypothesis explaining the cause of AIDS must predict the fundamental differences between the two main AIDS epidemics and the bewildering heterogeneity of the 25 AIDS diseases In addition, the cause of A merican/ European AIDS should make clear why-in an era of ever-improving health parameters, population growth and decreasing mortality (The Software Toolworks World A tlas ${ }^{\mathrm{TM}}$, 1992; A nderson and M ay, 1992) — suddenly a subgroup of mostly 20- to 45-year-old males would die from di verse mi crobial and nonmicrobial diseases. The mortality from all infectious diseases combined has been reduced to less than $1 \%$ in the Western World (Cairns, 1978) through advanced sanitation and nutrition (Section 6) (McKeown, 1979; M oberg and Cohn, 1991; Oppenheimer, 1992). Further, 20- to 45-year-olds are the 
least likely to die from any disease ( $M$ ims and White, 1984). Their relative immunity to all di seases is why they are recruited as soldiers. The correct AIDS hypothesis would also have to explain why only a small group of about 20,000 A fricans have developed AIDS diseases annually since 1985 (Table 1), during a time in which Central A frica enjoyed the fastest population growth in the world, i.e 3\% (The Software Toolworks World Atlas ${ }^{\mathrm{TM}}$, 1992).

The sudden appearance of AIDS could signal a new microbe, i.e infectious AIDS. Yet the suddenness of AIDS could just as well signal one or several new toxins, such as the many new psychoactive drugs that have become popular in A merica and Europe since the Vietnam War (Section 4).

Based on common characteristics of all orthodox infectious diseases, infectious AIDS would be predicted to:

(1) Spread randomly between the sexes. This is just as true for venereal as for other infectious diseases (Judson \&al., 1980; Haverkos, 1990).

(2) Cause primary disease within weeks or months after infection, because infectious agents multiply exponentially in susceptible hosts until stopped by immunity. They are self-replicating, and thus fast acting toxins. (Although "slow" viruses are thought to be pathogenic long after neutralization by antiviral immunity (Evans 1989c), slow pathogenicity by a neutralized virus has never been experimentally proven (Section 6.1).)

(3) Coincide with a common, active and abundant microbe in all cases of the same disease (I nactive microbes or microbes at low concentrations are harmless passengers, eg. Iysogenic bacteriophages, endogenous and latent retroviruses (Weiss \& al., 1985), latent herpes virus or latent ubiquitous Pneumocystis and Candida infections (F reeman, 1979; Pifer, 1984; Williford Pifer \& al., 1988). Hibernation is a proven microbial strategy of survival, which allows indefinite coexistence with the host without pathogenicity.)

(4) Coincides with a microbe that lyses or renders nonfunctional more cells than the host can spare or regenerate

(5) Generate a predictable pattern of symptoms. 
By contrast non-infectious AIDS, caused by toxins, would be predicted to:

(1) Spread nonrandomly, according to exposure to toxins. For example, lung cancer and emphysema were observed much more frequently in men than in women 20 years ago, because men consumed much more tobacco than women 30-40 years ago (Cairns, 1978).

(2) Follow intoxication after variable intervals as determined by lifetime dosage and personal thresholds for disease These intervals would be considerably longer than those between microbes and disease, because microbes are self-replicating toxins. For example, lung cancer and emphysema are "acquired" only after 10-20 years of smoking, and liver cirrhosis is "acquired" only after 10-20 years of alcoholism.

(3) M anifest toxin-specific and intoxication site-specific diseases, eg. cigarettes causing lung cancer and alcohol causing liver cirrhosis.

\subsection{AIDS Not Compatible with I nfectious Disease}

All direct parameters of AIDS are incompati ble with classical criteria of infectious disease:

(1) Unlike conventional infectious diseases, induding venereal diseases (J udson \& al., 1980), A merican/ European AIDS is nonrandomly (90\%) restricted to males, although no AIDS disease is male-specific (Table 1).

(2) The long and unpredictable intervals between infection and "acquiring" primary AIDS symptoms-averaging two years in infants and 10 years in adults, and termed "latent periods of HIV" - stand in sharp contrast to the short intervals of days or weeks between infection and primary di sease observed with all classical viruses, induding retroviruses (Duesberg, 1987; Duesberg and Schwart, 1992). These short intervals reflect thetime periods, that all exponentially growing microbes with generation times of half-hours, and viruses induding HIV (Clark \& al., 1991; Daar \& al., 1991) with generation times of 8-48 hr need to reach immunogenic and thus potentially pathogenic concentrations (Fenner \& al., 1974; F reeman, 1979; M ims and White, 1984). Once stopped by immunity, conventional viruses and microbes are no longer 
pathogenic. Thus long latent periods between immunity against a microbe and a given disease are incompatible with conventional microbial causes, including HIV (Section 3.5.14). The discrepancy of eight years between the hypothetical "latent periods of HIV" in infants and adults presents a secondary paradox.

Nevertheless, HIV could possibly play a role in AIDS if it wereconsistently reactivated by an "acquired immunodeficiency" - 10 years after it was neutralized by antibodies (Section 3.4.2) — just as Candida, Pneumocystis and cytomegal ovirus play roles in AIDS if they are activated by "acquired immunodeficiency." However, HIV is nearly always inactive even during acquired immunodeficiency (Sections 3.3.1 and 3.5.6). In the absence of HIV reactivation during AIDS, long hypothetical latent periods are simply statistical artifacts. They are conceived to link HIV with AIDS and to buy time for the real causes of AIDS to generate AIDS-defining diseases.

(3) There is no active microbe common to all AIDS patients, and no common group of target cells are lysed or rendered nonfunctional (Sections 3.3 and 3.5.10).

(4) There is no common, predictable pattern of AIDS symptoms in patients of different risk groups. I nstead, different risk groups have characteristic AIDS diseases (Sections 2.1.3, 3.4.4 and 3.4.5).

Thus AIDS does not meet even one of the classical criteria of infectious disease In a recent response to these arguments, Goudsmit, a proponent of the HIV-AIDS hypothesis, confirmed that "AIDS does not have the characteristics of an ordinary infectious disease This view is incontrovertible" (Goudsmit 1992). Likewise, the epidemiologists Eggers and Weyer conclude that "the spread of AIDS does not behave li ke the spread of a disease that is caused by a single sexually transmitted agent" (Eggers and Weyer, 1991) and hence have "simulated a cofactor [that] cannot be identified with any known infectious agent" "Weyer and Eggers, 1990). Anderson and M ay (1992) had to invent “assortative scenarios" for different AIDS risk groups to reconcile AIDS with infectious disease I ndeed, AIDS would never have been accepted as infectious without the numerous unique assumptions that have been made to accommodate HIV as its cause (Sections 3.5 and 6.1). 


\subsection{No Proof for the Virus-AIDS Hypothesis}

Despite research efforts that exceed those on all other viruses combined and have generated over 60,000 papers on HIV (Christensen, 1991), it has not been possible to prove that HIV causes AIDS. These staggering statistics illustrate that the virus-AIDS hypothesis is either not provable or is very difficult to prove

Proof for pathogenicity of a virus depends either on (1) meeting Koch's classical postulates, (2) preventing pathogenicity through vaccination, (3) curing disease with antiviral drugs or (4) preventing disease by preventing infection. However, the HIV-hypothesis fails all of these criteria.

\section{3. 1. Virus Hypothesis Fails to Mee Kodh's Postulates}

Koch's postulates may be summarized as follows: (i) the agent occurs in each case of a disease and in amounts sufficient to cause pathological effects; (ii) the agent is not found in other diseases; and (iii) after isolation and propagation in culture the agent can induce the disease anew (Merriam-Webster, 1965; Weiss and Jaffe, 1990).

But:

(i) HIV is certainly not present in all AIDS patients, and even antibody against HIV is not found in all patients who have AIDS-defining diseases HIV is not even present in all persons who die from multiple indicator-diseases plus general immune system failure- the paradigm AIDS cases (Sections 3.4 and 4.5). In addition, HIV is never present "in amounts sufficient to cause pathological effects" based on the following evidence:

(1) On average only 1 in 500 to $3000 \mathrm{~T}$-cells, or 1 in 1500 to 8000 leukocytes of AIDS patients are infected by HIV Schnittman $₫$ al., 1989; Simmonds \& al., 1990). (A bout 35\% of leukocytes are T-cells (Walton \& al., 1986).) A recent study, relying on in situ amplification of a proviral HIV DNA fragment with the polymerase chain reaction, detects HIV DNA in 1 of 10 to 1 of 1000 leukocytes of AIDS patients. However, the authors acknowledge that the in situ method cannot distinguish between intact and defective proviruses and may include false- 
positives, because it does not characterize the amplified DNA products (Bagasra \& al., 1992). Indeed the presence of 1 provirus per 10 or even 100 cells is exceptional in AIDS patients. This is why direct hybridization with viral DNA, a technique that is capable of seeing 1 provirus per 10 to 100 cells, typically fails to detect HIV DNA in AIDS patients (Duesberg, 1989C). According to one study, "Themost striking feature ... is the extremely low level of HIV provirus present in circulating PBM Cs (peripheral blood mononuclear cells) in most cases" Simmonds \&al., 1990).

Since on average only $0.1 \%$ (1 out of 500 to 3000) of T-cells are ever infected by HIV in AIDS patients, but at least 3\% of all T-cells are regenerated (Sprent 1977; Guyton, 1987) during the two days it takes a retrovirus to infect a cell (Duesberg, 1989c), HIV could never kill enough T-cells to cause immunodeficiency. Thus even if HIV killed every infected T-cell (Section 3.5.10), it could depleteT-cells only at $1 / 30$ of their normal rate of regeneration, let alone activated regeneration. The odds of HIV causing T-cell deficiency would be the same as those of a bicycle rider trying to catch up with a jet airplane

(2) It is also inconsistent with a common pathogenic mechanism that the fraction of HIV-infected leukocytes in patients with the same AIDS diseases varies 30 - to $100-$ fold. One study reports that the fraction of infected cells ranges from 1 in 900 to 1 in 30,000 Simmonds $\mathrm{A}$ al., 1990), and another reports that it ranges from 1 in 10 to 1 in 1000 (Bagasra \& al., 1992). In all conventional viral diseases the degree of pathogenicity is directly proportional to the number of infected cells.

(3) It is entirely inconsistent with HIV-mediated pathogenicity that there are over 40-times more HIV-infected leukocytes in many healthy HIV carriers than in AIDS patients with fatal AIDS Simmonds $\&$ al., 1990; Bagasra \& al., 1992). Simmonds \& al. report that there are from 1 in 700 to 1 in 83,000 HIV-infected leukocytes in healthy HIV carriers and from 1 in 900 to 1 in 30,000 in AIDS patients. Bagasra \& al. report that there are from 1 in 30 to 1 in 1000 infected leukocytes in healthy carriers and from 1 in 10 to 1 in 1000 in patients with fatal AIDS. Thus there are healthy persons with 43 times (30,000: 700) and 33 times (1000:30) more HIV-infected cells than in AIDS patients

(4) In terms of HIV's biological function, it is even more important 
that the levels of HIV RNA synthesis in AIDS are either extremely low or even nonexistent. Only 1 in 10,000 to 100,000 leukocytes express viral RNA in $50 \%$ of AIDS patients. In the remaining $50 \%$ no HIV expression is detectable (Duesberg, 1989C; Simmonds et al., 1990). The very fact that amplification by the polymerase chain reaction must be used to detect HIV DNA or RNA (Semple eal., 1991) in AIDS patients indicates that not enough viral RNA can bemade or is made in AIDS patients to explain any, much less fatal, pathogenicity based on conventional precedents (Duesberg and Schwartz, 1992). The amplification method is designed to detect a needle in a haystack, but a needle in a haystack is not sufficient to cause a fatal disease, even if it consists of plutonium or cyanide

(5) In several AIDS diseases, that are not caused by immunodeficiency (Section 3.5.8), HIV is not even present in the diseased tissues, eg. there is no trace of HIV in any Kaposi's sarcomas Salahuddin \& al., 1988) and there is no HIV in neurons of patients with dementia, because of the generic inability of retroviruses to infect nondividing cells like neurons (Sections 3.5.8 and 3.5.10) (Duesberg, 1989C).

As a result, there is typically no free HIV in AIDS patients (Section 3.5.6). Indeed, the scarcity of infectious HIV in typical AIDS patients is the reason that neutral izing antibodies, rather than virus, have become the diagnostic basis of AIDS. It is also the reason that on average 5 million leukocytes of HIV-positives must be cultured to activate ("isolate") HIV from AIDS patients. Even under these conditions it may take up to 15 different isolation efforts (!) to get just one infectious virus out of an HIV carrier (Weiss etal., 1988). The scarcity of HIV and HIV-infected cells in AIDS patients is also the very reason for the notorious difficulties experienced by leading A merican (Hamilton, 1991; Palca, 1991a; Crewdson, 1992) and British (Connor, 1991, 1992; Weiss, 1991) AIDS researchers in isolating, and in attributing credit for isolating HIV from AIDS patients.

(ii) HIV does not meet Koch's second postulate, because it is found not just in one, but in 25 distinct diseases, many as unrelated to each other as dementia and diarrhea, or Kaposi's sarcoma and pneumonia (Table 1, Section 2.1.2). 
(iii) HIV also fails Koch's third postulate, because it fails to cause AIDS when experimentally inoculated into dhimpanzees which make antibodies against HIV just like their human cousins (Blattner $\notin$ al., 1988; Institute of M edicine, 1988; Evans 1989b; Weiss and J affe, 1990). Up to 150 chimpanzees have been inoculated since 1983 and all arestill healthy (Duesberg, 1989c) (J org Eichberg, personal communication, see Section 1). HIV also fails to cause AIDS when accidentally introduced into humans (Duesberg, 1989c, 1991a).

There is, however, a legitimatelimitation of Koch's postulates, namely that most microbial pathogens are only conditionally pathogenic (Stewart, 1968; M cKeown, 1979; M oberg and Cohn, 1991). They are pathogenic only if the immune system is low, allowing infection or intoxication of the large numbers of cells that must be killed or altered for pathogenicity. This is true for tuberculosis bacillus, cholera, influenza virus, polio virus and many others (Freeman, 1979; M ims and White, 1984; Evans, 1989c).

However, even with such limitations HIV fails the third postulate The scientific literature has yet to prove that even one heal th care worker has contracted AIDS from the over 206,000 A merican AIDS patients during the last 10 years, and that even one of thousands of scientists has developed AIDS from HIV, which they propagate in their laboratories and companies (Section 3.5.16) (Duesberg, 1989, 1991a). AIDS is likewise not contagious to family members living with AIDS patients for at least 100 days in the same household (Friedland \& al., 1986; Sande, 1986; Hearst and Hulley, 1988; Peterman \& al., 1988). However the CDC has recently claimed that seven health care workers have developed AIDS from occupational infection Centers for Disease Control, 1992C). But the CDC has failed to provide any evidence against nonoccupational causation, such as drug addiction (see Section 4). Indeed thousands of health care workers, eg. 2586 by 1988 (Centers for Disease Control, 1988), have developed AIDS from nonprofessional causes. In addition the CDC has failed to report the AIDS diseases of the seven patients and those of their putative donors, has failed to report their sex (see next paragraph) and whether these patients developed AIDS only after AZT treatment (see Section 4) (Centers for Disease Control, 1992C). 
The failure of HIV to meet the third postulate is all the more definitive since there is no antiviral drug or vaccine I magine what would happen if there were 206,000 polio or viral hepatitis patients in our hospitals and no health care workers were vaccinated!

Contrary to expectations that heal th care workers would bethe first to be affected by infectious AIDS, the AIDS risk of those health care workers that have treated the 206,000 A merican AIDS patients is in fact lower than that of the general population, based on the following data. The CDC reports that about $75 \%$ of the A merican health care workers are females, but that $92 \%$ of the AIDS patients among health care workers are males (Centers for Disease Control, 1988). Thus the AIDS risk of male health care workers is 35 times higher than that of females, indicating nonprofessional AIDS causes.

Moreover, the CDC reports that theincidence of AIDS among health care workers is percentagewise the same as that in the general population, i.e by 1988, 2586 out of 5 million health care workers, or 1/ 2000 had developed AIDS (Centers for Disease Control, 1988), by the same time 110,000 out of the 250 million A mericans, or $1 / 2250$, had developed AIDS (Centers for Disease Control, 1992b). Since health care workers are nearly all over 20 years old and since there is virtually no AIDS in those under 20 (Table 1 ), but those under 20 make up about $1 / 3$ of the general population, it can be estimated that the AIDS risk of health care workers is actually $1 / 3$ lower (1/3 times $1 / 2000$ ) than that of the general population - hardly an argument for infectious AIDS.

In view of this, leading A IDS researchers have acknowledged that HIV fails Koch's postul ates as the cause of AIDS (Blattner \& al., 1988; Evans, 1989a, b; Weiss and J affe, 1990; Gallo, 1991). Nevertheless, they have argued that the failure of HIV to meet Koch's postulates invalidates these postulates rather than HIV as the cause of AIDS (Section 6.1) (Evans, 1989b, 1992; Weiss and J affe, 1990; Gallo, 1991). But the failure of a suspected pathogen to meet Koch's postulates neither invalidates the timeless logic of Koch's postulates nor any claim that a sus pect causes a disease (D uesberg, 1989b). It only means that the suspected pathogen cannot be proven responsible for a disease by Koch's postulates-but perhaps by new laws of causation (Section 6). 


\subsubsection{Anti-HIV I mmunity Does Not Protect Against AIDS}

Natural antiviral antibodies, or vaccination, against HIV - which com pletely neutralize HIV to virtually undetectable levels-are consistently diagnosed in AIDS patients with the "AIDS test." Yet these antibodies consistently fail to protect against AIDS diseases (Section 3.5.11) (Duesberg, 1989b, C, 1991a; Evans, 1989a,b). According to Evans, “The dilemma in HIV is that antibody is not protective" (Evans, 1989a).

By contrast, all other viral diseases are prevented or cured by antiviral immunity. Indeed, since J ennerian vaccination in the late 18th century, antiviral immunity has been the only protection against viral disease In view of this HIV researchers have argued that antibodies do not neutralize this virus (Section 3.5.11) instead of considering that HIV may not be the cause of AIDS.

\section{3.3. Antiviral Drugs Do Not Proted Against AIDS}

All anti-HIV drugs fail to prevent or cure AIDS diseases (Section 4).

\subsubsection{All AIDS-defining Diseases Ocaur in the Absence of HIV}

The absence of HIV does not prevent AIDS-defining diseases from occurring in all AIDS risk groups, it only prevents their diagnosis as AIDS (Sections 3.4.4, 4.5 and 4.7).

Thus, there is no proof for the virus-AIDS hypothesis- not even that AIDS is contagious. Instead, the virus-A IDS hypothesis is based only on circumstantial evidence, including epidemiological correlations and anecdotal cases (Sections 3.4 and 3.5).

\subsection{Noncorrelations Between HIV and AIDS}

Leading AIDS researchers acknowledge that correlations are the only support for the virus-AIDS hypothesis. For example, Blattner $\notin$ al. state, “... overwhelming seroepidemiologic evidence (is) pointing toward HIV as the cause of AIDS ... Better methods... show that HIV infection is present in essentially all AIDS patients" (Blattner \& al., 1988). According to an editorial in Science, Baltimore deduces from studies reporting an $88 \%$ correlation between antibodies to HIV and AIDS: "This was the kind of evidence we are looking for. It distinguishes between a virus that was a passenger and one that was the cause" 
(Booth, 1988). The studies Baltimore relied on are those published by Gallo \& al. in Science in 1984 that are the basis for the virus-AIDS hypothesis (Gallo \& al., 1984; Sarngadharan \& al., 1984), but their authenticity has since been questioned on several counts (Beardsley, 1986; Schupach, 1986; Connor, 1987; Crewdson 1989; Hamilton, 1991; Palca, 1991a; Crewdson 1992). Weiss and J affe concur that "the evidence that HIV causes AIDS is epidemiological ..." (Weiss and J affe, 1990), although Gallo concedes that epidemiology is just "one hell of a good beginning" (Gallo, 1991). In view of correlations it is argued that "persons infected with HIV will develop AIDS and those not so infected will not" (Evans, 1989a), or that "HIV ... is the sine qua non for the epidemic" (Gallo, 1991).

But correlations are only circumstantial evidence for a hypothesis. According to Sherlock Holmes, "Circumstantial evidence is a very tricky thing. It may seem to point very straight to one thing, but if you shift your point of view a little, you may find it pointing in an equally uncompromising manner to something entirely different" (Doyle, 1928). The risk in epidemiological studies is that the cause may be difficult to distinguish from noncausal associations. For example, yellow fingers are noncausally and smoking is causally associated with lung cancer. "In epidemiological parlance, the issue at stake is that of confounding" (Smith and Phillips, 1992). This is true for the "overwhelming seroepidemiologic evidence" claimed to support the virus-AIDS hypothesis on the following grounds.

\subsubsection{Only about Half of American AIDS is Confirmed HIV-antibody-positive}

In the U.S. antibodies against HIV are only confirmed in about $50 \%$ of all AIDS diagnoses; the remainder are presumptively diagnosed (Institute of M edicine, 1988; Selik $\notin$ al., 1990). Several studies indicate that the natural coincidence between antibodies against HIV and AIDS dis eases is not perfect, because all AIDS defining diseases occur in all AIDS risk groups in the absence of HIV (Section 4). I ronically, the CDC never records the incidence of HIV in its HIV/ AIDS Survillance Reports (Centers for D isease Control, 1992b).

It follows that the reportedly perfect correlation between HIV and 
AIDS is in reality an artifact of the definition of AIDS and of al lowances for presumptive diagnoses (Centers for Disease Control, 1987; Institute of M edicine, 1988). Since AIDS has been defined exclusively as diseases occurring in the presence of antibody to HIV (Section 2.2), the diagnosis of AIDS is biased by its definition toward a 100\% correlation with HIV. That is why "persons infected by HIV will develop AIDS and ... those not so infected will not" (Evans, 1989a), and why HIV is the "sinequa non" of AIDS (Gallo, 1991).

\subsubsection{Antibooly-positive, but Virus-negativeAIDS}

The correlations between AIDS and HIV are in fact not correlations with HIV, but with anti bodies against HIV (Sarngadharan \& al., 1984; Blattner e al., 1988; Duesberg, 1989c). But antibodies signal immunity against viruses, signal neutralization of viruses, and thus protection against viral disease - not a prognosis for a future disease as is claimed for antibodies against HIV. For example, antibody-positive against polio virus and measles virus means virus-negative, and thus protection against the corresponding viral diseases. The same is true for antibodies against HIV: antibody-positive means very much virus-negative Residual virus or viral molecules are almost undetectable in most antibody-positive persons (Sections 3.3 and 3.5.6). Thus antibodies against HIV are not evidence for a future or current HIV disease unless additional assumptions are made (Section 3.5.11).

\subsubsection{HIV: Just One of Many Harmless Miorobial Markers of Behavioral and Clinical AIDS Risks}

In addition to antibodies against HIV, there are antibodies against many other passenger viruses and mi crobes in AIDS risk groups and AIDS patients (Sections 2.3 and 4.3.2). These include cytomegal ovirus, hepatitis virus, Epstein-Barr virus, Human T-cell Leukemia Virus-I (HTLVI), herpes virus, gonorrhea, syphilis, mycoplasma, amoebae, tuberculosis, toxoplasma and many others (Gallo \& al., 1983; Sonnabend \& al., 1983; Blattner \& al., 1985; M athur-Wagh \& al., 1985; Darrow \& al., 1987; Quinn \&al., 1987; Messiah Æal., 1988; Stewart, 1989; Goldsmith, 1990; Mills and M asur, 1990; Root-Bernstein, 1990a, C; Duesberg, 1991a; Buimovici-Klein \& al., 1988). In addition, there are between 100 and 
150 chronically latent retroviruses in the human germ line ( $M$ artin \& al., 1981; Nakamura \&al., 1991). These human retroviruses are in every cell, not just in a few like HIV, and have the same genetic structure and complexity as HIV and all other retroviruses (Duesberg, 1989C). According to Quinn \& al., "Common to A frican patients with AIDS and outpatient controls and A merican patients with AIDS and homosexual men was the finding of extremely high prevalence rates of antibody to CMV (range, 92-100\%), HSV (range, 90-100\%), hepatitis B virus (range, 78-82\%), hepatitis A virus (range, 82-95\%), EBV capsid antigen (100\%), syphilis (11-23\%), and T. gondii (51-74\%). In contrast, the prevalence of antibody to each of these infectious agents was significantly lower among the 100 A merican heterosexual men ..." (Quinn \& al., 1987). Thus, theincidence of many human parasites, both rare and common, is high in typical AIDS patients and in typical AIDS risk groups (Sections 2.3 and 5). However, none of these microbes are fatal and nearly all are harmless to a normal immune system (Section 2.3).

M ost of these parasites including HIV, have been accumulated by AIDS risk behavior and by clinical AIDS risks (Blattner \& al., 1985; Institute of M edicine, 1988; Stewart 1989). Such behavior indudes the long-term injection of unsterile, recreational "street" drugs and large numbers of sexual contacts promoted by oral and injected aphrodisiac drugs (Section 4) (Dismukes \& al., 1968; Darrow \& al., 1987; DesJ arlais \& al., 1987; Espinoza \& al., 1987; M oss, 1987; M oss \& al., 1987; van Griensven \&al., 1987; DesJ arlais \& al., 1988; Messiah \&al., 1988; Chais. son \& al., 1989; Weiss, S.H., 1989; Deininger \& al., 1990; M cKegney \& al., 1990; Stark \& al., 1990; Luca-M oretti, 1992; Seage e al., 1992). Clinical risk groups, such as hemophiliacs, accumulate such viruses and mi crobes from occasionally contaminated transfusions (Section 3.4.4).

It follows that a high correlation between AIDS and antibodies against one particular virus, such as HIV, does not "distinguish between a virus that was a passenger and one that was a cause" (Baltimore, see above) (Booth 1988). It is an expected consequence or marker of behavioral and clinical AIDS risks, particularly in countries where the percentage of HIV carriers is low (Duesberg, 1991a). In addition to HIV, many other microbes and viruses which are rare and inactive, or just inactive, in the general population, such as hepatitis virus, are "spe- 
cific" for AIDS patients, and thus markers for AIDS risks (Sections 2.2, 2.3 and 4.3.2). For example, $100 \%$ of AIDS patients within certain cohorts, not just 50\% as with HIV (Section 2.2), were shown to have antibodies against, or acuteinfections of, cytomegal ovirus (Gottlieb et al., 1981; Francis, 1983; van Griensven \&al., 1987; Buimovici-Klein \& al., 1988). A comparison of 481 HIV-positive with 1499 HIV-negative homosexual men in Berlin found that the HIV-positives were "significantly more often carriers of antibodies against hepatitis A virus, hepatitis B virus, cytomegalovirus, Epstein-Barr virus and syphilis" (Deininger $\notin$ al., 1990). A nd the frequent occurrence of anti bodies agai nst hepatitis B virus in cohorts of homosexual AIDS patients, termed "hepatitis cohorts," was a precedent, that helped to convince the CDC to drop the "lifestyle" hypothesis of AIDS in favor of the "hepatitis analogy" (Francis e al., 1983; Centers for Disease Control, 1986; Oppenheimer, 1992) (Section 2.2).

The higher the consumption of unsterile, injected drugs, the more sexual contacts mediated by aphrodisiac drugs and the more transfusions received, the more accidentally contaminating microbes will be accumulated (Sections 3.4.4.5, 4.3.2 and 4.5). In A frica antibodies agai nst HIV and hepatitis virus are poor markers for AIDS risks, because millions carry anti bodies against these viruses (Table 1) Quinn $\notin$ al., 1987; Evans, 1989C; Blattner, 1991). Thus it is arbitrary to consider HIV the AIDS "driver" rather than just one of the many innocent microbial passengers of AIDS patients (Francis, 1983), because it is neither distinguished by its unique presence nor by its unique biochemical activity.

\subsubsection{Annual AIDS Risks of Different HIV-infeeted Risk Groups, Induding Babies, Homosexuals, Drug Addi ts, Hemophiliacs and Africans, Differ over 100-fold}

If HIV were the cause of AIDS the annual AIDS risks of all infected persons should be similar, particularly if they are from the same country. Failure of HIV to meet this prediction would indicate that HIV is not a sufficient cause of AIDS. The occurrence of the sameAIDS-defining diseases in HIV-free controls would indicate that HIV is not even necessary for AIDS. 
3.4.4. 1. Critically ill recipients of transfusions. The annual AIDS risk of HIV-infected A merican recipients of transfusions (other than hemophiliacs) is about 50\%, as half of all recipients die within oneyear after receiving a transfusion (Table 2 ) (Ward $\notin$ al., 1989).

\section{Table 2. A nnual AIDS Risks of HIV-infected}

\section{Groups*}

\section{HIV-infected group}

A merican recipients

of transfusions

A merican babies

Male homosexuals

using sexual stimulants

Intravenous drug users

A merican hemophiliacs

German hemophiliacs

A merican teenagers

American general population

Africans

Thais

*Based on controlled studies, it is proposed that the health risks of all HIV-infected AIDS risk groups are the same as those of matched HIV-free controls (Sections 3.4.4, 4 and 5). The virus hypothesis simply claims the specific morbidity of each of these groups for HIV.

Since the AIDS risk of transfusion recipients is much higher than the national 3-4\% average, nonviral factors must play a role(Table 1). I ndeed, about $50 \%$ of A merican recipients of transfusions without HIV also die within 1 year after receiving a transfusion $(\mathrm{Hardy} \notin \mathrm{al} ., 1985 ;$ Ward $\mathrm{A}$ al., 1989), and over $60 \%$ within 3 years (Bove $₫$ al., 1987). M oreover, the AIDS risk of transfusion recipients increases 3-6 times faster with the 
volume of blood received than their risk of infection by HIV $\mathrm{Hardy}$ et al., 1985; Ward Æal., 1989). This indicates that the illnesses that necessitated the transfusions are responsible for the mortality of the transfusion recipients. Yet the virus hypothesis daims the relatively high mortality of A merican transfusion patients for HIV without considering HIV-free controls. The hypothesis also fails to consider that the effects of HIV on transfusion mortality should be practically undetectable in the face of the high mortality of transfusion recipients and its postulate that HIV causes AIDS on average only 10 years after infection.

3.4.4.2. HIV-infected babies The second highest annual AIDS risk is reported for perinatally infected A merican babies, whose health has been compromised by maternal drug addiction or by congenital diseases like hemophilia (Section 2. 1.3). They develop AIDS diseases on average two years after birth (A nderson and M ay, 1988; Blattner \& al., 1988; Institute of M edicine, 1988; Blattner, 1991). This corresponds to an annual AIDS risk of $25 \%$ (Table 2).

Since the AIDS risk of babies is much higher than the national average of 3-4\% (Table 1), nonviral factors must play a role in pediatric AIDS. Based on correlations and controlled studies documenting AIDSdefining diseases in HIV-free babies, it is proposed below that maternal drug consumption (Section 4) and congenital diseases, like hemophilia (Section 3.4.4.5), are the causes of pediatric AIDS. I ndeed, before AIDS surfaced, many studies had shown that maternal drug addiction was sufficient to cause AIDS-defining diseases in newborns (Section 4.6.1). In accord with this proposal it is shown that HIV is naturally a perinatally transmitted retrovirus-and thus harmless (Section 3.5.2).

3.4.4.3. HIV-positivehomosexuals Theannual AIDS risk of HIV-infected male homosexuals with hundreds of sex partners, who frequently use aphrodisiac drugs (Section 4), was originally estimated at about $6 \%$ (Mathur-Wagh $\notin$ al., 1985; A nderson and M ay, 1988; Institute of M edicine, 1988; Lui \& al., 1988; M oss \& al., 1988; Turner \& al., 1989; Lemp Æ al., 1990; van Griensven đe al., 1990; Blattner, 1991). A s more HIVpositives became identified, lower estimates of about $4 \%$ were reported 
(Table 2) (Rezza \& al., 1990; Biggar and the I nternational Registry of Seroconverters, 1990; Munoz \& al., 1992).

Since the annual AIDS risk of such homosexual men is higher than the national average, group-specific factors must be necessary for their specific AIDS diseases. Based on correlations with drug consumption and studies of HIV-free homosexuals, it is proposed here that the cumulative consumption of sexual stimulants and psychoactive drugs determines the annual AIDS risk of homosexuals (Sections 4.4 and 4.5). Indeed, all AIDS-defining diseases were observed in male homosexuals from behavioral risk groups before HIV was discovered and have since been observed in HIV-free homosexuals from AIDS risk groups (Sections 4.5 and 4.7).

In the spirit of the virus-AIDS hypothesis, many of these HIV-free homosexual AIDS cases have been blamed on various retrovirus-like particles, papilloma viruses, other viruses and microbes by researchers who have not investigated drug use, particularly not oral drug use These cases include 153 immunodeficient HIV-free homosexuals with $\mathrm{T} 4 / \mathrm{T} 8$ cell ratios below 1 (Drew $\notin$ al., 1985; Weber \& al., 1986; Novick $\notin$ al., 1986; Collier \& al., 1987; Bartholomew \& al., 1987; Buimovici-K lein e al., 1988) and 23 HIV-free Kaposi's sarcomas (A frasiabi \& al., 1986; Ho \& al., 1989b; Bowden \& al., 1991; Safai \& al., 1991; Castro \& al., 1992; Huang $₫$ al., 1992) (see also Note added in proof).

3.4.4.4. HIV-positiveintravenous drug users. A pplication of the annual AIDS risk of male homosexual risk groups led to valid predictions for the annual AIDS risk of intravenous drug users (Lemp \& al., 1990). Therefore the annual AIDS risk of HIV-infected intravenous drug users was originally estimated to be6\% (Table2) Lemp \& al., 1990; Blattner 1991; Goudsmit. 1992). More recent studies have concluded that the annual AIDS risk of intravenous drug users is about 4\% (Table 2) (Rezza \& al., 1990; Munoz \& al., 1992).

These findings argue against a sexually transmitted cause, because sexual transmission predicts a much higher AIDS risk for homosexuals with hundreds of sexual partners than for intravenous drug users (Section 4) (Weyer and Eggers, 1990; Eggers and Weyer, 1991). Indeed, numerous controlled studies have indicated that the morbi dity and mor- 
tality of intravenous drug users is independent of HIV (Sections 4.4, 4.5 and 4.7). On the basis of such studies it is proposed that the lifetime dose of drug consumption determines the annual AIDS risk of intravenous drug users (Section 4).

3.4.4.5. HIV-positivehemophiliacs The hemophiliacs provide the most accessible group to test the virus hypothesis, because the time of infection can be estimated and because the role of other health risks can be controlled by studying HIV-free hemophiliacs.

A bout 15,000 , or $75 \%$ of the 20,000 A merican hemophiliacs have HIV from transfusions received before the "AIDS test" was developed in 1984 (Tsoukas \& al., 1984; Hardy \& al., 1985; Institute of M edicine, 1986, 1988; Stehr-Green đ al., 1988; Goedert đ al., 1989; Koerper, 1989). Based on limited data and antibodies against selected viral antigens, it is generally estimated that most of these infections occurred between 1978 and 1984 (Evatt $\notin$ al., 1985; J ohnson \& al., 1985; M cG rady \& al., 1987; Goedert \& al., 1989). This high rate of infection reflects the practice, developed in the 1960s and 1970S, of preparing factor VIII from blood pools collected from large numbers of donors J ohnson $\notin$ al., 1985; Aronson, 1988; Koerper, 1989). Since only about 300 of the 15,000 HIV-infected A merican hemophiliacs have developed AIDS annually over the last 5 years (M organ \& al., 1990; Centers for Disease Control, 1992a, b), the annual AIDS risk of HIV-infected A merican hemophiliacs is about $2 \%$ (Table 2). Data from Germany extend these results: about $50 \%$ of the 6000 German hemophiliacs are HIV-positive Koer. per, 1989), and only 37 (1\%) of these developed AIDS-defining diseases during 1991 and 303 (1\% annually) from 1982 until 1991 Bundesge. sundheitsamt (Germany), 1991; Leonhard 1992). An international study estimated the annual AIDS risk of adult hemophiliacs at $3 \%$ and that of children at $1 \%$ over a 5-year period of HIV-infection (Biggar and the International Registry of Seroconverters, 1990).

A ccording to the virus-AIDS hypothesis, one would have expected that by now (about one 10-year-HIV-latent-period after infection) at least $50 \%$ of the 15,000 HIV-positive A merican hemophiliacs would have developed AIDS or died from AIDS. But the $2 \%$ annual AIDS risk indicates that the average HIV-positive hemophiliac would have to 
wait for 25 years to develop AIDS diseases from HIV, which is the same as their current median age The median age of American hemophiliacs has increased from 11 years in 1972, to 20 years in 1982 and to over 25 years in 1986, despitethe infiltration of HIV in 75\% (Johnson etal., 1985; Institute of M edicine, 1986; K oerper 1989). Thus, one could make a logical argument that HIV, instead of decreasing the lifespan of hemophiliacs, has in fact increased it.

Considering the compromised health of many hemophiliacs compared to the general population, it is also surprising, that the $1-2 \%$ annual AIDS risk of HIV-infected hemophiliacs is lower than the $3-4 \%$ risk of the average HIV-infected, nonhemophilic European or A merican (Table 1). There is even a bigger discrepancy between the annual AIDS risks of hemophiliacs and those of intravenous drug users and male homosexuals, which are both about 4-6\% (Table 2). In an effort to reconcile the relatively low annual AIDS risks of hemophiliacs with that of homosexuals, the hematologists Sullivan \&al. (1986) noted "The reasons for this difference remain unclear." A nd Biggar and colleagues (1990) noted that "AIDS incubation ... was significantly faster" for drug users and homosexuals than for hemophiliacs.

In view of the many daims that HIV causes AIDS in hemophiliacs, it is even more surprising that there is not even one controlled study from any country showing that the morbidity or mortality of HIV-positive hemophiliacs is higher than that of HIV-negative controls.

Instead, controlled studies show that immunodeficiency in hemophiliacs is independent of HIV, and that the lifetime dosage of transfusions is the cause of AIDS-defining diseases of hemophiliacs. Studies describing immunodeficiency in HIV-free hemophiliacs are summarized in Table 3 (Tsoukas e al., 1984; AIDS Hemophilia French Study Group, 1985; Ludlam \& al., 1985; Gill \& al., 1986; Kreiss \& al., 1986; Madhok etal., 1986; Sullivan et al., 1986; Sharp e al., 1987; M atheson e al., 1987; A ntonaci \& al., 1988; M ahir e al., 1988; A ledort, 1988; J in \& al., 1989; J ason \&al., 1990; Lang, \& al., 1989; Becherer \& al., 1990). One of these studies even documents an AIDS-defining disease in an HIV-free hemophiliac (Kreiss e al., 1986). I mmunodeficiency in these studies is typically defined by a T 4 to T 8-cell ratio of about 1 or less than 1 , compared to a normal ratio of 2 . 
M ost of the studies listed in Table 3 and additional ones conducted before HIV had been discovered have conduded or noted that immunodeficiency is directly proportional to thenumber of transfusions received over a lifetime (Menitove et al., 1983; Kreiss \& al., 1984; Johnson \& al., 1985; Hardy \& al., 1985; Pollack \& al., 1985; Prince 1992; Ludlum \& al., 1985; Gill \& al., 1986). According to the hematologists Pollack $\notin$ al. (1985) "derangement of immunefunction in hemophiliacs results from transfusion of foreign proteins or a ubiquitous virus rather than contracting AIDS infectious agent." The "ubiquitous virus" was a reference to the virus-AIDS hypothesis but a rejection of HIV, because in 1985 HIV was extremely rare in blood concentrates outside the U.S., but immunodeficiency was observed in Israeli, Scottish and A merican hemophiliacs (Pollack $\notin$ al., 1985). M adhok \& al. also arrived at the conclusion that "clotting factor concentrate impairs the cell mediated immune response to a new antigen in the absence of infection with HIV" (Madhok \& al., 1986). A ledort observed that "chronic recipients ... of factor VIII, factor IX and pooled products... demonstrated significant T-cell abnormalities regardless of the presence of HIV antibody" (Aledort, 1988). Even those who claim that clotting factor does not cause immunodeficiency show that immunodeficiency in hemophiliacs increases with both the age and the cumulative dose of clotting factor received during a lifetime (Becherer $₫$ al., 1990).

One controlled study showed directly that protein impurities of com mercial factor VIII, rather than factor VIII or HIV, were immunosuppressive among factor VIII-treated, HIV-positive hemophiliacs. Over a period of two years the T-cells of HIV-positive hemophiliacs treated with commercial factor VIII dedined two-fold, whilethose of matched HIV-positive controls treated with purified factor VIII remained unchanged (Table 3) de Biasi \& al., 1991).

BeforeAIDS, a multicenter study investigating the immunesystems of 1551 hemophiliacs treated with factor VIII from 1975 to 1979 documented lymphocytopenia in 9.3\% and thrombocytopenia in 5\% (Eyster etal., 1985). Accordingly, AIDS-defining opportunistic infections, including $60 \%$ pneumonias and $20 \%$ tuberculosis, have been recorded in hemophiliacs between 1968 and 1979 (J ohnson \& al., 1985). These transfusion-acquired immunodeficiencies could morethan account for 


\section{Table 3. I mmunosuppression in HIV-negative and-positive Hemophiliacs}

\begin{tabular}{|c|c|c|}
\hline \multirow[b]{2}{*}{ Study } & \multicolumn{2}{|c|}{$\begin{array}{l}\text { Immunosuppression } \\
\text { (T4/ T8 about or less than 1) }\end{array}$} \\
\hline & HIV-negative & HIV-positive \\
\hline I. Tsoukas \& al. (1984) & $6 / 14$ & $9 / 15$ \\
\hline 2. Ludlameal. (1985) & 15 & - \\
\hline 3. French Study Group (1985) & 33 & 55 \\
\hline 4. Sullivan $\notin$ al. (1986) & 28 & 83 \\
\hline 5. Madhok e al. (1986) & 9 & 10 \\
\hline 6. Kreiss et al. (1986) & $6 / 17$ & $22 / 24$ \\
\hline 7. Gill $\notin$ al. (1986) & $8 / 24$ & $30 / 32$ \\
\hline 8. Sharp \& al. (1987) & $5 / 12$ & - \\
\hline 9. Matheson đal. (1987) & 5 & 3 \\
\hline 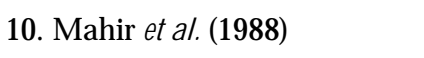 & 6 & 5 \\
\hline 11. A ntonaci $\notin$ al. (1988) & 15 & 10 \\
\hline 12. Aledort (1988) & 57 & 167 \\
\hline 13 J in e al. (1989) & 12 & 7 \\
\hline 14. Lang \& al. (1989) & 24 & 172 \\
\hline 15. Becherer $₫$ al. (1990) & 74 & 136 \\
\hline 16. J ason \& al. (1990) & 31 & - \\
\hline 17. de Biasi \& al. (1991) & - & $10 / 20$ \\
\hline \multicolumn{3}{|c|}{$\begin{array}{l}\text { *In a normal immune system, the T } 4 \text { to T8T-cell ratio is about 2, in immunodefi- } \\
\text { cient persons and in many AIDS patients it is about } 1 \text { or below } 1 \text {. Studies which } \\
\text { list the fraction of immunodeficient hemophiliacs in HIV-positive and HIV-nega- } \\
\text { tive groups indicate, that HIV-positives are more likely to be immunodeficient. This } \\
\text { is because HIV is a marker for the number of transfusions received and transfusion } \\
\text { of foreign proteins causes immune deficiency. The study by de Biasi et al. (1991) } \\
\text { showed that among } 20 \text { HIV-positive hemophiliacs only those } 10 \text { who received com- } \\
\text { mercially purified factor VIII, but not those who received further purified factor } \\
\text { VIII developed immunodeficiency over a period of two years. See text for } \\
\text { references }\end{array}$} \\
\hline
\end{tabular}


the $2 \%$ annual incidence of AIDS-defining diseases in HIV-positive hemophiliacs recorded now (Centers for Disease Control, 1992b). An A merican hematologist who recorded opportunistic infections in hemophiliacs occurring between 1968 and 1979, induding 2 candidiasis and 66 pneumonia deaths, commented in 1983 “. ... it seems possible that many of the unspecified pneumonias in hemophiliacs in the past would be classified today as AIDS" (A ronson, 1983).

It follows that long-term transfusion of foreign proteins causes immunodeficiency in hemophiliacs with or without HIV. The virus hypothesis has simply claimed normal morbidity and mortality of hemophiliacs for HIV, by ignoring HIV-free controls.

Nevertheless several investigators comparing HIV-negative to HIVpositive hemophiliacs have noted that immunodeficiency is more often associated with HIV-positives (Table 3), and have observed that HIV correlates with the number of transfusions received (Tsoukas $\notin$ al., 1984; Kreiss \& al., 1986; Sullivan \& al., 1986; Koerper, 1989; Becherer \& al., 1990). A ccording to Kreiss \& al. "seropositive hemophiliac subjects, on average, had been exposed to twice as much concentrate... as seronegative[s]" (Kreiss \& al., 1986). And according to Goedert \&al. “the prevalence of HIV-1 antibodies was directly associated with the degree of severity (of hemophilia)" Goedert et al., 1989). Thus HIV appears just to be a marker of the multiplicity of transfusions, rather than a cause of immunodeficiency.

The condusion that long-term transfusion of foreign proteins causes immunodeficiency makes three testable predictions:

(1) It predicts that hemophiliacs with "AIDS" would be older than average hemophiliacs. Indeed, the median age of hemophiliacs with AIDS in the U.S. Evatt \& al., 1984; Koerper 1989; Stehr-Green $\notin a l .$, 1989), England (Darby $\notin$ al., 1989) and other countries (Biggar and the International Registry of Seroconverters, 1990; Blattner, 1991) is significantly higher (about 34 years in the U.S.; Iohnson \& al., 1985; Koerper, 1989; Becherer $₫$ al., 1990) than the average age of hemophiliacs (20-25 years in the U.S., see above). Goedert \& al. reported that the annual AIDS risk of 1- to 17-year-old hemophiliacs was 1.5\%, that of 18- to 34 -year-old hemophiliacs was $3 \%$ and that of 64 -year-old hemo- 
philiacs was 5\% Goedert $₫$ al., 1989). This confirms that the cumulative dose of transfusions received is the cause of AIDS-defining diseases among hemophiliacs. According to the hematologist Koerper, "this may reflect lifetime exposure to a greater number of units of concentrate, ..." and to Evatt $\&$ al., "This age bias may be due to differences in duration of exposure to blood products..." Evatt $\notin$ al., 1984; Koerper, 1989).

By contrast, AIDS caused by an autonomous infectious pathogen would be largely independent of the age of the recipient. Even if HIV were that pathogen, the hemophiliac population with AIDS should have the same age distribution as the hemophiliac population over 10 years, because HIV is thought to take 10 years to cause AIDS and nearly all hemophiliacs were infected about 10years ago Johnson $₫$ al., 1985; McGrady \&al., 1987; Koerper, 1989).

(2) Foreign protein-mediated immunodeficiency further predicts that all AIDS diseases of hemophiliacs are opportunistic infections If hemophilia AIDS were due to HIV only $62 \%$ of their AIDS diseases would be opportunistic infections, because $38 \%$ of all A merican AIDS patients have diseases, that are not dependent on, and not consistently associated with, immunodeficiency (Table 1 , Section 3.5.8). These indude wasting disease (19\%), Kaposi's sarcoma (10\%), dementia (6\%) and lymphoma (3\%) (Table 1).

The AIDS pathology of hemophiliacs confirms the prediction of the foreign protein-hypothesis exactly. In A merica 99\% of the hemophiliacs with AIDS have opportunistic infections, of which about $70 \%$ are fungal and viral pneumonias, and less than $1 \%$ have Kaposi's sarcoma (Evatt) eal., 1984; Selik \&al., 1987; Stehr-Green \&al., 1988; Goedert \& al., 1989; Koerper, 1989; Becherer \&al., 1990). The small percentage of Kaposi's sarcoma is due to the nitrite inhalants used by male homosexual hemophiliacs as sexual stimulants (Section 4). There are no reports of wasting disease and dementia in hemophiliacs.

(3) If hemophilia AIDS is due to transfusion of foreign proteins, the wives of hemophiliacs should not contract AIDS from their mates But if it were due to a parenterally or sexually transmitted virus, hemophilia AIDS would be sexually transmissible Indeed, AIDS researchers daim that the wives of hemophiliacs develop AIDS from sexual transmission 
of HIV (Lawrence $\notin$ al., 1990; Weiss and J affe, 1990; Centers for Disease Control, 1992b). For example AIDS researcher Fauci asks: “How about the 60-year-old wife of a hemophiliac who gets infected? Is she cruising, too?" (Booth, 1988).

However, (a) statistical scrutiny and (b) a controlled study unconfirm the hypothesis that hemophilia AIDS is sexually transmissible: (a) The CDC reports that 94 wives of hemophiliacs have been diagnosed with unnamed AIDS diseases since 1985 Centers for Disease Control, 1992b). If one considers that there have been 15,000 HIV-positive hemophiliacs in the U.S. since 1985 and assumes that a third are married, then there are 5000 wives of HIV-positive hemophiliacs. A bout 13 of these women have developed AIDS annually during the 7 years (94:7) from 1985 to 1991 (Centers for Disease Control, 1992b). By contrast, at least 80 of these women would be expected to die per year, considering the human lifespan of about 80 years and that on average at least $1.6 \%$ of all those over 20 years of age die annually. Thus, until controls show that among 5000 HIV-negative wives of hemophiliacs only 67 (80-13) dieannually, the daim that wives of hemophilics diefrom sexual transmission of HIV is unfounded speculation.

M oreover, it has been pointed out that all AIDS-defining diseases of the wives of hemophiliacs are typically age-related opportunistic infections, induding 81\% pneumonia (Lawrence $\notin$ al., 1990). Kaposi's sarcoma, dementia, lymphoma and wasting syndrome are not observed in wives of hemophiliacs (Lawrence $\&$ al., 1990). Thus the virus-AIDS hypothesis seems to claim, once more, normal morbidity and mortality of the wives of hemophiliacs for HIV.

(b) To test the hypothesis that immunodeficiency of hemophiliacs is sexually transmissible the T 4 to T 8 cell-ratio of 41 spouses and female sexual partners of immunodeficient hemophiliacs were analyzed (Kreiss \& al., 1984). Twenty-two of the females had relationships with hemophiliacs with $\mathrm{T}$-cell ratios below 1 and 19 with hemophiliacs with ratios of 1 and greater. The mean duration of relationships was 10 years, the mean number of sexual contacts was 111 during the previous year, and only $12 \%$ had used condoms Kreiss \& al., 1984). SincetheT-cell ratios of all spouses were normal, averaging 1.68-exactly like those of 57 normal controls, the authors concluded that “there is no evidence to 
date for heterosexual or household-contact transmission of T-cell subset abnormalities from hemophiliacs to their spouses..." Kreiss \& al., 1984).

It follows that the foreign protein-hypothesis, but not the HIV-hypothesis, correctly predicts (1) the pathology, (2) the age bias, (3) the noncontagiousness of hemophilia AIDS and (4) HIV-freeimmunodeficiency in hemophiliacs. It also explains the discrepancies between the annual AIDS risks of hemophiliacs and other risk groups (Table 2).

Since the virus hypothesis has becometotally domi nant in 1988, no new studies have described HIV-free immunodeficient hemophiliacs (Table 3) and the question whether HIV-free immunodeficient hemophiliacs ever developed AIDS-defining diseases became a taboo. The study by Jason \& al. described data collected in the mid 1980s, thestudies by J in \& al. and Becherer $₫$ al. collected data before 1988 and the one by de Biasi $₫$ al. compared the effects of purified to unpurified factor VIII only in HIV-positive hemophiliacs (Table 3).

In response to the argument that hemophiliacs only began to develop AIDS diseases when HIV appeared (Centers for Disease Control, 1986; Oppenheimer, 1992), it is proposed that "new" AIDS-defining diseases among hemophiliacs are an indirect consequence of extending their life with factor VIII treatment. Long-term treatment with factor VIII has prolonged the median life of hemophiliacs from 11 in 1972 to 25 in 1986. But contaminating foreign proteins received over periods of 10 years of treatment have also caused immunodeficiencies, and various viral and microbial contaminants have caused infections in some, and HIV infection in $75 \%$. HIV has been a marker for the number of transfusions and factor VIII treatments received, just like hepatitis virus infection was a marker of the number of transfusions received until it was eliminated from the blood supplies (Anonymous 1984; Koerper 1989). Prior to factor VIII therapy most hemophiliacs died as adolescents from internal bleeding (Koerper 1989).

3.4.4.6. HIV-positiveteenagers. The annual AIDS risk of HIV-infected A merican teenagers can be calculated as follows: There are about 30 million A merican teenagers, of which $0.03 \%(10,000)$ Burke $\notin$ al., 1990) to $0.3 \%(100,000)$ (St Louis \& al., 1991) are HIV-positive Since only 
160 developed AIDS in 1991 and only 170 in 1990 Centers for Disease Control, 1992b), their annual AIDS risk is between $0.16 \%$ and $1.7 \%$ (Table 2).

Thus the AIDS risk of teenagers with HIV is less than the national average of 3-4\%. There are no statistics to indicate that the annual risk for AIDS-defining diseases of the HIV-infected teenage population is higher than that of HIV-free controls (Section 3.5.2). Since most A merican teenagers with AIDS are either hemophiliacs (38\%), intravenous drug users ( $25 \%$ ) or male homosexuals (25\%) (Section 2.1.3), it is proposed that the associated risk factors, rather than HIV, are the cause of teenage AIDS (Sections 3.4.4.5 and 4).

3.4.4.7. HIV-positivegeneral U.S. population. The CDC reports that $3 \%$ of all A merican AIDS cases are from the general population, corre sponding to 900-1200 of the 30,000 40,000 annual AIDS cases (Table 1) Centers for Disease Control, 1992b). Since at least 0.03\% to $0.3 \%$, or 80,000 to 800,000 , of the general A merican population of $250 \mathrm{mil}-$ lion are infected (Section 3.5.2) U.S. Department of Health and Human Services, 1990; Burke \& al., 1990; M organ \& al., 1990; St L ouis \& al., 1991), the annual AIDS risk of the general population must be between $0.1 \%$ and $1 \%$ (Table 2). Thus the annual AIDS risk of HIV-infected A mericans of the general population is similar to that of teenagers.

There are no statistics to indicate that the annual AIDS risk of the general HIV-infected population is higher than the annual risk for AIDSdefining diseases in HIV-free controls. Because the incidence of AIDS in the general population is exceedingly low, it is proposed again that it reflects the normal, low incidence of AIDS-defining diseases, rather than HIV-mediated diseases.

3.4.4.8. HIV-positiveAfricans. The annual AIDS risks of HIV-infected A fricans is only $0.3 \%$ (Tables 1 and 2), because 6 million HIV carriers generated 129,000 A I DS cases from 1985 to the end of 1991 (Table 1). There are no controlled studies indicating that the risk for AIDS-defining diseases of HIV-infected A fricans differs from that of HIV-negative controls.

Since the annual AIDS risk of HIV-infected A fricans is (1) 10-times 
lower than the average A merican and European risk, (2) up to 100-fold less than that of A merican/ European risk groups, (3) the same for both sexes unlike that in A merica and Europe and (4) very low considering that the annual mortality in A frica is around $2 \%$ and that AIDS includes the most common African diseases, it is proposed that A frican AIDS is just a new name for indigenous A frican diseases (Section 2.1.2).

Instead of a new virus, malnutrition, parasitic infections and poor sanitary conditions have all been proposed as causes of A frican AIDSdefining diseases (Editorial, 1987; KonoteyA hulu, 1987, 1989; R appoport, 1988; A dams, 1989). Further, it has been proposed that the incidence of tuberculosis, diarrhea, fever and other A frican AIDS-defining diseases may be the same in A fricans with and without HIV (Editorial, 1987). A nd prior to the discovery of HIV, protein malnutrition was identified by the AIDS researchers Fauci \& al. as the world's leading cause of immunodeficiency, particularly in underdeveloped countries (Seligmann \& al., 1984).

Indeed, recent studies document that only 2168 out of 4383 (49.5\%) A frican AIDS patients with slim disease, tuberculosis and other A fricaspecific diseases, who all met the WHO definition of AIDS, wereinfected by HIV. These patients were from A bidjan, I vory Coast De Cock \& al., 1991; Taelman \& al., 1991), Lusaka, Zambia and Kinshasa, Zaire (Taelman \& al., 1991). A nother study reports 135 (59\%) HIV-free AIDS patients from $\mathrm{G}$ hana out of 227 diagnosed by clinical criteria of the WHO. These patients suffered from weight loss, diarrhea, chronic fever, tuberculosis and neurological diseases (Hishida \& al., 1992). An earlier study documents 116 HIV-negatives among 424 A frican patients that meet the WHO definition of AIDS (Widy-Wirski $\notin$ al., 1988). A ccording to an A frican AIDS doctor, "Today, because of AIDS, it seems that A fricans are not allowed to die from these conditions any longer" (Konotey-A hulu, 1987). A nother asks "W hat use is a clinical case definition for AIDS in A frica?" (Gilks, 1991).

The 10-fold difference between the average annual AIDS risks of A fricans and A mericans/ Europeans (Table 1) can thus be resolved as follows: (1) The high AIDS risk of HIV-positive A mericans and Europeans is the product of the low absolute numbers of HIV carriers in the U.S. and Europe compared to A frica (Table 1) and of the concentra- 
tion of HIV in AIDS risks groups, eg. consumers of recreational drugs and the antiviral drug AZT (Section 4) and recipients of transfusions (Section 3.4.3). (2) The low AIDS risk of A fricans is a product of large absolute numbers of HIV carriers and their relatively low, spontaneous and malnutrition-mediated AIDS risks.

3.4.4.9. HIV-positiveThais Given that there have been only 123 Thai AIDS cases in the last 1-2 years and an estimated 300,000 HIV carriers in Thailand (Weniger \& al., 1991), the annual AIDS risk of HIVinfected Thais can be calculated to be less than $0.05 \%$ (Table 2). Since most of these 123 were either intravenous drug users or "sex workers" (Section 2.1.3), it is proposed that these specific health risks are their cause of AIDS (Section 4), rather than the HIV that they share, unspecifically, with 300,000 healthy Thais.

The over 100-fold range in the annual AIDS risks of different AIDS risks groups, summarized in Table 2, clearly indicates that HIV is not sufficient to causeAIDS. It confirms and extends an earlier CDC conclusion: "The magnitude of some of the differences in rates is so great that even gross errors in denomi nator estimates can be overcome" (Hardy \& al., 1985). M oreover, analysis of the specific health risks of each risk group has identified nonviral health risks that are necessary and sufficient causes of AIDS (Table 3 and Section 4.5).

\subsubsection{Spedfic AIDS Diseses Predetermined by Prior Health Risks}

If HIV were the cause of AIDS, every AIDS case should have the same risk of having one or more of the 25 AIDS diseases. However, the data listed above (Section 2.1) and in Table 2 indicate that per AIDS case different risk groups have very specific AIDS diseases:

(1) Male homosexuals have 20 times more Kaposi's sarcoma than all other A merican and European AIDS risk groups.

(2) Hemophiliacs and other recipients of transfusions have fungal and viral pneumonia and other opportunistic infections, and practically no Kaposi's sarcoma or dementia.

(3) The AIDS diseases of the "general population" are either spontaneous, hemophilia- or age-related opportunistic infections. Typical 
examples are cited below (Section 3.5.16).

(4) Babies exclusively have bacterial infections (18\%) and a high rate of dementia (14\%), compared to adults (6\%) (Table I).

(5) A fricans develop A frica-specific AIDS diseases 10 times more and Kaposi's sarcoma 1o times less often than A mericans or Europeans.

The epidemiological data summarized in Section 3.4 indicate that HIV is sufficient to determine neither the annual AIDS risk, nor the type of AIDS disease an infected person may develop. Instead, prior health risks including drug consumption, malnutrition and congenital diseases like hemophilia and their treatments and even the country of residence, predetermine AIDS diseases The correlations between HIV and AIDS that are claimed to support the virus-A IDS hypothesis are not direct, not complete, not distinctive and, above all, not controlled. Controlled studies indicate that the incidence of AIDS-defining diseases in intravenous drug users, male homosexuals practicing risk behavior and hemophiliacs is independent of HIV.

Therefore it is proposed that various group-specific health risk factors, including recreational and antiviral drugs (Section 4) and malnutrition, are necessary and sufficient causes of AIDS. The existence of risk group-specific AIDS-defining diseases in the absence of HIV confirms this conclusion (Sections 3.4.4 and 4.5).

\subsection{Assumptions and Anecdotal Cases that Appear to Support the Virus-AIDS Hypothesis}

The following assumptions and anecdotal cases are frequently daimed to prove the virus-AIDS hypothesis. Despite the popularity of these claims they are either uncontrolled for alternative explanations or they are natural coincidences between HIV infection and naturally-occurring diseases.

\subsubsection{HIV is Presumed New BecauseAIDS isNew}

HIV is presumed new in all countries with AIDS, because AIDS is new (Blattner \& al., 1988; Gallo and M ontagnier, 1988; Weiss and J affe, 1990). The presumed newness of HIV is used as a primary argument for the virus-AIDS hypothesis: ... the time of occurrence of AIDS in each country is correlated with the time of introduction of HIV into 
that country; first HIV is introduced, then AIDS appears" (Blattner et al., 1988) or: "I n every country and city where AIDS has appeared, HIV infection preceded it just by a few years" (Weiss and Jaffe, 1990).

However, according to Farr's law, the age of a microbe in a population is determined by changes in its incidence over time Bregman and Langmuir, 1990). If a mi crobe is spreading from a low to a high incidenceit is new; however, if its incidence in a population is constant, it is old (Fig. 1) (Freeman, 1979; Duesberg, 1991a). Figure 1 shows the incidences of long established microbes in the U.S. population, i.e Candida and Pneumocystiseach at about 100\% (Freeman, 1979; Pifer 1984;

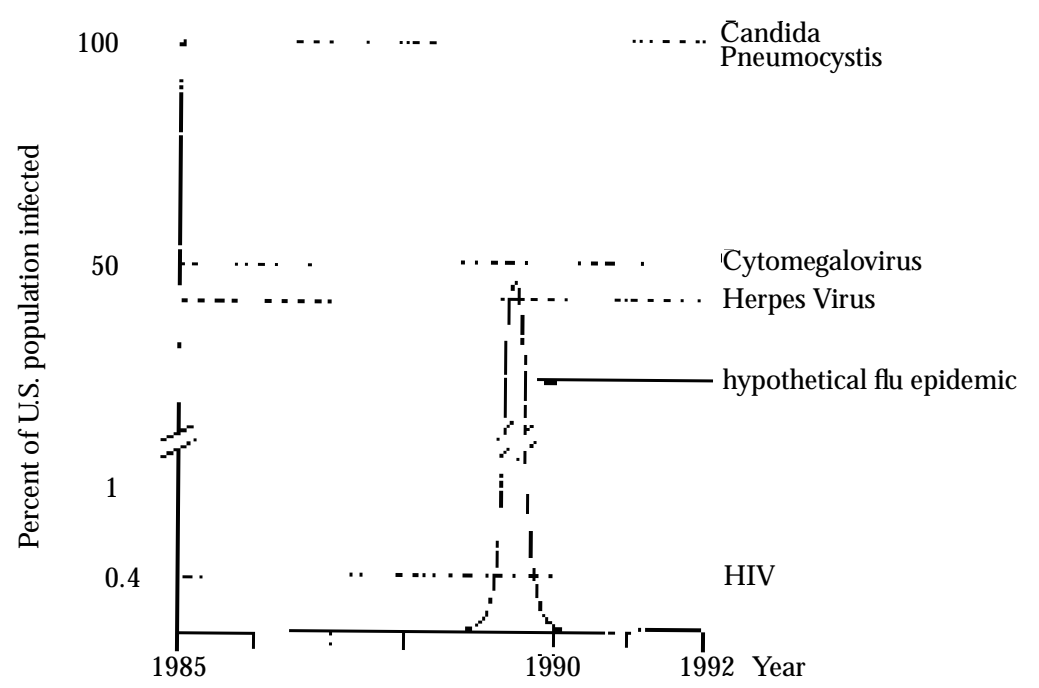

Figure1. Determination of the age of a microbe in a population based on Farr's law. Farr's law holds that a mi crobeentering a population spreads exponentially until a susceptible pool is saturated. Subsequently those microbes that are incompatible with long term survival of the host are el iminated exponentially, to generate a bell-shaped curve The rise and fall of a hypothetical flu epidemic caused by a new strain of influenza virus is an example. But microbes that can coexist with their host become established. Examples are Candida, Pneurnocystis (Freeman, 1979), cytomegal ovirus, herpes virus (Evans, 1989c) and HIV (see text), these are shown at the percentages at which they are established in the American population. 
Williford Pifer \& al., 1988), and cytomegalovirus and herpes virus at about $50 \%$ and $40 \%$, respectively (Evans 1989). In addition, it shows the typical exponential rise and subsequent fall of a hypothetical epidemic by a new influenza virus strain (Freeman, 1979).

Ever since antibodies against HIV were first detected by the "AIDS test" in 1985, the number of antibody-positive A mericans has been fixed at a constant population of 1 million, or $0.4 \%$ (Section 2.2. and Table 1). The U.S. A rmy also reports that from 1985 to 1990 an unchanging $0.03 \%$ of male and female applicants have been HIV-positive Burke $\mathrm{A}$ al., 1990). This is the predicted distribution of a long established virus (Fig. 1 ). Since there are over 250 million uninfected A mericans, and since there is no antiviral vaccine or drug to stop the spread of HIV, the non-spread of HIV in the U.S. in the last 7 years is an infallible indica tion that the A merican "HIV epidemic" is old. The Central A frican HIV epidemic has also remained fixed at about $10 \%$ of the population since 1985 (Section 2.2). Likewise, HIV has remained fixed at 500,000 Europeans since 1988 (World Health Organization, 1992a). The nonspread of HIV confirms exactly the condusion reached below that HIV behaves in a population as a quasi-genetic marker (Section 3.5.2). Hence, the assumption that HIV is new in the U.S. or in A frica is erroneous.

Indeed HIV existed in the U.S. long before its fictitious origin in A frica (Gallo, 1987; Gallo and M ontagnier, 1988; A nderson and M ay, 1992) and its fictitious entry into this country in the 1970 (Shilts, 1987). For example, in the U.S. in 1968 an HIV-positive, male homosexual prostitute died from Kaposi's sarcoma and immunodeficiency (Garry \& al., 1988), and 45 out of 1129 A merican intravenous drug users were found to be HIV-positive in 1971 and 1972 (M oore $₫$ al., 1986).

The putative novelty of HIV is an anthropocentric interpretation of new technology that made it possible to discover HIV and many other latent retroviruses like HTLV-I (Duesberg and SchwartZ, 1992). Indeed, the technology to detect a latent virus like HIV only became available around the time AIDS appeared. Given a new virus-scope, the assertion that HIV is new is just like daiming the appearance of "new" stars with a new telescope Thus the daims that ". . f first HIV is introduced, then AIDS appears" (Blattner \& al., 1988) and that "HIV ... preceded it (AIDS)" (Weiss and J affe, 1990) are ironically more true than the 
proponents of the virus hypothesis had anticipated. HIV preceded AIDS by many, perhaps millions, of years.

\subsubsection{HIV-Assumed to beSexually Transmitted—Depends on Perinatal} Transmission for Sunvival

AIDS is said to be a sexually transmitted disease, because HIV is thought to be a sexually transmitted virus (Section 2.2). However, HIV is not by nature a sexually transmitted virus. Sexual transmission of HIV is extremely inefficient. Based on studies measuring heterosexual and homosexual transmission, it depends on an average of 1000 heterosexual contacts and 100-500 homosexual contacts with antibody-positive people (Rosenberg and Weiner, 1988; L awrence $₫$ al., 1990; Blatther) 1991; Hearst and Hulley, 1988; Peterman \& al., 1988). According to Rosenberg and Weiner, "HIV infection in non-drug using prostitutes tends to be low or absent, implying that sexual activity alone does not place them at high risk" (Rosenberg and Weiner, 1988). M oreover, unwanted pregnancies and venereal diseases, but not HIV infections, have increased significantly in the U.S. sinceHIV has been known (Insttute of M edicine, 1988; A ral and Holmes, 1991). This argues directly against sexual transmission of HIV.

Sexual transmission is so inefficient because there is no free nonneutralized HIV anywhere in antibody-positive persons, particularly not in semen (Section 3.3). In a group of 25 antibody-positive men, only one single provirus of HIV could be found in over 1 million cells of semen in one of the men and no HIV at all was found in the semen of the other 24 (Van Voorhis $\&$ al., 1991). Likewise, HIV could only be isolated or reactivated from ejaculates of 9 out of 95 antibody-positive men by cocultivation with 2 million phytohemagglutinin-activated leukocytes (Anderson $\notin$ al., 1992). No virus or microbe could survive if it depended on a transmission strategy that is as inefficient as 1 in 1000 contacts.

Indeed, HIV depends on perinatal, instead of sexual, transmission for survival - just likeother animal and human retroviruses. Therefore, the efficiency of perinatal transmission must be high. This appears to bethe case Based on HIV-tracking via the "AIDS test," perinatal trans mission from the mother is estimated to be $13-50 \%$ efficient Blattner 
Aal., 1988; Blattner, 1991; Duesberg 1991a; Institute of M edicine, 1988; European Collaborative Study, 1991). This number does not include paternal HIV transmission to the baby via semen, for which there are currently no data. The real efficiency of perinatal transmission must be higher than the antibody-tests suggest, because in a fraction of recipients HIV only becomes immunogenic when its hosts are of an advanced age Quinn \&al., 1986; St L ouis \& al., 1991). During the antibody-negative phase, latent HIV can be detected by the polymerase chain reaction (Rogers \& al., 1989, European Collaborative Study, 1991). This is also true for other perinatally transmitted human (Blattner, 1990; Dues berg, 1991a) and animal retroviruses (Rowe, 1973; Duesberg, 1987).

HIV survival via perinatal transmission leads to two predictions: (1) HIV cannot be inherently pathogenic_-just like all other perinatally transmitted viruses and mi crobes (Freeman, 1979; M ims and White, 1984). N o mi crobe-host system could survive if the microbe were perinatally transmitted and at once fatal. (2) HIV must function as a quasigenetic marker, because it is quasi-nontransmissible by sex, or other natural horizontal modes of transmission, just like known murine retrovirus prototypes (Rowe, 1973; D uesberg 1987). Both predictions are confirmed:

(1) Overwhelming statistical evidence from the U.S. and A frica documents that the risk for AIDS-defining diseases for HIV-positive babies, in the absence of other risk factors (Sections 3.4.4 and 4), is the same as that of HIV-free controls:

(a) "AIDS tests" from applicants to theU.S. A rmy and theU.S. J ob Corps indicate that between 0.03\% (Burke \& al., 1990) and 0.3\% St Louis e al., 1991) of the 17- to 19-year-old applicants are HIV-infected but heal thy. Since there are about 90 million A mericans under the age of 20 , there must be between 27,000 and 270,000 (0.03\%-0.3\% of 90 million) HIV carriers. In Central A frica there are even more, since 1- $2 \%$ of healthy children are HIV-positive Quinn \& al., 1986).

M ost, if not all, of these adolescents must have acquired HIV from perinatal infection for the following reasons: sexual transmission of HIV depends on an average of 1000 sexual contacts, and only 1 in 250 A mericans carries HIV (Table 1). Thus, all positi ve teenagers would 
have had to achieve an absurd 1000 contacts with a positive partner, or an even more absurd 250,000 sexual contacts with random A mericans to acquire HIV by sexual transmission. It follows that probably all of the heal thy adolescent HIV carriers were perinatally infected, as for example the 22-year-old Kimberly Bergalis (Section 3.5.16).

The AIDS risk of perinatally infected babies of the general population can be estimated as follows. Between 27,000 and 270,000 A mericans under the age of 20 carry HIV. But only about 4260 A IDS cases have been recorded in this age group in the last 10 years Centers for Disease Control, 1992b). Therefore, between $85 \%$ and $98 \%$ of HIVinfected youths do not develop AIDS up to 20 years after perinatal infection (Section 2.1). Since the above number includes the AIDS babies from drug-addicted mothers (Sections 3.4.2 and 4), the AIDS risk of HIV-infected babies from mothers that don't use drugs probably reflects normal infant mortality.

(b) A controlled study from A frica compared 218 newborns from HIV-positive mothers to 218 from HIV-negative mothers, and the "rates of prematurity, low birth weight, congenital malformations and neonatal mortality were comparable in the two groups" (Lepage $\&$ al., 1991). The mothers were matched for age and parity and the "frequency of signs and symptoms was not statistically different in the two groups"

(2) Theincidence of HIV in A merican teenagers of different ethnic backgrounds is predictable on genetic grounds. It is about 10-fold higher in blacks than in whites, i.e. 0.3\% compared to 0.03\% (U.S. Department of Health and Human Services, 1990; Burke $\notin$ al., 1990; Blattner 1991; Palca, 1991b; St Louis et al., 1991; Vermund, 1991). HIV was even 50-fold more common in black mothers in inner-city hospitals in New York (36\%) than in whites (0.7\%) (Landesmann \&al., 1987). This reflects the 25- to 50-fold higher incidence of HIV in the blacks' A frican ances tors ( $10 \%$ ) compared to the whites' European ancestors ( 0.2 to $0.4 \%$ ) (Section 2.2, Table 1). Likewise, the different ethnic groups of the Caribbean reflect the distinct HTLV-I incidences of their ancestors in A frica, Europe and J apan, despite generations of coexistence on the Caribbean islands (Blattner, 1990). The unchanging incidence of HIV in the American population (Fig. I) also confirms the view that HIV is a quasi-genetic marker. Since there is virtually no horizontal transmis 
sion of retroviruses, murine retroviruses have functioned as classical genetic markers of mice that could only be distinguished from cellular genes by fastidious genetic crosses (Rowe, 1973).

Thus the assumption that AIDS is sexual ly transmitted by HIV is not consistent with the natural perinatal mode of HIV transmission. If natural transmission of HIV caused a disease, AIDS would be a pediatric disease Instead, HIV is merely a marker of either an average of 1000 sexual contacts and thus of many other possi ble AIDS risks associated with very high sexual activity or of long-term intravenous drug use (Sections 3.4.3 and 5).

\subsubsection{AIDS Assumed to beProportional to HIV I nfection}

Theincidence of AIDS is assumed to be proportional to the incidence of HIV via a constant factor. For example, a 10-fold higher incidence of AIDS in A merican and European males compared to females is assumed to reflect a 10-fold higher incidence of HIV in men (Blattner Æal., 1988: Blattner, 1991; Goudsmit, 1992).

However, there is no evidence that the incidence of HIV is 10 times higher in males than in females of the general A merican and European population, although this is the case for AIDS (Table I). Indeed, the most recent claim for a $90 \%$ bias of HIV for males of the general population (Blattnen 1991) is only supported by a reference to an editorial (Palca, 1991b), which itself provides nothing more than an unreferenced cartoon showing global patterns of HIV infection. According to a CDC epidemiologist, estimates of how HIV is distributed between the sexes of the general population are "approximations" based on the distribution of AIDS (Tim Dondero, CDC, personal communication; see also A nderson and M ay, 1992) - a tautology.

Proportionality between HIV and AIDS via a constant is al so incompatiblewith the following statistics. The U.S. A rmy (Burke et al., 1990) and the U.S. Job Corps (St Louis \& al., 1991) report, based on millions of tests, that HIV has been equally distributed between the sexes among 17- to 21-year-olds of the general population over the last five years for which data were available (Sections 3.5.1 and 3.5.2). Since testing 17to 19-year-olds annually for 5 years is equi valent to testing 17- to 24year-olds, the U.S. A rmy data predict that among 17- to 24-year-olds, 
AIDS risks should be distributed equally between the sexes. However, the CDC documents that $85 \%$ of the AIDS cases among 17- to 24-yearolds were males (Centers for Disease Control, 1992b).

In response to this, some proponents of the virus-AIDS hypothesis have speculated that teenage homosexuals exclude themsel ves from the A rmy. However, Randy Shilts, a homosexual writer, reports that just the opposite is true (Shilts, 1991). M oreover, most teenagers are not as yet aware of a definite homosexual persuasion and are not likely to understand the implications nor to fear the consequences of a positive "AIDS test."

The over 100-fold discrepancies between the AIDS risks of different $\mathrm{HIV}$-infected risk groups also disprove the claim that the incidence of AIDS is proportional via a constant to the incidence of HIV (Table 2). The proportionality between HIV and AIDS only holds if the analysis is restricted to groups with the sameAIDS risks In groups with the same percentage of HIV but with different AIDS risks, AIDS segregates specifically with nonviral AIDS risks, eg. illicit recreational drugs, the antiviral drug AZT (Section 4) and frequent transfusions (Section 3.4.4).

\subsubsection{AIDS Assumed to beHomosexually Transmitted in theU.S. and Europe}

In view of a sexually transmitted AIDS virus, it is paradoxical that AIDS is 90\% male in A merica and $86 \%$ male in Europe (Sections 3.1 and 3.2). Therefore it is assumed that "the virus first got its footing in the U.S." in male homosexuals (Booth, 1988) and has remained with homosexuals because it is transmitted preferentially by anal intercourse and because homosexuals have no sex with heterosexuals (Centers for Disease Control, 1986; Shilts, 1987; Blatter et al., 1988; Institute of M edicine, 1988; Blattner 1991; Bardach 1992; Project I nform, 1992).

However, this assumption is inconsistent with the fact that about $10 \%$ of all males and females prefer anal intercourse (Bolling and Voeller, 1987; Turner \& al., 1989) and that A merican and European heterosexuals have sufficient access to HIV. The females would be infected by HIV-positive, heterosexual intravenous drug users, hemophiliacs, and bisexual males. Thus, if HIV were transmitted by anal intercourse, about the same percentage of women as men should develop AIDS, particu- 
larly since the efficiencies of transmission of anal and vaginal intercourse are approximately the same, eg. between 1 to 100 and 1 to 500 for anal and 1 to 1000 for vaginal intercourse (Blattner, 1991) (see also Section 3.5.2). Yet, despite widespread alarm, this has not occurred in the last 10years in the U.S. (Table 1), although the first women with AIDS had been diagnosed as early as in 1981 (Centers for Disease Control, 1986; Guinan and Hardy, 1987). The risk of women for both HIV infection and AIDS is the same for those who practice anal intercourse as for those who practice other types of intercourse (Guinan and Hardy, 1987).

The preferred anal-transmission hypothesis is also incompatible with the sexually equal distribution of HIV and AIDS in A frica. Since it is postulated that HIV appeared in A merica and A frica at about the same time 10-20 years ago (I nstitute of M edicine, 1986; Blattner \& al., 1988; Gallo and Montagnier, 1988), HIV should have reached the same equilibria between the sexes in all countries.

Instead it is shown below that the male bias for AIDS in A merica and Europe reflects male-specific behavior, induding the facts that over $75 \%$ of all intravenous drug users are males and that long-term consumption of sexual stimulants, like amylnitrite and ethylchloride inhalants, is almost entirely restricted to male homosexuals (Section 4). HIV is just a marker of the many sexual stimulants used to achieve 500-1000 sexual contacts (Section 4). The difference between the AIDS risks of men in America and Europe, namely drugs, and those of A fricans, namely country-specific, but not sex-specific, risk factors (Section 3.4.4.8) resolves the paradox between the different sexual distributions of AIDS in these countries.

\subsubsection{AIDS Assumed to beHeterosexually Transmitted}

by African "Lifestyle"

AIDS in A frica is assumed to affect both genders equally, because HIV is distributed equally between the sexes by "prostitution" Institute of Medicine, 1988), lack of "circumcision" (Klein, 1988; M arx, 1989; Blatther, 1991), A frican “lifestyle” (Quinn \& al., 1987; Blattner \& al., 1988; Goodgame 1990) and "voodoo rituals" (Gallo, 1991). These assumptions are compatible with the sexually equal distributions of HIV and AIDS in A frica. 
However, AIDS in A frica is hard to reconcile with the known efficiency of sexual transmission of HIV. Since it takes 1000 HIV-positive sexual contacts to transmit HIV and about $10 \%$ of all Central A fricans, or 6 million, are HIV-positive (Section 2.2), 6 million A fricans would have had to achieve on average at least 10,000 sexual contacts with random A fricans to pick up HIV. Since this is highly improbable, it is also highly improbable that sexual transmission of HIV is the cause of AIDS in A frica. The true reason for the sexually equal distribution of HIV in A frica is perinatal transmission of HIV (Section 3.5.2). N onsexual, country-specific risk factors are the reason for the "sexually" equal dis tribution of AIDS in A frica (Section 3.4.4.8).

\subsubsection{HIV Clai med to beAbundant in AIDS Cases}

HIV is said to beabundant or viremic in AIDS patients (Baltimore and Feinberg, 1989; Coombs \& al., 1989; Ho \&al., 1989a; Semple \& al., 1991) and thus compatible with orthodox viruses which cause disease only at high titers (D uesberg and Schwart, 1992). In other words HIV is assumed to meet Koch's first postulate (Section 3.3). The assumption is based on two papers which reported HIV titers of $10^{2}$ to $10^{3}$ infectious units per $\mathrm{mL}$ of blood in $75 \%$ of AIDS patients and in $25-50 \%$ of asymptomatic HIV carriers Coombs $₫$ al., 1989; Ho $₫$ al., 1989a). The authors and an accompanying editorial, HIV Reveded, Toward a Natural History of the I nfection (Baltimore and Feinberg, 1989), concluded that these findings established HIV viremia as an orthodox criterion of viral pathogenicity. Viremia of similar titers was recently also implied in someAIDS patients and asymptomatic carriers based on an indirect assay that amplifies HIV RNA in vitro (Semple et al., 1991).

However, several arguments cast doubt on the daim that HIV viremia is relevant for AIDS:

(1) Since viremia was observed in $25-50 \%$ of asymptomatic HIV carriers (Coombs \& al., 1989; Ho \& al., 1989a; Semple \& al., 1991), it cannot be sufficient for AIDS.

(2) Since no viremia was observed in $25 \%$ of the AIDS cases studied by two groups (Coombs \& al., 1989; Ho $₫$ al., 1989a), it is not necessary for AIDS.

(3) Viremia initiated from a previously suppressed virus and observed 
years after infection is a classical consequence, rather than the cause of immunodeficiency. Indeed, many normally latent parasites become activated and may cause chronic "opportunistic infections" in immunodeficient persons, as for example Candida, Pneumocystis herpes virus, cytomegal ovirus, hepatitis virus, tubercul osis bacillus, toxoplasma (Sections 2.3 and 3.4.3) - and sometimes even HIV. It is consistent with this view that HIV viremia is observed more often in AIDS patients than in asymptomatic carriers (Duesberg, 1990c).

(4) The HIV s that make up the "viremias" are apparently not infectious in vivo, because only a negl igi ble fraction of leukocytes, on average only 1 in 1500 to 8000 , of AIDS patients are infected (Section 3.3). The probable reason is that the "viremias" consist of viruses that are neutralized by theantiviral antibodies of "seropositive" AIDS patients (Duesberg, 1992d). Since viruses, as obligatory cellular parasites, can only be pathogenic by infecting cells, these noninfectious viremias cannot be relevant to the cause of AIDS. If assayed in vitro, in the absence of free antiviral antibodies, antibodies may dissociate from neutral ized viruses and thus render the virus infectious for cells in culture This explains the discrepancy between the noninfectious "viremias" in vivo and the relatively high infectivity recorded in vitro Coombs $\notin$ al., 1989; Ho e al., 1989a).

Thus HIV viremia is a rare, predictable consequence of immunodeficiency rather than its cause.

\subsubsection{HIV to Depend on Cofactors for AIDS}

Conceding that HIV is not sufficient to cause AIDS, it is assumed to depend on cofactors. M ontagnier Goldsmith, 1990; Lemaitre \& al., 1990; Balter 1991) and Lo (Lo \& al., 1991) have proposed mycoplasmas that were discovered in their laboratories; Gallo has proposed two viruses, herpes virus- 6 and HTLV-I, which were both discovered in his laboratory (Cotton, 1990; Gallo, 1990, 1991; L usso \& al., 1991). Others have proposed cytomegalovirus, Epstein-Barr virus Quinn \& al., 1987; Evans, 1989a; Root-Bernstein, 1990C), “age” (Evans 1989a; Goed. ert $₫$ al., 1989; Weiss and Jaffe, 1990; Biggar and the I nternational Registry of Seroconverters, 1990), unidentified "coagents" (Weyer and Eggers, 1990; Eggers and Weyer, 1991), “dinical illness promotion fac- 
tors" (Evans, 1989b, 1992) and even "pre-existing immune abnormalities" Ludlam \& al., 1985; Marion \& al., 1989; Ludlam, 1992) as cofactors of HIV.

However, cofactor hypotheses only replace HIV-specific AIDS problems with the following HIV-plus-cofactor-specific AIDS problems:

(1) SinceHIV is extremely rareand dormant in most antibody-positive AIDS patients (Sections 2.2 and 3.3), it is hard to imagine how its various AIDS-allies could benefit from their dormant "cofactor" HIV.

(2) Since HTLV-I is just as dormant and unable to kill cells as HIV (Duesberg, 1987; Blattner, 1990; Duesberg and Schwart, 1992), it is even harder to imagine how one dormant virus could help another dormant virus to generate the biochemical activity that would be necessary to cause a fatal disease

(3) Since mycoplasma (Freeman, 1979; Cotton, 1990; Goldsmith, 1990; Balter 1991), herpes virus-6 (Cotton, 1990; L usso \& al., 1991), cytomegalovirus and Epstein-Barr virus ( $M$ ims and White, 1984; Evans, 1989C) are each very common, if not ubiquitous, parasites (Freeman, 1979; Froesner, 1991), A IDS should develop in most people as soon as they are infected by HIV. Likewise, "aged" people should develop AIDS as soon as they are infected by HIV. Yet not more than 3-4\% of HIVantibody-positive A mericans or Europeans and $0.3 \%$ of antibody-positive A fricans develop AIDS per year (Tables 1 and 2).

M oreover, if infectious cofactors helped HIV to cause AIDS, the AIDS risk of A fricans would beexpected to behigher than that of Americans. This is because the incidence of hypothetical, microbial cofactors in A fricans without AIDS was found to be the same as in those with AIDS, while the incidence of microbial cofactors in A mericans without AIDS risks was significantly lower than in those with AIDS (Section 3.4.3) Quinn et al., 1987). Even the cofactor HIV was present in 6\% of A frican AIDS-free controls Quinn $\notin$ al., 1987). Yet the annual AIDS risk of HIV-infected A fricans is 10-times lower than that of A mericans (Table 1).

(4) Contrary to the claims that "age" is an AIDS cofactor of HIV, the virus-AIDS hypothesis postulates that the latent period for HIV is longer in adults (10years) than in children (2 years) (Section 2.2). How- 
ever, the proposal that "age" is a cofactor for HIV becomes more compelling the more the hypothetical "Iatent period" of HIV grows. Clearly, if a 70-year-old will be infected by a virus with a "latent period" of 10 years, "age" will be a predictable cofactor (see, for example, hemophiliacs, Section 3.4.4.5 and Paul Gann, Section 3.5.16).

(5) The daims that HIV depends on "dinical illness promotion factors" (Evans, 1992) or on a "pre-existing immune abnormality" (Mar. ion \& al., 1989; Ludlam, 1992) for AIDS are euphemisms for saying that HIV cannot cause A IDS until something el se does (Duesberg, 1989b). The additional hypothesis that a "pre-existing immune abnormality" (Ludlam, 1992) or a "prior immune dysfunction" (Marion $\mathrm{A}$ al., 1989) makes a subject more susceptible to HIV is erroneous, because a preexisting immune deficiency only affects the progression of an infection, but not the risk of infection.

In view of this, I share Gallo's concerns about cofactors of HIV, which he expresses with a quotation from Lewis Thomas: "M ultifactorial is multi-ignorance M ost factors go away when we learn the real cause of a disease" (Gallo, 1991). The "cofactor" HIV may be no exception. Until any one of these hypothetical cofactors is actually shown to depend on HIV to cause AIDS, HIV must be considered just one of many innocent bystanders found in AIDS patients (Section 3.4.3).

\subsubsection{All AIDS Diseases to Result from I mmunodeficiency}

All AIDS diseases are said to reflect a primary immunodeficiency (Cof. fin $₫$ al., 1986; I nstitute of M edicine, 1986; Blattner $₫$ al., 1988).

However, immunodeficiency is not a common denominator of all AIDS diseases. A bout $38 \%$ of all AIDS diseases, i.e dementia, wasting disease, Kaposi's sarcoma and lymphoma (Table 1), are neither caused by, nor necessarily associated with, immunodeficiency. Cancer is not a consequence of immunodeficiency (Stutman, 1975; Duesberg, 1989C). Indeed, K aposi's sarcoma frequently has been diagnosed in male homosexuals in the absence of immunodeficiency. For example, the immune systems of 20 out of $37 \mathrm{HIV}$-positive homosexuals with Kaposi's sarcoma were normal when their disease was first diagnosed (Spornraft $\notin$ al., 1988). A nother study al so describes 19 male homosexual Kaposi's sarcoma patients with normal immune systems Mur- 
ray \& al., 1988). Likewise, Kaposi's sarcomas have been diagnosed in HIV-free male homosexuals with normal immune systems Afrasiabi \&al., 1986; A rcher \& al., 1989; Friedman-Kien \& al., 1990; M arquart $\notin$ al., 1991).

Dementia and wasting disease also are not consequences of immunodeficiency (Duesberg, 1989C, 1991a). Thus, the assumption that all AIDS diseases are caused by immunodeficiency is erroneous.

\subsubsection{HIV to I nduceAIDS via Autoimmunity and Apoptosis}

In view of the extremely low number of HIV-infected cells in AIDS patients (Section 3.3), HIV has recently been proposed to cause AIDS by inducing autoi mmunity (Hoffmann, 1990; M addox, 1991a; M athé, 1992) or apoptosis (Laurent-Crawford e al., 1991; Goudsmit, 1992). According to these new ideas HIV is assumed either to confuse the immune system into attacking itself or to persuade the immune cells to commit suicide, termed apoptosis. The autoimmune hypothesis postulates homology between HIV and human cells, and currently relies only on mouse and monkey models (Hoffmann, 1990; Maddox, 1991a), and on precedents for autoimmunity induced in humans as a consequence of graft rejection and blood transfusions (Root-Bernstein, 1990a, b; M athe 1992). One autoimmunologist claims that "each of Duesberg's paradoxes might be understood in the context of the model without sacrificing theidea that HIV is usually involved in pathogenesis" (Hoffmann, 1990). This strategy of crediting me rather than the virus-AIDS hypothesis for its paradoxes shifts the discussion from a problem with science to a problem with a scientist (Booth, 1988; Weiss and J affe, 1990).

However, both the autoimmune and the apoptosis hypotheses are incompatible with human AIDS on several grounds:

(1) Autoimmunity or apoptosis cannot account for all those AIDS diseases that are not caused by immunodeficiency, eg. Kaposi's sarcoma, dementia, wasting disease and lymphoma (Section 3.5.8).

(2) A utoimmunity or apoptosis fail to explain risk group-specific AIDS di seases (Section 2.1.3, Tables 1 and 2).

(3) A utoimmunity and apoptosis fail to explain the long average intervals, "latent periods," from conventional immunity against HIV, 
detected by the "AIDS test," to hypothetical autoimmunity 10 years later (Section 3.2).

(4) A utoimmunity and apoptosis fail to explain the over 100-fold discrepancies between theannual AIDS risks of different HIV-infected groups (Table 2).

(5) HIV-induced autoimmunity or apoptosis fail to explain the consistent $90 \%$ bias of A merican/ European AIDS for males (Section 2.1, Table 1).

(6) In view of the autoimmunity or apoptosis hypothesis, it is paradoxical that $80 \%$ of antibody-positive A mericans ( 1 million minus the 206 , 000 who have developed AIDS) and $98 \%$ of antibody-positive A fricans ( 6 million minus the 129,000 who have developed AIDS) have not developed AIDS since 1984 (Table 1). Obviously, these figures are not even corrected for the normal and drug-induced incidence of AIDSdefining diseases in those groups (Section 3.4.4, Table 2).

(7) There is no sequence homology between HIV and human DNA detectable by hybridization to predict autoimmunity (Shaw $\notin$ al., 1984). Therefore, autoimmunologists argue that antibodies against those antibodies, which are directed at the viral proteins that bind to cellular receptors, would also react with cellular receptors and thus cause AIDS (Hoffmann, 1990). However, if this were true, all viruses should cause AIDS.

Thus the HIV-autoimmunity and apoptosis hypotheses of AIDS are (a) not compatible with essential parameters of human AIDS and (b) arbitrary, because they are not based on an autoimmunogenic or apoptogenic property of HIV that is distinct from all other viruses.

\subsubsection{HIV Assumed to Kill T-cells}

Based on an early observation by Gallo \& al. HIV is assumed to cause immunodeficiency by specifically killing T-cells Gallo etal., 1984; Weiss and J affe, 1990). Gallo's observation was restricted to primary T-cells Gallo $\notin$ al., 1984) but not to established T-cell lines (Rubinstein, 1990). However, according to M ontagnier, the discoverer of HIV, "In a search for a direct cytopathic effect of the virus on (primary) T-lymphocytes, no gross changes could be seen in virus-producing cultures, with regard to cell lysis or impairment of cell growth" (M ontagnier \& al., 1984). 
Others have confirmed that HIV does not kill infected, primary T-cells in vitro (Hoxie \&al., 1985; Anand \& al., 1987; Langhoff \& al., 1989; Dues berg, 1989C). M oreover HIV-infected primary T-cells are considered the natural "reservoir" of HIV in vivo (Schnittman \& al., 1989).

Thus Gallo's controversial observation probably reflects the notorious difficulties experienced by his laboratory in maintaining primary blood cells alive in culture instead of a genuine cytocidal function of HIV (Crewdson, 1989; Culliton, 1990; Rubinstein, 1990; Hamilton, 1991). Gallo showed in a later study from his laboratory that about $50 \%$ of uninfected T-cells died within 12 days in culture (Gallo, 1990).

Indeed, the assumption that HIV is cytocidal is incompatible with generic properties of retroviruses and with specific properties of HIV:

(1) The hallmark of retrovirus replication is to convert the viral RNA into DNA and to deliberately integrate this DNA as a parasitic gene into the cellular DNA (Weiss \& al., 1985). This process of integration depends on mitosis to succeed, rather than on cell death (Rubin and Temin, 1958; Duesberg, 1989c). The resulting genetic parasite can then beeither active or passive, just like other cellular genes (Duesberg, 1987). Transcription of viral RNA from chromosomally integrated proviral DNA also only works if the cell survives infection, because dying cells are not transcriptionally active Thus, this strategy of replication depends entirely on the survival of the infected cell.

Noncytocidal replication is the reason that retroviruses were all considered potential carcinogens before AIDS (Weiss \& al., 1985; Dues. berg, 1987). For example, Gallo's first candidate for an AIDS virus is called Human T-cell Leukemia Virus-I (Gallo \&al., 1983), and Gallo's second candidate for an AIDS virus was originally described at a press conference in A pril 1984 by Gallo and the Secretary of Health and Human Services as "a variant of a known human cancer virus called HTLV III" (Crewdson, 1989; Rubinstein, 1990). It used to be called Human T-cell Leukemia Virus-III by Gallo Gallo eal., 1984; Shav e al., 1984) before it was renamed HIV in 1986 (Coffin \& al., 1986).

(2) Limited cytotoxicity of HIV has been observed soon after infection of cells in vitro (Duesberg. 1989c; Bergeron and Sodroski, 1992). Therefore, it has been proposed that multiple copies of unintegrated 
proviral DNA, generated by multiple infections before all cellular receptors are blocked by newly replicated viruses, could kill T-cells (Bergeron and Sodroski, 1992). However, cells infected by every retrovirus, including HIV (Bergeron and Sodroski, 1992), survive multiple unintegrated proviral DNAs during the early phase of the infection (Weiss \& al., 1985). Rare cell death during this phase of infection is a consequence of cell fusion, which is mediated by viruses on the surface of infected cells binding to receptors of uninfected cells. In some conditions retrovirus-mediated fusion occurs so reliably that it has been used to quantitate retroviruses in tissue culture However, virus-mediated fusion is blocked by antiviral antibodies and thus not relevant to the loss of T-cells in persons with antibodies against HIV (Duesberg, 1989c).

Alternatively, it has been proposed that HIV proteins are directly toxic because of structural similarities with scorpion and snake poisons (Gallo, 1991; Garry \& al., 1991; Garry and Koch, 1992). However, no such toxicity is observed in millions of asymptomatic HIV carriers, and there is no reason that it should occur, if it did, only after latent periods of 10 years.

(3) The propagation of HIV in indefinitely growing human T-cells for the "AIDS test" was patented by Gallo \& al. in 1984 Rubinstein, 1990) and was recently confirmed by M ontagnier (Lemaître $\notin a l ., ~ 1990)$. It is totally incompatible with Gallo's daim that HIV kills T-cells. Such HIV-producing T-cells have been growing in many laboratories and companies since 1984 producing virus at titers of up to $10^{6}$ virus particles per $\mathrm{mL}$, which is many orders of magnitude more than is ever observed in humans with or without AIDS (Duesberg, 1989,, 1991a).

In view of this, Gallo postulates that T-cell lines in culture have all acquired resistance to HIV killing (Gallo, 1991). However, there is no precedent for this ad hochypothesis, as no other cytocidal virus has ever been observed that is cytocidal in vivo and in primary cells in vitro, but is noncytocidal in cell lines in culture It is also implausible that a potentially life-saving cellular mutation, such as resistance to the hypothetical "AIDS virus," would be restricted just to cells in culture, particularly if these mutations occur so readily that they are found in all T-cell lines. There is not even one T-cell line that is consistently killed by HIV.

(4) HIV, like all other retroviruses, does not specifically infect T-cells. 
It also infects monocytes, epithelial cells, B-cells, glial cells and macrophages, etc. and none of these are killed by HIV (Levy, 1988; Duesberg, 1991a). M ost other retroviruses also infect T-cells, which is why so many of them are suspected "T-cell leukemia" viruses (Weiss \& al., 1985; Duesberg, 1987; Blattner, 1990).

Thus, the assumption that HIV causes AIDS by killing T-cells is not tenable

\subsubsection{Antibodies Assumed not to NeutralizeHIV}

A ntibodies against HIV, detected by a positive "AIDS test," are daimed not to protect against AIDS because they do not neutralize HIV (Insti. tute of M edicine, 1988; Evans, 1989a; Weiss and J affe, 1990; Gallo, 1991). "It is a test for anti-HIV antibodies and not, as Duesberg states, 'neutralizing antibodies' " (Baltimore and Feinberg, 1990).

However, antiviral immunity completely neutralizes HIV and restricts it to undetectable levels in healthy HIV-carriers as well as in AIDS patients (Section 3.3.1) (D uesberg, 19896, G). Indeed, two recent studies have just confirmed that HIV activity is "rapidly and effectively limited" by antiviral immunity (Clark \& al., 1991; Daareal., 1991) to less than 1 in 1000 T-cells (Section 3.3). By contrast, HIV replicates in the absence of antiviral immunity in human T-cells in culture to titers of $10^{6}$ virus particles per $\mathrm{mL}$ (Section 3.5.10). Thus, the assumption that HIV causes AIDS because of inadequate antiviral immunity is unconfirmed. Baltimore's, Feinberg's and Evans' paradox “that antibody is not protective" (Evans, 1989a) is their failure to recognizethenon-role of HIV in AIDS (Section 3.3.2).

\subsubsection{HIV Claimed to CauseAIDS in 50\% Within 10 Years}

All HIV-infected persons are said to die from AIDS after a medium latent period of 10 years (A nderson and $M$ ay, 1988; Institute of M edicine, 1988; M oss \& al., 1988; Lemp \& al., 1990; Blattner, 1991; Duesberg, 1991a).

However, according to statistics from the CDC, only about 30,000-40,000, or 3-4\%, of a reservoir of 1 million HIV-infected Americans develop AIDS annually (Table 1). Likewise, 3\% of infected Europeans develop AIDS per year (Table 1). Accordingly, 50\% of 
HIV-infected A mericans and Europeans would have to wait 12-16 years and $100 \%$, 24-33 years to develop AIDS. During this time, many would die from other causes. Since only $0.3 \%$ of infected A fricans develop AIDS diseases annually (Tables 1 and 2 ), 50\% of A fricans would have to wait about 150 years and $100 \%$ would have to wait 300 years to develop AIDS.

Thus, it is presumptuous to claim that HIV causes AIDS in $50 \%$ of infected persons after median latent periods of 10 years, particularly since the virus has only been known for nine years.

\subsection{HIV Said to DerivePathogeni ity from Constant Mutation}

During its long latent periods, HIV is claimed to acquire pathogenicity by mutation, for example by generating variants that escape immunity (Hahn eal., 1986; Levy, 1988; Eigen, 1989; Gallo, 1990; Weissand J affe, 1990; A nonymous, 1992; A nderson and M ay, 1992) or by generating defective variants (Eigen, 1989; Haas, 1989; Weiss, R.A., 1989).

However, a recent study just demonstrated that the replicative and functional properties of HIV s from AIDS patients are the same as those from asymptomatic carriers Lu and A ndrieu, 1992). Indeed, most essential structural and replicative proteins of a virus cannot be mutated without eliminating its viability. Functionally relevant mutations of any virus are al so severely restricted by the necessity to remain compatible with the host (Duesberg, 1990b). M oreover, there is no precedent for an immune system that has been able to neutralize a virus completely and is then unable to catch up with an occasional subsequent mutation. If viruses in general could evade the immune system by mutation, the immune system would be a useless burden to the host.

Likewise, the proposals that defective HIVs could generate pathogenicity is untenable Defective viruses are only viable in the presence of nondefective hel per viruses and thus unlikely to survive in natural transmission from host to host at low multiplicity of infection, particularly with helper viruses that never achieve high titers like HIV Dues. berg, 1989a).

There are, however, examples of new antigenic variants of retroviruses (Beemon \& al., 1974) or influenza viruses (Duesberg, 1968), that have arisen upon rare double infection by two antigenically distinct 
virus strains via genetic recombination. Yet antigenically new variants of HIV have never been observed in A merican and European AIDS patients, as all HIV strains diagnosed to date crossreact with the very same standard HIV-1 strain that is patented in A merica and Europe for the "AIDS test" (Connor, 1991, 1992; Palca, 1991a; Weiss, 1991).

M oreover, if recombination or spontaneous mutation could generate pathogenic HIV mutants from nonpathogenic strains, one would expect all those who are infected by HIV from AIDS patients to develop AIDS within weeks after infection. Such HIV mutants should be pathogenic just as soon as conventional, nonpathogenic HIV strains are immunogenic. But this is not observed.

Thus, the assumption that HIV acquires pathogenicity by mutation during the course of the infection is not tenable

\subsubsection{HIV Assumed to CauseAIDS}

\section{with Genes UniqueAmong Retroviruses}

AIDS researchers assert that HIV causes AIDS with unique genetic information that all other animal and human retroviruses lack and that these unique genes would regulate HIV down during the "latent period" and up during AIDS Gallo and M ontagnier, 1988; Haseltineand WongStaal, 1988; Institute of M edicine, 1988; Eigen, 1989; Temin, 1990; Fauci, 1991; Gallo, 1991). Further, it is claimed that HIV-infected cells export factors encoded by these genes that promote neoplastic growth of uninfected cells to cause, for example, Kaposi's sarcoma (Salahuddin \& al., 1988; Ensoli \& al., 1990; Gallo, 1990); at the same time such genes are said to export "scorpion poison"-related toxins that kill uninfected neurons to cause dementia (Gallo, 1991; Garry eal., 1991; Garry and Koch, 1992). By contrast, all other known bacterial, animal and human viruses, including retroviruses, are only ableto kill or alter those cells they infect, because viruses are manufactured inside cells and would not benefit from proteins released to uninfected cells.

However, the claims of unique retroviral HIV genes with unique control functions raises several unresolvable problems:

(1) Despite its presumed unique properties HIV has the same genetic complexity, i.e 9000 nucleotides, and the same genetic structure as all 
other retroviruses (Beemon \& al., 1974; Wang \& al., 1976; Institute of Medicine, 1988). It shares with other retroviruses the three major genes gag-pd-env, which are linked in this order in all animal and human retroviruses (Wang \& al., 1976). Although "novel" genes that overlap with the major retroviral genes have been discovered in HIV by computerized sequence analysis, and by new protein detection technology (Varmus, 1988), such genes have also been found with the same technology in other retroviruses that do not cause AIDS, such as HTLV-I, other human retroviruses, bovine retroviruses, simian retroviruses and sheep retroviruses (Varmus, 1988; Weiss, 1988; Duesberg, 1989c; Palca, 1990). Thus there is no unique genetic material and no uncommon genetic structure in HIV RNA that could indicate where this unique AIDSspecific information of HIV is hiding.

(2) Since all retroviral genes share just one common promoter, it would be impossible to differentially activate one HIV gene while the others are latent. Thus the idea that different viral genes would regulate latency and virulence, as with lambda phage, is not compatible with HIV (Haseltine and Wong-Staal, 1988; Eigen, 1989; Temin, 1990; Fauci, 1991). Sinceall HIV genes share the same promotor, latent HIV can only be activated by the host-just like all other latent retroviruses. In addition HIV cannot make specific AIDS factors, while its major genes are dormant. Since viral RNA synthesis in vivo is only detectable in 1 out of 10,000 to 100,000 leukocytes and then only in half of all AIDS patients (Section 3.3), HIV cannot make Kaposi's sarcomagenic and neurotoxic factors in amounts sufficient to cause fatal tumors and dementias. This is why such factors have not been detectable in vivo (Weiss and Jaffe, 1990; Gallo, 1991).

Thus, based on the structure, information and function of its RNA, HIV is a profoundly conventional retrovirus It does not contain unique genes that distinguish it from other retroviruses, nor can its genes be differentially regulated at the transcriptional level.

\subsection{Simian Retroviruses to Provethat HIV Causes AIDS}

A nimal retroviruses may cause diseases in experimental animals that overlap with the wide spectrum of AIDS diseases. Such systems are now studied for analogies to gain experimental support for the virus- 
AIDS hypothesis (Blattner $\notin$ al., 1988; Weiss and J affe, 1990; Goudsmit, 1992). For example, a retrovirus isolated from macaques (Fult $\notin$ al., 1990), termed simian immunodeficiency virus (SIV), that is $40 \%$ related to HIV, is said to cause AIDS-like diseases in rhesus monkeys Kestler \& al., 1990; Temin, 1990). According to an editorial in Science, "if SIV infection is all that is needed to cause simian AIDS, that's one more indication that HIV is all that is needed to cause human AIDS" (Palca, 1990).

However, the presumed role of SIV in the diseases of infected monkeys is very different from that of HIV in human AIDS:

(1) According to one study, about half of the infected monkeys developed diseases within several months to one year after infection Kestler etal., 1990). By contrast only 3-4\% of HIV-infected A mericans or Europeans and $0.3 \%$ of infected A fricans develop AIDS annually (Table 1).

(2) In the same study, the absence of antiviral antibodies predicted the incidence of diseases in monkeys, while theopposite is claimed for humans infected with HIV. A nother study has confirmed that themonkey's risk of disease is directly proportional to the titer of SIV Fultz \& al., 1990).

(3) The simian retroviruses barely reduce the T-cell levels of ill monkeys (Kestler \& al., 1991), while HIV is claimed to depleteT-cells in humans.

(4) The spectrum of diseases observed in the SI V-infected monkeys is different from AIDS, including bacteremia and lacking, among others, Kaposi's sarcoma and dementia Kestler \& al., 1990; Fult \& al., 1990).

(5) In follow-up studies, SIV failed to cause disease in rhesus and mangabey monkeys despite extensive sequence variation which is thought to enhance pathogenicity of the virus Fultz $\notin$ al., 1990; Burns and Desrosiers, 1991; Villinger e al., 1991).

(6) SinceSIV has never caused any disease in wild monkeys, al though about 50\% are naturally infected (D uesberg, 1987, 1989C; Blattner \& al., 1988; Fult \& al., 1990; Burns and Desrosiers, 1991; Villinger \& al., 1991), SIV is not an appropriate model for the hypothesis that HIV causes AIDS in naturally infected humans.

It would appear that SIV causes disease in monkeys like all viruses 
cause disease soon after infection and in the absence of effective immunity. This is not a model for the hypothesis that HIV causes AIDS 10 years after it is neutralized by antibodies. I ndeed, in the vast literature on retroviruses there is not even one proven example of a latent retrovirus that, in the presence of antiviral immunity, has ever caused a disease in any animal, including chickens, mice, cattle, and monkeys (Weiss \& al., 1985; Duesberg, 1987, 1989C).

M oreover, the observation that a retrovirus that is $60 \%$ unrelated to HIV causes disease in monkeys cannot prove that HIV causes AIDS in humans, even if all parameters of infection were completely analogous. It can only prove that under analogous conditions other retroviruses may also cause disease, which has been demonstrated with numerous avian and murine retroviruses long ago (Weiss $₫$ al., 1985).

\subsubsection{Anecdotal AIDS Cases from the General Population}

Rare AIDS cases occurring outside the major risk groups are claimed to prove that HIV alone is sufficient to cause AIDS in persons with no other AIDS risks (Blattner e al., 1988; Booth, 1988; Baltimore and Feinberg, 1989; Weiss and Jaffe, 1990). Four examples illustrate this point:

(1) Ryan White, an 18-year-old hemophiliac, was said to have died from A IDS in A pril 1990. However, information from the $\mathrm{N}$ ational Hemophilia Foundation revealed that $W$ hite had died from unstoppable internal bleeding and had also been treated for an extended period with the cytotoxic DNA chain terminator AZT prior to his death (Duesberg and Ellison, 1990). It appears that hemophilia and AZT (Section 4) would each be sufficient causes of death, and certainly a combination of both would be more than adequate to explain the death of Ryan White Thus there is no convincing evidence that White died from HIV.

To prove that HIV played a role in White's death, it would be necessary to compare mortality of matched hemophiliacs with and without HIV. To prove that AZT contributed to his death, matched HIV-positive hemophiliacs with and without AZT must be compared. Without such evidence the HIV-death of White is just a hypothesis. Yet White was generally described as an innocent victim of HIV (practicing no risk behavior), which is why the U.S. Senate approved the Ryan 
White Comprehensive AIDS Resources Act for over $\$ 550$ million in aid to hospitals for AIDS emergencies and treatment of children (Anonymous, 1990).

(2) In 1989 the California tax-reformer Paul Gann was reported to have died from AIDS at the age of 77 after receiving HIV from a blood transfusion. However, a close examination of Gann's case reveals that he had 5-bypass heart surgery for blocked arteries in 1982, when he may have received the bl ood transfusion with HIV. In 1983 he needed further bypass surgery for blocked intestinal arteries. In 1989, at the age of 77 , he was hospitalized again for a broken hip. While recovering from the hip fracture, Gann was immobilized for weeks and developed a pneumonia from which he died (Folkart, 1989). This is a rather typical death for a 77-year-old man in poor health.

To determine whether HIV played any role at all in his death, a controlled study would be necessary showing that the mortality of HIVpositive 77-year-old bypass patients with broken hips is higher than that of HIV-negative counterparts. No such study exists.

(3) Kimberly Bergalis, a 22-year-old woman, developed candidiasis and a transient pneumonia 17 and 24 months, respectively, after the extraction of two molars (Centers for Disease Control, 1990). After her dentist had publicly disclosed that "he had AIDS," she was tested for $\mathrm{HIV}$, although Bergalis was a virgin and did not belong to an AIDS risk group (Breo and Bergalis, 1990). Since she was HIV-antibody-positive the CDC concluded that she had contracted AIDS from her dentist (Centers for Disease Control, 1990), who was a homosexual with Kaposi's sarcoma (Ou $₫$ al., 1992).

Clearly prior to the virus-AIDS hypothesis, the story of a doctor transmitting his K aposi's sarcoma in the form of a yeast infection to his dient via a common infectious cause would have hardly madeThe New York Times and certainly not the scientific literature (L ambert, 1991). But since the two entirely unrelated diseases are both labeled AIDS and because of the tremendous popularity of the virus-AIDS hypothesis, the paradoxical story became a case célèbre for AIDS in the general population.

Once diagnosed for AIDS Bergalis was treated with the cytotoxic DNA chain terminator $A Z T$, which is prescribed to inhibit HIV, until 
she died in December 1991 with weight loss (15 kg), hair loss, uncontrollable candidiasis, anemia and muscle atrophy (requiring a wheelchair) (Breo and Bergalis, 1990; A nonymous, 1991; Lauritsen, 1991) - the symptoms of chronic AZT toxicity (Section 4). It is not clear whether her AZT therapy started before or after her pneumonia, since it was only mentioned in an edited interview conducted for the A merican M edical Association (Breo and Bergalis, 1990) and in some newspapers (A nonymous, 1991), but not in a single one of several scientific reports (Centers for Disease Control, 1990; Witte and Wilcox, 1991; Ou \& al., 1992; Palca, 1992a b) and not in TheNew York Times (L ambert, 1991). Since her fatal condition was attributed to HIV, she received \$1 million in compensation from her dentist's, rather than from her AZT doctor's (Section 4), mal practice insurance (Pal ca, 1992a).

In view of the celebrity of the case and the fear it inspired among patients, 1100 further patients of the dentist came forward to be tested for HIV $\mathrm{Ou} \notin$ al., 1992; Palca, 1992a). Seven of these, including Bergalis, tested positive Four or 5 of these, including Bergal is and another woman, did not belong to an AIDS risk group, but 2 or 3 did. At least three of those who did not belong to a risk group received $\$ 1$ million settlements from the dentist's mal practice insurance (Palca, 1992b). However, a plausible mechanism of HIV transmission from the dentist to his 4-5 positive clients without AIDS risks was never identified, and there is no consensus as to whether the viruses of the three carriers studied by the CDC and the insurance companies were sufficiently related to daim a common source (Palca, 1992ab).

Statistically, it can be shown that the incidence of HIV-infections among the dentist's clients reflects, almost to the decimal point, the national incidence of the virus in the U.S. The national incidence of HIV-positives among all A mericans is 0.4\% (1 out of 250) (Table 1), the incidence of HIV-positives among 1100 patients of the F lorida dentist was $0.4 \%$ ( 4 to 5 out of 1100 ) and the incidence among 15,795 patients from $32 \mathrm{HIV}$-positive doctors, determined by the CDC for the Bergalis case, was $0.5 \%$ (84 out of 15,795$)$. Thus theincidence of HIV in patients from HIV-positive doctors reflects the national incidence of HIV. This suggests noniatrogenic and, most likely, perinatal infection as the source of HIV in these patients, particularly in the case of the virgin Bergalis 
(Section 3.5.2). In addition, it identifies a rich source of insurance income for $0.4 \%$ of A merican patients of HIV-positive doctors!

To determine whether HIV had contributed to Bergalis' death, a controlled study would be necessary comparing the mortality of women with yeast infections, with and without antibodies against HIV, and with and without AZT therapy. Sincesuch a study is not available, the assumption that Bergalis died from HIV is pure speculation.

(4) A doctor, presumably infected with HIV from a needlestick in 1983 (Aoun, 1992), described himself in a letter to the New Engand J ournal of Medicineas an AIDS patient Aoun, 1989). He was diagnosed HIV-positive in 1986 (Aoun, 1992). His only AIDS symptom at that time was a weight loss of $4.5 \mathrm{~kg}$ (A oun, 1989). In 1991, then 8 years after the presumed date of the infection, the doctor described his case again in a speech "From the eye of the storm ..." published in the Annals of I nternal Medicine(A oun, 1992). The speech did not describe any current AIDS symptoms. This case has been cited as an example that HIV is sufficient to cause AIDS (Baltimore and Feinberg, 1989).

However, the weight loss diagnosed in 1986 could have been the result of the anxiety that HIV infection causes in believers of the HIVAIDS hypothesis, rather than the work of HIV. This interpretation is consistent with the fact that since 1985 at least 800,000 A mericans (1 million minus the 206,000 AIDS cases recorded by theend of 1991; see Table 1) have not lost weight or developed other AI DS diseases (Duesberg, 1991a). Likewise 6 million Central Africans (minus the 129,000 with AIDS) have been healthy HIV-carriers since at least 1985 (Table 1).

Thus, there are no convincing anecdotal cases to prove that HIV causes AIDS in persons outsi de the major risk groups. The use of the above assumptions and anecdotal cases as proof for the virus-AIDS hypothesis is misleading, although they may provide valuable dues for future research.

\subsection{Consequences of the Virus-AIDS Hypothesis}

Despite the lack of proof and numerous discrepancies with orthodox criteria of infectious disease, the virus-AIDS hypothesis has remained since 1984 the only basis for all efforts in predicting preventing, investigating and even treating AIDS. AIDS prevention is based entirely on 
preventing the spread of HIV. This includes promotion of safe sex (Booth, 1988; Institute of M edicine, 1988; Weiss and J affe, 1990; Mann and the Global AIDS Policy Coalition, 1992; A nderson and M ay, 1992), dean injection equipment for intravenous drugs (National Commission on AIDS, 1991) and the exclusion of HIV antibody-positive blood donations from transfusions (Vermund, 1991; Duesberg and Schwartz, 1992).

The Food and Drug A dmi nistration mandated in 1985 that the 12 million plus annual blood donations in the U.S. (Williams \&al., 1990) are tested for HIV-1, and as of 1992 also for HIV-2, although there is as yet only onesingleA merican AIDS patient infected by HIV-2 O'Brien \& al., 1992). Since 1985 over 2 million tests have also been performed annually by the U.S. A rmy (Burke \& al., 1990). By 1986 al ready over 20 million "AIDS tests" were performed in theU.S. (Institute of M edicine, 1986), at a minimum cost to the client of $\$ 12$ to $\$ 70$ (I rwin M emorial Blood Bank, San Francisco, personal communication) or \$45 (U.S. I mmigration Service). The former U.S.S.R. conducted 20.2 million "AIDS tests" in 1990 and 29.4 million in 1991 to detect 112 and 66 antibody-positives, respectively (Voevodin, 1992).

The detection of antibodies in healthy persons is interpreted as a $50 \%$ certain prognosis for AIDS within 10 years (Section 3.5.12). Therefore, a positive "AIDS test" is psychologically toxic Grimshaw, 1987; Albonico, 1991b) and often the basis for the physiologically toxic antiviral therapy with AZT (Section 4) (Duesberg, 19926, d). A negative test for HIV is a condition for admission to the U.S. Army (Burke \& al., 1990), for admission to health insurance programs, for residence in many countries and even for travel into the U.S. and China. Currently, over 50 countries restrict one or more dasses of entrants based on positive antibody-tests for HIV (Duckett and Orkin, 1989). Antibody-positive A mericans who had sex with antibody-negatives have been convicted of "assault with a deadly weapon" (Duesberg, 1991c; McKee, 1992). In communist Cuba about 600 antibody-positive persons are quarantined in the name of thevirus-A IDS hypothesis (Scheper-Hughes and Herrick, 1992; Treichler, 1992).

Based on the assumption that HIV had either originated recently or spread recently from isolation to its current levels, at the same rates as AIDS had spread in the risk groups in theU.S. and Europe, and on the 
assumption that AIDS would follow the presumed spread of HIV with a hiatus of 10 years, epidemiologists have made apocalyptic predictions about an AIDS epidemic that has raised fears and funding to unprece dented levels (Heyward and Curran, 1988; Mann \& al., 1988; Mann and the Global AIDS Policy Coalition, 1992; Anderson and May, 1992).

A bove all, over 180,000 antibody-positives, with and without AIDS, are currently treated indefinitely with the cytotoxic DNA chain terminator AZT in an effort to inhibit HIV (Section 4.4).

\section{The Drug-AIDS Hypothesis}

After the global acceptance of the virus-AIDS hypothesis, several inves tigators have recently revived the original hypothesis that AIDS is not infectious (Section 2.2). In view of (1) the almost complete restriction (97\%) of A merican AIDS to groups with severely compromised health, (2) the predetermination for certain AIDS diseases by prior health risks, and (3) the many links between AIDS and drug consumption (Sections 2.1.3 and 3.4, Tabl e2), it has been proposed that recreational drugs and AZT may cause AIDS Lauritsen and Wilson, 1986; Haverkos, 1988a, 1990; Holub, 1988; Papadopulos-Eleopulos, 1988; Rappoport, 1988; Duesberg, 1990a, 1991a, 1992 ff Lauritsen, 1990; Albonico, 1991a b; Pillai \& al., 1991; Cramer 1992; Leonhard, 1992). Herethe hypothesis is investigated that all A merican and European AIDS diseases, above the normal background of hemophilia and transfusion-related diseases, are the result of the long-term consumption of recreational and antiHIV drugs.

\subsection{Chronological Coincidence Between the Drug and AIDS Epidemics}

The appearance of AIDS in A merica in 1981 followed a massive escalation in the consumption of psychoactive drugs that started after the Vietnam War (N ewell etal., 1985b; Kozel and A dams, 1986; National Institute on Drug A buse, 1987; Bureau of J ustice Statistics, 1988; Haverkos, 1988b; Office of National Drug Control Policy, 1988; Flanagan and M aguire, 1989; Lemer 1989; Shanon \&al., 1990). The Bureau of J ustice Statistics reports that the number of drug arrests in theU.S. 
has increased from about 450,000 in 1980 to 1.4 million in 1989 (Bureau of J ustice Statistics, 1988; Shannon \& al., 1990). A bout $500 \mathrm{~kg}$ of cocaine were confiscated by the Drug Enforcement Administration in 1980, about $9000 \mathrm{~kg}$ in 1983, 80,000 kg in 1989, and 100,000 kg in 1990 (Bureau of J ustice Statistics, 1988, 1991; Flanagan and Maguire, 1989). In 1974, 5.4 million A mericans had used cocaine at some point in their lives and in 1985 that number had gone up to 22.2 million Kozel and A dams, 1986). Currently about 8 million A mericans are estimated to use cocaine regularly (Weiss, S.H., 1989; Finnegan \& al., 1992). The number of dosage units of domestic stimulants confiscated, such as amphetamines, increased from 2 million in 1981 to 97 million in 1989 (Flanagan and Maguire, 1989).

Several arguments indicate that these increases reflect increased drug consumption rather than just improved drug control, as has been suggested (M addox, 1992a):

(1) The Bureau of J ustice Statistics estimates that at most $20 \%$ of the cocaine smuggled into the U.S. was confiscated each year Ander. son, 1987).

(2) The National Institute on Drug A buse reports that between 1981 and 1990 cocainerelated hospital emergencies increased 24-fold from 3296 to 80,355 and deaths from 195 to 2483 Koze and A dams, 1986; National Institute on Drug A buse, 1990a,b). Thus cocainerelated hos pital emergencies had increased 24-fold during 9 of the 1oyears in which cocaine seizures had increased 100-fold.

(3) It is highly improbable that, before the jet-age, theU.S. would have imported annually as much cocaine as it did in 1990 plus the $100,000 \mathrm{~kg}$ that were confiscated in that year.

Further, the recreational use of psychoactive and aphrodisiac nitrite inhalants began in the 19605 and reached epidemic proportions in the mid-1970S, a few years before AIDS appeared (N ewell $₫$ al.,, 1985b. 1988). The N ational Institute on Drug A buse reports that in 1979-1980 over 5 million people used nitrite inhalants in the U.S. at least once a week (Newell e al., 1988), a total of 250 million doses per year (Wood, 1988). In 1976 the sales of nitrite inhalants in one A merican city alone amounted to \$50 million annually ( $\mathrm{N}$ ewell $\notin$ al., 1985b 1988) at \$5 per $12 \mathrm{~mL}$ dose (Schwart, 1988). 
Since 1987 the cytocidal DNA chain terminator AZT has been prescribed as an anti-HIV drug to AIDS patients (Kolata, 1987; Yarchoan and Broder, 1987b) and since 1990 to asymptomatic carriers of HIV (Editorial, 1990). Currently about 120,000 A mericans and 180,000 HIVpositive persons worldwide, with and without AIDS, takeAZT in efforts to inhibit HIV. This estimate is based on the annual AZT sales of \$364 million and a wholesale price of \$2000 per year for a daily dose of 500 mg A ZT per person (Burroughs Wellcome Public Relations, 3 A pril 1992). In addition, an unknown number take other DNA chain terminators like ddl and ddC (Smothers 1991; Yarchoan \& al., 1991).

\subsection{Overlap Between Drug-Use and AIDS Statistics}

Drugs and AIDS appear to claim their victims from the same risk groups. For instance, the CDC reports that the annual mortality of 25- to 44year-old A merican males increased from $0.21 \%$ in 1983 to $0.23 \%$ in 1987, corresponding to about 10,000 deaths among about 50 million in this group (Buehler $\notin$ al., 1990). Since the annual AIDS deaths had also reached 10,000 by 1987, HIV was assumed to be the cause (Institute of M edicine, 1986; Centers for Disease Control, 1987, 1992b). Further, HIV infection was blamed for a new epidemic of immunological and neurological deficiencies including mental retardation, in American children Blattner \& al., 1988; Institute of M edicine, 1988; Centers for Disease Control, 1992b).

However, mortality in 25- to 44-year-old males from septicemia, considered an indicator of intravenous drug use, rose al most 4-fold from 0.46 per 100,000 in 1980 to 1.65 in 1987, and direct mortality from drug use doubled (National Center for Health Statistics, 1989; Buehler \& al., 1990), indicating that drugs played a significant role in the increased mortality of this group (Buehler \& al., 1990). In addition, deaths from AIDS diseases and nonAIDS pneumonia and septicemia per 1000 intravenous drug users in New York increased at exactly the same rates, from 3.6 in 1984 to 14.7 and 13.6, respectively, in 1987 Selwyn \& al., 1989). Indeed, the cocaine-related hospital emergencies al one could more than account for the $32 \%$ of A merican AIDS patients that are intravenous drug users (Section 2.1.3). The emergencies had increased from “a negligible number of people" in 1973 to 9946 non-fatal and 580 
fatal cases in 1985 (Kozel and A dams, 1986), when a total of 10,489 AIDS cases were recorded and to 80,355 nonfatal and 2483 fatal cases in 1990 (National Institute on Drug Abuse, 1990a,b), when a total of 41,416 A IDS cases were recorded by the CDC (Centers for Disease Control, 1992a). M oreover $82 \%$ of the cocainerelated and $75 \%$ of the morphine-related hospital emergencies were $20-39$ years old ( $N$ ational Institute on Drug A buse, 1990a), the age distribution typical of AIDS patients (Section 2.1.1).

A nother striking coincidence is that over $72 \%$ of all A merican AIDS patients Centers for Disease Control, 1992b) and about 75\% of all A mericans who consume "hard" psychoactive drugs such as cocaine, amphetamines and inhalants (N ational Institute on D rug A buse, 1987, 1990a, b; Ginzburg, 1988) or get arrested for possession of such drugs (Bureau of J ustice Statistics, 1988) or are treated for such drugs (National Institute on Drug A buse, 1990a) are 20- to 44-year-old males. Thus there is substantial epidemiological overlap between the two epidemics (Lerner, 1989), reported as "The twin epidemics of substance use and HIV" by the National AIDS Commission (National Commission on AIDS, 1991).

M oreover, maternal drug consumption was blamed by some for the new epidemic of immunological and neurological deficiencies, induding dementias, of A merican children (Toufexis, 1991). In view of this, the CDC adknowledges, "We cannot discern, however, to what extent the upward trend in death rates from drug abuse reflects trends in illicit drug use independent of the HIV epidemic" Buehler $\notin$ al., 1990).

\subsection{Drug Usein AIDS Risk G roups}

\subsubsection{Intravenous Drug Users Generatea Third of All AIDS Patients}

Currently $32 \%$ of the A merican National Commission on AIDS, 1991; Centers for Disease Control, 1992b) and 33\% of the European (Brenner \& al., 1990; World Health Organization, 1992a) AIDS patients are intravenous or intrauterine users of heroin, cocaine, and other drugs (Section 2.1.3). These indude:

(1) $75 \%$ of all heterosexual AIDS cases in A merica and about $70 \%$ of those in Europe, 
(2) $71 \%$ of the A merican and $57 \%$ of the European females with AIDS,

(3) over $10 \%$ of the A merican and $5 \%$ of the European male homosexuals,

(4) $10 \%$ of the A merican hemophiliacs with AIDS,

(5) $70 \%$ of A merican children with AIDS including $50 \%$ born to mothers who are confirmed intravenous drug users and another $20 \%$ to mothers who had "sex with intravenous drug users" and are thus likely users themselves (A maro \& al., 1989),

(6) $80-85 \%$ of the European children with AIDS who were born to drug-addicted mothers M ok \& al., 1987; European CollaborativeStudy, 1991).

In an artide entitled "AIDS and intravenous drug use the real heterosexual epidemic" the AIDS researcher M oss points out that " $90 \%$ of infected prostitutes reported in Florida, Seattle, New York and San Francisco have been intravenous drug users ... Drug use is also the source of most neonatal AIDS, with $70 \%$ of cases occurring in children of intravenous drug users..." (M oss 1987). Indeed, all studies of A merican and European prostitutes indicate that HIV infection is almost exclusively restricted to drug users (Rosenberg and Weiner, 1988), although all prostitutes should have the same risks of HIV infection, if HIV were sexually transmitted. Surprisingly, all of these studies only mention the incidence of HIV, rather than of AIDS, in prostitutes.

\subsubsection{Homosexual Users of Aphrodisiac Drugs Generate about $60 \%$ of AIDS Patients}

A pproximately $60 \%$ of A merican AIDS patients are male homosexuals over the age of 20 (Table 1 ). They are generated by risk groups that have sex with large numbers of partners (Centers for Disease Control, 1982; Jaffe \& al., 1983b; Darrow $\notin$ al., 1987; Oppenheimer, 1992) that often average over 100 per year and have exceeded 1000 over a period of several years (M athur-Wagh \& al., 1984; Newell \& al., 1985a; Turner \&al., 1989; Callen, 1990). The following evidence indicates that these sexual activities and the corresponding conventional venereal diseases are directly proportional to the consumption of toxic sexual stimulants, which include nitrite- and ethylchloride inhalants, cocaine, ampheta- 
mines, methaqualone, lysergic acid, phenylcyclidine, and more (Blatther \& al., 1985; Shilts, 1987; Lauritsen and Wilson, 1986; Darrow \& al., 1987; Haverkos, 1988a; Rappoport, 1988; Raymond, 1988; Adams, 1989; Turner \& al., 1989; Weiss, S.H., 1989; Ostrow \& al., 1990; Lesbian and Gay Substance A buse Planning Group, 1991a).

An early CDC study of 420 homosexual men attending clinics for sexually transmitted diseases in N ew York, A tlanta and San Francisco reported that $86.4 \%$ had frequently used amyl- and butylnitrites as sexual stimulants. The frequency of nitrite use was proportional to the number of sexual partners (Centers for Disease Control, 1982).

In 1983J affe $\&$ al. investigated A IDS risk factors of 170 male homosexuals from sexual disease clinics, induding 50 with Kaposi's sarcoma and pneumonia and 120 without AIDS. In this group, 96\% were regular users of nitrite inhalants and $35-50 \%$ of ethylchloride inhalants. In addition, 50-60\% had used cocaine, 50-70\% amphetamines, $40 \%$ phenylcyclidine, 40-50\% lysergic acid, 40-60\% methaqualone, $25 \%$ barbiturates, 90\% marijuana and 10\% heroin (I affe \& al., 1983b). Over 50\% had also used prescription drugs. A bout $80 \%$ of thesemen had past or current gonorrhea, $40-70 \%$ had syphilis, $15 \%$ mononucleosis, 50\% hepatitis and $30 \%$ parasitic diarrhea. Those with Kaposi's sarcoma had a median of 61 sex partners per year and those without AIDS about 26. The study points out that "lifetime exposure to nitrites... (and) use of various 'street' drugs ... was greater for cases than controls." The lifetime drug dose of "cases" was reported to betwo times higher than of asymptomatic HIV carriers (Jaffe $₫$ al., 1983b).

A study of a group of 359 homosexual men in San Francisco reported in 1987 that $84 \%$ had used cocaine, $82 \%$ alkyl nitrites, $64 \%$ amphetamines, $51 \%$ methaqualone, $41 \%$ barbiturates, $20 \%$ injected drugs and $13 \%$ shared needles (Darrow $\notin$ al., 1987). A bout $74 \%$ had past or current infection by gonococcus, $73 \%$ by hepatitis B virus, $67 \%$ by HIV, $30 \%$ by amoebae and $20 \%$ by treponema (Darrow $\notin$ al., 1987). This group had been randomly selected from a list of homosexuals who had volunteered to be investigated for hepatitis B virus infection and to donate antisera to hepatitis B virus between 1978 and 1980. For the same group the $50 \%$ "progression rate" from HIV to AIDS was calcur lated to be 8-11 years (Table 2) (M oss \& al., 1988; Lemp \& al., 1990)_- 
and reported to be relevant for "the (HIV-infected) population as a whole" (Moss \&al., 1988)!

A study investigating AIDS risk factors among French homosexuals reported that $31 \%$ of those with AIDS, but only $12 \%$ of those without AIDS, had achieved "over 100 nitrite inhalations" (Messiah \& al., 1988). Thestudy included 53 , or $45 \%$, of all homosexual AIDS patients recorded in France by 1987.

The staggering oral drug use among male homosexuals at risk for AIDS was confirmed in 1990 by the largest survey of its kind. It reports that $83 \%$ of 3916 self-identified American homosexual men had used one, and about $60 \%$ two or more drugs with sexual activities during the previous six months (Ostrow $\notin$ al., 1990). Similar drug use has been reported for European homosexuals at risk for AIDS van Griensven \& al., 1987).

A survey of homosexual men from Boston, conducted between 1985 and 1988, documented that among 206 HIV-positives $92 \%$ had used nitrite inhalants, $73 \%$ cocaine, 39\% amphetamines, $29 \%$ lysergic acid in addition to six other psychoactive drugs as sexual stimulants; among 275 HIV-negative controls $71 \%$ had used nitrites, 57\% cocaine, $21 \%$ amphetamines, $17 \%$ lysergic acid again in addition to six other psychoactive drugs (Seage $\notin$ al., 1992). A similar survey of 364 HIV-positive homosexual men in Berlin conducted between 1983 and 1987 stated that 194 (53.3\%) had used nitrite inhalants (Deininger \& al., 1990).

A ccording to N ewell \&al. (1985b), volatile nitrites had penetrated "every corner of gay life" by 1976. Surveys studying the use of nitrite inhalants found that in San Francisco 58\% of homosexual men were users in 1984 and $27 \%$ in 1991, compared to less than $1 \%$ of heterosexuals and lesbians of the same age group (Lesbian and Gay Substance A buse Planning Group, 1991b).

Several investigators have pointed out that nitrite inhalants, and possibly other drugs, are preferred by male homosexuals as aphrodisiacs because they facilitate anal intercourse by relaxing smooth muscles (Section 4.4.1) (M invish and Haverkos, 1987; Newell e al., 1985b; Ostrow \& al., 1990; Lesbian and Gay Substance A buse Planning Group, 1991a; Seage $\notin$ al., 1992). “Nitrites were used primarily for heightened sexual stimulation during sexual activity by reducing social and sexual inhi- 
bitions, prolonging duration, heightening sexual arousal, relaxing the anal sphincter during anal intercourse, and prolonging orgasm" Newell $\notin$ al., 1985b).

\subsubsection{AsymptomaticAZT Users Generatean Unknown Percentage of AIDS Patients}

The DNA chain terminator AZT has been licensed in the U.S. since 1987 as a treatment for AIDS patients (Chernov, 1986; Kolata, 1987; Lauritsen, 1990; Yarchoan \& al., 1991) based on a placebo controlled study sponsored by Burroughs Wellcome, the manufacturer of AZT (Section 4.4.2) (Fischl \& al., 1987; Richman \&al., 1987). In 1990 AZT was also licensed as AIDS prophylaxis for healthy HIV carriers (Section 4.4.2) (Volberding \& al., 1990; Yarchoan \& al., 1991).

The choice of this drug as anti-A IDS treatment is based entirely on the virus-AIDS hypothesis. A ccording to Broder \& al., "The rationale for anti-retroviral therapy for AIDS is... that HIV is the etiologic agent of AIDS" and that HIV RNA-dependent DNA synthesis is inhibited by AZT (Yarchoan $\&$ al., 1991). In view of this and their faith in the virus-AIDS hypothesis, about 120,000 A merican HIV carriers, with and without AIDS, and 180,000 worldwide currently take AZT every day (Section 4.1). It follows that probably a high percentage of the 40,000 A mericans and 15,000 Europeans that currently develop AIDS per year (Table 1 ) have used AZT and other DNA chain terminators prior to AIDS.

The drug is now recommended as AIDS prophylaxis for all AIDSfree persons with less than $500 \mathrm{~T}$-cells per microliter by the director of AIDS research at the NIH (Kolata, 1992) and with some reservations also by the $\mathrm{N}$ ational Hemophilia Association of $\mathrm{N}$ ew York (personal communication), despite recent doubts about its usefulness (Kolata, 1992). For instance, AZT has been used indefinitely by over 1200 AIDSfree, but presumably HIV-infected, homosexual men from the M ulticenter A IDS Cohort Study referenced above (Ostrow \& al., 1990), including $7 \%$ of 3670 with over $500 \mathrm{~T}$-cells per microliter, $16 \%$ of 1921 with $350-499$ T-cells, $26 \%$ of 1374 with $200-349$ T-cells and $51 \%$ of 685 with fewer than 200 T-cells Graham \& al., 1991). Yet the large study acknowledges finding “... no effects (of AZT) on rates of progression 
to lower CD 4+ lymphocyte counts in any of the transition intervals" Graham $₫$ al., 1991). In San Francisco 3.3\% of 151 AIDS-free male homosexuals with over $500 \mathrm{~T}$-cells, $11 \%$ of 128 with $200-500 \mathrm{~T}$-cells and $36 \%$ of 42 with less than 200 T-cells were on AZT in 1989 (Lang \&al., 1991). A nother study reports that, in 1989, 26 out of $322 \mathrm{HIV}$ positive but AIDS-free homosexuals from San Francisco, Chicago and Denver had taken AZT for less than 6 months and 101 for over 6 months (Holmberg \& al., 1992).

To distinguish between HIV and drugs as causes of AIDS, it is necessary to identify either HIV-carriers that develop AIDS only when they use drugs (Section 4.4) or to identify HIV-free drug users that develop AIDS indicator diseases (Section 4.5) and to demonstrate drug toxicity (Section 4.6).

\subsection{Drug Use Necessary for AIDS in HIV-Positives}

Studies demonstrating that drugs are necessary for AIDS among HIVpositives fall into two subgroups: (1) those demonstrating that AIDS among HIV-positives depends on the long-term use of recreational drugs and (2) those demonstrating that HIV-positive AIDS-free persons and AIDS patients on the antiviral drug AZT develop new AIDS diseases or AZT-specific diseases Sincethe health of AIDS-free persons selected for AZT prophylaxis is compromised by prior AIDS risks, eg. less than 500 T-cells, and since nearly all A merican and European AIDS patients have used recreational drugs or have been immunosuppressed by longterm transfusions, evaluating the role of AZT in the progression of AIDS is complicated by these confounding risk factors (Sections 3.4.4 and 4.3.3).

\subsubsection{AIDS From Recreational Drugs}

(1) A study of $65 \mathrm{HIV}$-infected drug users from $\mathrm{N}$ ew York showed that their T-cell count dropped over nine months in proportion with drug injection, on average $35 \%$, compared to controls who had stopped (DesJarlais \& al., 1987).

(2) The incidence of AIDS diseases and death among HIV-positive, asymptomatic intravenous drug users over 16 months were 19\% (23/ 124) 
among those who persisted in injecting psychoactive drugs, 5\% (5/93) among those who had stopped injecting drugs and 6\% ( 5/ 80) among those on methadone treatment (Weber $\&$ al., 1990).

(3) A mong male homosexuals, receptive anal intercourse carries a 2.75 times (Warren Winkelstein, personal communication) to 4.4 times (Haverkos, 1988b) higher AIDS risk than insertive intercourse, presumably reflecting a higher risk of infection by HIV (M oss \& al., 1987; van Griensven \& al., 1987; Winkelstein \& al., 1987; Seage \& al., 1992). However, if HIV were the cause of AIDS, the donors should have the sameAIDS risk as the recipients, because recipients can only be infected by HIV donors. No microbe can survive that is only unidirectionally transmitted. All venereal microbes are therefore bitransitive Indeed, Haverkos found no differences in sexually transmitted diseases between those practicing receptive and insertive intercourse (Haverkos, 1988b). The probable reason for the higher AIDS risk associated with receptive anal intercourse is that this sexual practice directly correlates with a 2-fold (van Griensven \& al., 1987; Seage e al., 1992) to an 8-fold (M oss \&al., 1987; Haverkos 1988b) enhanced use of nitrite inhalants and other aphrodisiac drugs that facilitate anal intercourse (Sections 4.3.2 and 4.6).

(4) A Canadian study reports that every one of $87 \mathrm{HIV}$-positive male homosexual AIDS patients had used nitrite inhalants. Those who had used over 20 "hits" per month were more likely to have Kaposi's sarcoma and sarcoma plus pneumonia than those who had used less than 20 hits per month. HIV-free controls, described in a previous report of the same cohort (Section 4.5) (M arion e al., 1989), were not mentioned in this study (Archibald $₫$ al., 1992). The authors concluded that a "sexually transmitted agent," which is even more difficult to transmit than HIV(!) (Section 3.5.1), would explain the K aposi's sarcomas among the AIDS patients. The nitrites were proposed to be a cofactor of this cofactor of HIV (A rchibald e al., 1992). Thus nitrites were necessary for AIDS in HIV-positives.

To determine whether HIV was indeed necessary for these AIDS cases, the incidence of AIDS-defining diseases in HIV-positiveand negative homosexuals who are matched for the duration and extent of drug consumption must be compared. This is what the Canadian team has 
recently attempted to do in a study termed "HIV causes AIDS: a controlled study" (Craib \& al., 1992). The study asserts to meet the challenge of “Duesberg [who] wrote in 1988 (Science, 1988; 242: 997-998) and repeated in public addresses in 1991 that the necessary comparisons in controlled cohorts were not available ..."

However the study failed to match the HIV-free control group with the HIV-positives for the extent and duration of drug consumption. It mentions that $49 \%$ of the HIV-negatives had used "psychoactive drugs," but fails to mention the percentage of drug users among the HIV-positives. In their previous study $100 \%$ of the HIV-positive AIDS patients had used such drugs (Archibald \& al., 1992). In addition the authors failed to recognize that HIV-infection is a marker for the duration of drug consumption. Sincean average of 1000 sexual contacts is required for sexual transmission of HIV (Section 3.5.2), HIV is a marker for the dosage of sexual stimulants that is used for 1000 contacts. Thus HIVpositives would have used more sexual stimulants, the equi valent for 1000 contacts, than HIV-negatives. I ndeed the authors acknowledge problems with "daims that AIDS is caused by other exposures and not by HIV ... the problem may be semantics. No one has ever disputed that cofactors play a very important role..." (Craib \& al., 1992). M oreover the authors failed to mention whether AZT was prescribed to the HIV-positives.

(5) A survey of 99, including 92 "gay or bisexual," AIDS patients from an "HIV clinic" at St. M ary's Hospital in London reports that $78 \%$ used "poppers" (nitrite inhalants), 78\% cannabis, 76\% cigarettes, $68 \%$ alcohol, and $48 \%$ "ecstasy" (amphetamines). In addition, the patients received an average of three unspecified medications, probably induding AZT (Valentine $₫$ al., 1992). HIV-tests were not reported, but are assumed to be positive because the patients were in an "HIV clinic." Clearly, the multiplicity of drugs consumed by these patients could be relevant to their pathogenesis.

(6) A European survey of HIV-positive infants with AIDS found that "nearly all children were born to intravenous-drug-abusing mothers" and that AIDS was 9.4 times more likely in children whose mothers had AIDS symptoms before delivery than in those who had no symptoms (M ok \& al., 1987). "Children with drug withdrawal symp- 
toms" were most likely to develop diseases, those with no withdrawal symptoms but "whose mothers had used recreational drugs in the final 6 months of pregnancy were intermediate on all indices, whereas children of former drug users did not significantly differ from those born to women who had no history of i.v. drug use" (European CollaborativeStudy, 1991). An A merican survey reported that 63 of 68 infants "with symptomatic HIV infections" had "at least one parent who had AIDS or was in an AIDS high-risk group" (Belman $\notin$ al., 1988). Since the risk of infants to develop AIDS increased with maternal drug consumption and increased 10-fold with maternal AIDS symptoms, it would appear that disease or subclinical deficiencies during pregnancy rather than perinatal infection by HIV are responsible for pediatric AIDS.

\subsubsection{AIDS from $A Z T$ and $A Z T$ Plus Confounding Recreational Drug Use}

(1) A placebo-controlled study, sponsored by Burroughs Wellcome the manufacturer of AZT, investigated 289 patients with "unexplained" weight loss, fever, oral candidiasis, night sweats, herpes zoster and diarrhea for the licensing of the drug as AIDS therapy in the U.S. [Fischl \&al., 1987; Richman \&al., 1987). All but 13 of thesepatients were males The study was planned for 6 months, but it was interrupted after 4 months, because by then the therapeutic benefits of AZT seemed too obvious to continue the placebo control:

(a) after 4 months on AZT 1 out of 145 in the AZT group but 19 out of 137 in the placebo group had died. Therefore the study claimed that AZT can "decrease mortality";

(b) T-cell counts first increased from 4-8 weeks and then declined to pretreatment levels within 4 months;

(c) the lymphocyte count decreased over $50 \%$ in $34 \%$ of the AZT recipients but in only $6 \%$ of the control group;

(d) 66 in the AZT group suffered from severe nausea, compared to only 25 in the control group;

(e) muscle atrophy was observed in 11 AZT recipients but in only 3 from the control group. Yet, the primary daim of the study, "decreased mortality" from AZT is not realistic if one considers that 30 out of the 145 in the AZT-group depended on multiple transfusions to survive 
anemia, compared to only 5 out of the 137 in the placebo group. Thus the number of subjects in the AZT-group who would have died from severe anemia if untreated was larger, i.e 30, than the AIDS deaths and anemias of the control group combined, namely 19+5. The "decreased mortality"-claim is further compromised by numerous "concomitant medications" other than transfusions for AZT-specific diseases and failure to match the AZT and placebo groups for the cumulative effects of prior and parallel recreational drug use In addition some of the AZTspecific AIDS diseases observed in the placebo group appear to be due to patient-initiated "drug sharing" between AZT and placebo recipients (Lauritsen, 1990; Duesberg, 1992d; Freestone, 1992) and falsification of the case report forms (Lauritsen, 1992).

M oreover the low mortality of $0.7 \%$ ( $1 / 145)$ claimed by the licensing study for the first 4 months on AZT could not beextended in a follow-up study which found the "survival benefits" of AZT rapidly declining after the original 4 month period. By 18 months $32 \%$ of the original AZT group had died and $35 \%$ of the former control group, which by then had also received AZT for 12 months (Fischl $\notin$ al., 1989).

Since the original study considered AZT effective in decreasing AIDS mortality, subsequent placebo-controlled studies were deemed unethical. But the low mortality daimed by thelicensing study has not been confirmed by later studies, which observed mortalities of $12-72 \%$ within 9-18 months (see items ( 3 ) to (6) below). In addition, a CDC study has recently reported a mortality of $82 \%$ in a cohort of 55 AIDS patients that had been on AZT for up to 4 years (Centers for Disease Control, 1991) - hardly recommending AZT as an AIDS therapy.

The brief transient gains of $\mathrm{T}$-cells observed upon AZT treatment by the licensing study may reflect compensatory hemopoiesis, random killing of pathogenic parasites (Elwell $\&$ al., 1987) and the influence of concomitant medication, induding multiple transfusions Richman \& al., 1989). Indeed the study concluded, based on the "hematological toxicity" described above, that "... the initial beneficial immunological effects of AZT may not be sustained" (Richman \& al., 1987). A French study confirms “. ... the decrease of cell counts below the initial value after a few months of $A Z T$ suggests that this drug might betoxic to cells" (seeitem (3) below) (Dournon \& al., 1988). And a recent A mer- 
ican study also confirms “... no effects on rates of progression to lower CD4 + lymphocyte counts in ( 6 month) transition intervals" (Section 4.3.3) Graham et a]., 1991). M oreover, the manufacturer states, "A modest increase in mean CD 4 (T 4) counts was seen in the zidovudine group but the significance of this finding is unclear as the CD 4 (T4) counts declined again in some patients" (M edical Economics Data, 1992).

(2) In view of the reported success of AZT as AIDS therapy, the drug was also tested for licensing as AIDS prophylaxis by much of the same team, induding Fischl, Richman and Volberding, and again with support from the manufacturer Burroughs Wellcome (Volberding \& al., 1990). The study treated AIDS-free, HIV-positive 25- to 45-year-old male homosexuals and intravenous drug users with "fewer than 500 T-cells" for one year either with AZT or with a placebo. The expected annual AIDS risk for intravenous drug users and male homosexual risk groups is about 4-6\% per year without AZT (Section 3.4.4.4).

The study reports AIDS diseases in: (1) 11 out of 453 on $500 \mathrm{mg}$ AZT per day, (2) 14 out of 457 on $1500 \mathrm{mg}$ AZT per day and (3) 33 out of 428 on a placebo (Volberding et a]., 1990). Thus the AZT-groups appeared to do better than expected and the placebo group did as expected. Therefore it was claimed that AZT prevents AIDS.

However, the price for the presumed savings of 22 (33-11) and 19 (33-14) AIDS cases with AZT, compared to the placebo group, was high because 19 AZT-specific cases of potentially fatal anemia, neutropenia and severe nausea appeared in the $500 \mathrm{mg}$ AZT-group, and 72 such cases, including 29 anemi as requiring life-saving blood transfusions, appeared in the $1500 \mathrm{mg}$ AZT-group. This indicates cytocidal effects of $A Z T$ on hemopoiesis and on the intestines. Although the AZT-specific diseases were not diagnosed as AIDS, neutropenia generates immunodeficiency (Walton \& al., 1986) and thus AIDS. If these AZT-specific cases were included in the calculation of benefits from AZT compared to the placebo group, the 500 mg-group no longer benefited and the 1500 mg-group tripled its disease risk.

The study was further compromised by its failure to match the treatment groups for their cumulative recreational drug use prior to and during the study and for the many compensatory treatments for the 
AZT-specific diseases of the subjects analyzed. The fact that 8 cases in the control group but only 3 and 1 in the $500 \mathrm{mg}$ and $1500 \mathrm{mg}-\mathrm{AZT}$ groups developed AIDS cancers suggests that the control group could have been exposed to higher recreational drug doses

Since the licensing study considered AZT effective in preventing AIDS, subsequent controlled trials were deemed unethical. However, several subsequent studies cast further doubt on the daim that AZT is a useful AIDS prophylactic. One study reported that persons with "early" AIDS, i.e AIDS-free persons at risk for AIDS, died at the same rate of $12-14 \%$ as AIDS controls and that $82 \%$ developed leukopenia within less than a year (seeitem 6 below) (Hamilton $\notin a l .$, 1992). A nother study described "no effects on rates of progression to lower CD4+ lymphocytes..." recorded within 6 month periods in over 1200 AIDS-free men on AZT (Section 4.3.3) Graham \& al., 1991). A third study reported that 26 out of $127 \mathrm{HIV}$-positive, AIDS-free homosexuals had discontinued an unreported dose of AZT within less than 6 months, most because of severe toxicity (Section 4.3.3) (Holmberg \& al., 1992). In view of these and other data, it is surprising that a loss of T-cells was not noted in the licensing study (Kolata, 1987).

(3) A F rench study investigated the effects of AZT on 365 AIDS patients The patients included $72 \%$ male homosexuals and $11 \%$ intravenous drug users with a median age of 36 years and with opportunis tic infections and K aposi's sarcoma. The study, the largest of its kind, observed new AIDS diseases, including leukopenia, in over $40 \%$ and death in $20 \%$ within 9 months on AZT (Dournon \& al., 1988). The AIDS diseases of $30 \%$ worsened during AZT treatment. The study reported no therapeutic benefits 6 months after initiating AZT therapy. The authors conduded: “ . . . the rationalefor adhering to high-dose regimens of $A Z T$, which in many instances leads to toxicity and interruption of treatment, seems questionable"

(4) A Dutch study treating 91 male AIDS patients, averaging 39 years, after 67 weeks on AZT, observed mortality in $72 \%$ and AZT-specific myelotoxicity, requiring on average 5 blood transfusions, in $57 \%$. A bout $34 \%$ of the myelotoxicity manifested in anemia and $20 \%$ in leukopenia. The authors concluded that "the majority of patients ... cannot be maintained on these (AZT) regimens, most commonly due 
to the development of hematological toxicity" (van Leeuwen \& al., 1990).

(5) An A ustralian study involving 308 homosexual and bisexual men with Kaposi's sarcoma, lymphoma and opportunistic infections and a median age of 36 years, reported $30 \%$ mortality within $1-1.5$ years on AZT. In addition one or more new AIDS diseases, induding pneumonia, candidiasis, fever, night sweats and diarrhea were observed in 172 (56\%) within one year (Swanson \& al., 1990). M oreover, $50 \%$ needed at least one blood transfusion and $29 \%$ needed multiple blood transfusions to survive A ZT treatment. Yet the authors concluded that the "risk:benefit ratio (is) advantageous to AIDS patients" (Swanson \& al., 1990).

(6) A comparison of the effects of indefinite AZT treatment on 170 HIV-positive AIDS-free persons with "early" AIDS to 168 with "late" AIDS indicated that the mortality was the same in both groups, i.e. $12-14 \%$ per $1-1.5$ years (Hamilton $\&$ al., 1992). The median age of the AZT recipients was 40 years; $63 \%$ were male homosexuals and $25 \%$ were intravenous drug users. AZT-specific diseases were observed in most "early AIDS" cases, i.e leukopenia in 82\%, severe leukopenia in $14 \%$, anemia in $20 \%$, severe anemia requiring transfusions in $5 \%$, nausea in $40 \%$ and skin rashes in $47 \%$. This indicates directly that AZT is toxic for AIDS-free HIV carriers, and that AZT toxicity is sufficiently dominant over other AIDS causes that it accelerates the progression to death of AIDS-free HIV carriers to the same rate that is observed in lateAIDS patients (Duesberg, 1992d). Theauthors conduded that AZT, contrary to the Wellcome-sponsored study from 1987 conducted for licensing $A Z T$, does not extend life.

(7) The annual lymphoma incidence of AZT-treated AIDS patients, with Kaposi's sarcoma, pneumonia and wasting disease, was reported to be $9 \%$ by the N ational Cancer I nstitute and was calculated to be $50 \%$ over three years (Pluda \& al., 1990). The estimate of the 3-year incidence of lymphoma from this study was recently revised down to $31 \%$ (Yarchoan $\notin$ al., 1991). A $n$ independent study observed in a group of 346 A IDS patients in London, most of whom were on AZT, "during the past three years a progressive increase in the number of patients dying from lymphoma, ..." to a current total of $16 \%$ in 1991 (Peters 
etal., 1991). And a CDC study reported a 15\% lymphoma incidence during 24 months on AZT (Centers for Disease Control, 1991).

The lymphoma incidence of untreated, HIV-positive AIDS risk groups is $0.3 \%$ per year, derived from the putative average progression rate of 10years from HIV to AIDS (M oss \& al., 1988; Lemp \& al., 1990; Duesberg, 1991a) and the $3 \%$ incidence of lymphoma in AIDS patients (Centers for Disease Control, 1992b). Therefore, the annual lymphoma risk of $A Z T$ recipients is about 30 times higher than that of untreated HIV-positive counterparts It appears that the chronic levels of the mutagenic AZT, at 20-60 $\mu \mathrm{M}$ ( $500-1500 \mathrm{mg} /$ person/ day), were responsible for the lymphomas (Section 4.6.2).

An alternative interpretation suggests that AZT had prolonged life sufficiently to allow HIV to induce the lymphomas directly or via immunodeficiency (Pluda \& al., 1990; Centers for Disease Control, 1991). However, this interpretation is flawed for several reasons: (1) Cancers, including malignant lymphomas, are not consequences of a defective immune system (Section 3.5.8). (2) There is as yet only a model for how HIV, the presumed killer of T-lymphocytes, could also cause cancer (Section 3.5.14) Gallo, 1990). (3) AZT-induced lymphomas lack HIVspecific markers (M CD unn \& al., 1991). (4) Several studies indicate that AZT does not prolong life (see above) (Dournon \& al., 1988; van Leeuwen \& al., 1990; Hamilton \&al., 1992; Kolata, 1992).

(8) Ten out of 11 HIV antibody-positive, AZT-treated AIDS patients recovered cellular immunity after discontinuing $A Z T$ in favor of an experimental HIV vaccine (Scolaro \& al., 1991). The vaccine consisted of an HIV strain that was presumed to beharmless, because it had been isolated from a healthy carrier who had been infected by the virus for at least 1oyears. Since there was no evidence that the hypothetical vaccine strain differed from that by which the patients were al ready naturally vaccinated, the only relevant difference between the patients before and during the vaccine trial was the termination of their AZT treatment. It follows that A ZT treatment is at least a necessary, if not a sufficient, cause of immunodeficiency in HIV-positives.

(9) Four out of 5AZT-treated AIDS patients recovered from myopathy two weeks after discontinuing AZT; two redeveloped myopathy on 
renewed AZT treatment (Till and M acD onnell, 1990), indicating that AZT is at least necessary for myopathy in HIV-positives

(10) Four patients with pneumonia developed severe pancytopenia and bonemarrow aplasia 12 weeks after the initiation of AZT therapy. Three out of 4 recovered within 4-5 weeks after AZT was discontinued (Gill $\notin$ al., 1987), indicating that $A Z T$ is necessary for pancytope nia in HIV-positives.

\subsection{Drug Use Sufficient for AIDS I ndicator Diseases in the Absence of HIV}

Studies demonstrating AIDS-defining diseases in drug users in the absence of HIV are chronologically and geographically censored by the virus-AIDS hypothesis. Before the general acceptance of this hypothesis in theU.S., there were numerous A merican studies blaming AIDS on recreational drugs, but afterwards there was but one A merican report describing HIV-free Kaposi's sarcomas in homosexuals who had used such drugs, and only a few A merican and some European studies describing AIDS-defining diseases in HIV-free intravenous drug users (see below).

If HIV were necessary for AIDS among drug users, only HIV-positive drug users should devel op AIDS. However, there is not even one controlled study showing that among matched drug users only HIVpositives get AIDS. On the contrary, such studies all indicate that drugs are sufficient to cause AIDS.

\subsubsection{Drugs Used for Sexual Adivities Sufficient for AIDS Diseases}

(1) The first five AIDS cases, diagnosed in 1981 before HIV was known, were male homosexuals who had all consumed nitriteinhalants and presented with Pneumocystis pneumonia and cytomegalovirus infection (Gottlieb \& al., 1981).

(2) In 1985 and again in 1988 Haverkos analyzed the A IDS risks of 87 male homosexual AIDS patients with Kaposi's sarcoma (47), Kaposi's sarcoma plus pneumonia (20) and pneumonia only (20) (Haverkos ef al., 1985; Haverkos, 1988b). All men had used several sexual stimulants, 98\% had used nitrites Those with Kaposi's sarcomas reported double 
the amount of sexual partners and 4.4-times more receptive anal intercourse than those with only pneumonia. The median number of sexual partners in the year prior to theillness was 120 for those with Kaposi's and 22 for those with pneumonia only. The Kaposi 's cases reported $\sigma$ times more amylnitrite and ethylchloride use, 4-times more barbiturate use, and twice the methaqualone, Iysergic acid and cocaine use than those with pneumonia only. Since no statistically significant differences were found for sexually transmitted diseases among the patients, the authors concluded that the drugs had caused Kaposi's sarcoma.

Although the data for Haverkos' analysis had been collected before HIV was declared the cause of AIDS, Haverkos' conclusion is valid. This is because (1) all patients had AIDS but only the heavy drug users had Kaposi's sarcoma in addition to immunodeficiency and because (2) not all can be assumed to be infected by HIV becausetransmission depends on an average of 1000 contacts (Section 3.5.2). Indeed, HIV was found in only $24 \%$ (Deininger \& al., 1990), 31\% (van Griensven \& al., 1990), 43\% (Graham \& al., 1991; Seage \& al., 1992), 48\% (Winkel. stein \& al., 1987), 49\% (Lemp \& al., 1990), 56\% (M arion \& al., 1989) and $67 \%$ (Darrow \& al., 1987) of cohorts of homosexuals at risk for AIDS in Berlin, A msterdam, Chicago-Washington DC-Los A ngelesPittsburgh, Boston, San Francisco and Canada that were similar to those described by Haverkos.

(3) A 4.5 year tracking study of 42 homosexual men with lymphadenopathy but not AIDS reported that 8 had developed AIDS within 2.5 years (M athur-Wagh $\notin$ al., 1984) and 12 within 4.5 years of observation (M athur-Wagh \& al., 1985). All of these men had used nitrite inhalants and other recreational drugs including amphetamines and cocaine, but they were not tested for HIV. The authors conduded that "a history of heavy or moderate use of nitrite inhalant before study entry was predictive of ultimate progression to AIDS" (Mathur-Wagh $\notin$ al., 1984).

(4) Before HIV was known, three controlled studies compared 20 homosexual AIDS patients to 40 AIDS-free controls (M armor $\notin$ al., 1982), 50 patients to 120 controls (Jaffe $\notin$ al., 1983b) and 31 patients to 29 controls (Newell $\notin$ al., 1985a) to determineAIDS risk factors. Each study reported that multiple "street drugs" were used as sexual stimu- 
lants. And each study conduded that the "lifetime use of nitrites" (J affe e al., 1983b) were $94 \%$ to $100 \%$-consistent risk factors for AIDS (N ewell $\notin$ al., 1985a).

(5) Early CDC data indicate that $86 \%$ of male homosexuals with AIDS had used oral drugs at least once a week and $97 \%$ occasionally (Centers for Disease Control, 1982; Haverkos, 1988b). The $N$ ational Institute on Drug A buse reports correlations from 69\% (L ange $\notin$ al., 1988) to virtually $100 \%$ (Haverkos. 1988a; Newell $\notin$ al., 1988) between nitrite inhalants and other drugs and subsequent $K$ aposi's sarcoma and pneumonia.

(6) A 27- to 58-fold higher consumption of nitrites by male homosexuals compared to heterosexuals and lesbians (Lesbian and Gay Substance A buse Planning Group, 1991 a,b) correlates with a 2o-fold higher incidence of Kaposi's sarcoma (Selik \& al., 1987; Beral \& al., 1990) and a higher incidence of all other AIDS diseases in male homosexuals compared to most other risk groups (Tables 1 and 2).

(7) During the last 6-8 years the use of nitrite inhalants among male homosexuals decreased, eg. from 58\% in 1984 to $27 \%$ in 1991 in San Francisco (Lesbian and Gay SubstanceA buse Planning Group, 1991b). In parallel, the incidence of Kaposi's sarcoma among American AIDS patients decreased from a high of 50\% in 1981 (Haverkos 1988b), to $37 \%$ in 1983 (Jaffe etal., 1983a), to a low of 10\% in 1991 (Centers for Disease Control, 1992b). It follows that the incidence of K aposi's sarcoma is proportional to the number of nitrite users.

(8) After the discovery of HIV, 5 out of 6 HIV-free male homosexuals from $\mathrm{N}$ ew York with $\mathrm{K}$ aposi's sarcoma have reported the use of nitrite inhalants (Friedman-Kien $\notin$ al., 1990). Some of these men had no immunodeficiency. Soon after another six cases of HIV-free Kaposi's sarcoma were reported in a "high risk population" from N ew York (Safai $\notin$ al., 1991). This indicates directly that HIV is not necessary and suggests that drugs are sufficient for AIDS.

(9) A 44-year-old, HIV-free homosexual man from Germany developed Kaposi's sarcoma and had a T4 to T8-cell ratio of only 1.2. The man "had used nitrite inhalants for about 10 years," but had no apparent immunodeficiency (M arquart \& al., 1991). Likewise, K aposi's sarcoma was diagnosed in a 40-year-old, promiscuous HIV-free homosexual 
from England who admitted "frequent use of amyl nitrite" The patient was otherwisesymptom-free with a normal T4/ T8 cell ratio A rcher et al., 1989). In 1981 an English male homosexual with a "history of amylnitrite inhalation," hepatitis B, gonorrhea and syphi lis was also diagnosed with Kaposi's sarcoma. In 1984 he was found to be free of HIV, but in 1986 he became antibody-positive (Lowdell and Glaser, 1989).

(10) A prospective study from Canada identified immunodeficiency in 33 out of 166 HIV-free homosexual men (Marion \& al., 1989). The study did not mention drug consumption, but a later report on homosexual men with AIDS from the same cohort documented that all had been using either more or less than 20 "hits" of nitrites per month (Section 4.4) (A rchibald e al., 1992). Thus nitrites and possibly other drugs were sufficient for immunodeficiency.

Likewise, Lang, \& al. (1989) described a steady decline of T4-cells in 37 homosexual men in San Francisco from 1200 per $\mu \mathrm{L}$ prior to HIV infection to 600 or less at the time of infection. Although recreational drug use and AZT werenot mentioned, other studies of the same cohort of homosexual men from San Francisco described extensive use of recre ational drugs (Section 4.3.2) (Darrow $\notin$ al., 1987; M Oss, 1987) and AZT (Langeal., 1991).

\subsubsection{Long-termI ntravenous Drug UseSufficient} for AIDS-defining Diseases

(1) A mong intravenous drug users in N ew York representing a "spectrum of HIV-related diseases," HIV was observed in only 22 out of 50 pneumonia deaths, 7 out of 22 endocarditis deaths, and 11 out of 16 tuberculosis deaths (Stoneburner e al., 1988).

(2) Pneumonia was diagnosed in 6 out of 289 HIV-free and in 14 out of 144 HIV-positive intravenous drug users in N ew York Selwyn A al., 1988).

(3) Among 54 prisoners with tuberculosis in New York state, 47 were street-drug users, but only 24 were infected with HIV Braun $\mathrm{B}$ al., 1989).

(4) In a group of 21 long-term heroin addicts, the ratio of helper to suppressor T-cells declined during 13 years from a normal of 2 to less 
than 1, which is typical of AIDS (Centers for Disease Control, 1987; Institute of M edicine, 1988), but only 2 of the 21 were infected by HIV (Donahoe $\notin$ al., 1987).

(5) Thrombocytopenia and immunodeficiency were diagnosed in 15 intravenous drug users on average 10 years after they becameaddicted, but 2 were not infected with HIV (Savona $\notin$ al., 1985).

(6) The annual mortality of $108 \mathrm{HIV}$-free Swedish heroin addicts was similar to that of $39 \mathrm{HIV}$-positive addicts, i.e 3-5\%, over several years (A nnell \& al., 1991).

(7) A survey of over a thousand intravenous drug addicts from Germany reported that the percentage of HIV-positives among drug deaths (10\%) was exactly the same as that of HIV-positives among living intravenous drug users (Puschel and M ohsenian, 1991). A nother study from Berlin also reported that the percentage of HIV-positives among intravenous drug deaths was essentially the same as that among living intravenous drug users, i.e 20-30\% (Bschor \& al., 1991). This indicates that drugs are sufficient for and that HIV does not contribute to AIDS-defining diseases and deaths of drug addicts.

(8) In 1989, the annual mortality of 197 HIV-positive, parenteral drug users from $A$ msterdam with an average age of 29 years was $4 \%$ and that of 193 age-matched HIV-negatives was 3\% Mientjes \& al., 1992). The annual incidence of pneumonia was $29 \%$ in the HIV-positives and 9\% in the negatives Clearly, a 3-fold higher morbidity is intrinsically inconsistent with a near identical mortality. However, the slightly higher mortality of HIV-positives is compatible with the fact that the positives had injected more drugs for a longer time, eg. $84 \%$ of the positives vs $64 \%$ of the negatives had injected over the last 5 years, $85 \%$ vs $72 \%$ over the last 6 months and 59\% vs 50\% had injected heroin and cocaine

(9) Lymphocyte reactivity and abundance were depressed by the absolute number of injections of drugs not only in 111 HIV-positive, but also in 210 HIV-free drug users from Holland (M ientjes \& al., 1991).

(10) The same lymphadenopathy, weight loss, fever, night sweats, diarrhea and mouth infections were observed in 49 out of 82 HIV-free, and in 89 out of $136 \mathrm{HIV}$-positive, long-term intravenous drug users in New York (Des Jarlais \&al., 1988). 
(11) A mong intravenous drug users in F rance, lymphadenopathy was observed in 41 and an over 10\% weight loss in 15 out of $69 \mathrm{HIV}$ positives, and in 12 and 8, respectively, out of $44 \mathrm{HIV}$-negatives Espinoza \& al., 1987). The French group had used drugs for an average of 5 years, but the HIV-positives had injected drugs about 50\% longer than the negatives.

(12) In a group of $510 \mathrm{HIV-positive} \mathrm{intravenous} \mathrm{drug} \mathrm{users} \mathrm{in} \mathrm{Balti-}$ more, $29 \%$ reported one and $19 \%$ reported two or more AIDS-defining di seases. In a control group of $160 \mathrm{HIV}$-negative intravenous drug users matched with the HIV-positives for "current drug use," again $29 \%$ reported one and $13 \%$ reported two or more AIDS-defining diseases (MunOz \&al., 1992).

Nevertheless, the average T-cell count of HIV-negatives was about 2-times higher than that of HIV-positives (M unOz $\notin$ al., 1992). A sin the above $F$ rench study (Espinoza $\&$ al., 1987), this appears to reflect a higher lifetime dose of drugs, because HIV is a marker for the duration and extent of drug consumption (Sections 3.4.3, 4.4 and 5).

(13) A mong 97 intravenous drug users in N ew York with active tuberculosis, 88 were HIV-positive and 9 were HIV-negative; and among 6 "crack" (cocaine) smokers with tuberculosis, 3 were HIV-negative and 3 were positive (Brudney and Dobkin, 1991).

(14) The mental development and psychomotor indices of 8 HIVinfected and 6 uninfected infants were observed from 6-21 months of age The mothers of each group were HIV-positiveand had used intravenous drugs and alcohol during pregnancy Koch, 1990; Koch \& al., 1990; T. Koch, R. Jeremy, E. Lewis, P. Weintrub, C. Rumsey and M. Cowan, unpublished data). The median indices of both groups were significantly below average eg. 80/100 mental development and 85/100 psychomotor units. The uni infected infants remai ned on average about 5/ 100 units higher. A control group of 5 infants, born to HIV-negative mothers who had also used intravenous drugs and alcohol during pregnancy, also had subnormal indices averaging about 95/ 100 for both criteria.

The degree of neurological retardation of the infants correlated directly with maternal drug consumption: $80 \%$ of the mothers of infected infants were "heavy" and 10\% occasional parenteral cocaine users and 
$33 \%$ were "heavy" and 33\% occasional alcohol users during pregnancy; $45 \%$ of the mothers of uninfected infants were "heavy" and 30\% occasional parenteral cocaine users and 35\% were "heavy" and 30\% occasional alcohol users; and $21 \%$ of the HIV-free mothers were "heavy" and $58 \%$ occasional parenteral cocaine users and $12 \%$ were "heavy" and $44 \%$ occasional alcohol users. In addition $66 \%$ of the HIV-positive and $63 \%$ of the negative mothers reported the use of opiates during pregnancy (T. Koch, R. Jeremy, E. Lewis, P. Weintrub, C. Rumsey and M. Cowan, unpublished data).

(15) The psychomotor indices of infants "exposed to substance abuse in utero" were "significantly" lower than those of controls, "independent of HIV status" Their mothers wereall drug users but differed with regard to drug use during pregnancy. The mean indices of 70 children exposed during pregnancy were 99 and those of 25 controls were 109. Thus maternal drug use during pregnancy impairs children independent of HIV Aylward \&al., 1992).

Thesamestudy also reports a "significant difference" based on the HIV status of these children. The mean scores of 12 HIV-positives was 88 and that of 75 negatives was 102 . But the study did not break down the scores of the HIV-positive infants based on "exposure to substance abuse in utero." Indeed, the scores of 4 of the 12 HIV-infected infants were "above average" i.e. 100-114, and 4 of the 12 mothers did not inject drugs during pregnancy.

(16) Ten HIV-free infants born to intravenous drug-addicted mothers had the following AIDS-defining diseases, "failure to thrive, persistent generalized lymphadenopathy, persistent oral candidiasis, and developmental delay ..." (Rogers \& al., 1989).

(17) One HIV-positive and $18 \mathrm{HIV}$-free infants born to intravenous drug-addicted mothers had only half as many leukocytes at birth than normal controls. At 12 months after birth, the capacity of their lymphocytes to proliferate was 50-70\% lower than that of lymphocytes from normal controls (Culver $\notin$ al., 1987).

(18) Two studies to test the role of HIV on neurological function confirm the drug-AIDS hypothesis indirectly and directly. The first of these, which excluded users of psychoactive drugs, found that neuropsychometric functions of $50 \mathrm{HIV}$-negative homosexuals were the 
sameas those of 33 HIV-positives (Clifford \& al., 1990). A nother study of intravenous drug users on methadone found that neither the drugimpaired neuropsychological functions of $137 \mathrm{HIV}$-negatives nor those of 83 HIV-positives were deteriorating over 7.4 months (M cKegney \& al., 1990). However, the study notes that the functions of HIV-positives were lower than those of HIV-negatives because "a greater number of injections per month, more frequent use of cocaine... were strongly associated with HIV seropositivity."

Thus, a critical lifetime dosage of drugs appears necessary in HIVpositives and sufficient in HIV-negatives to induce AIDS-indicator and other diseases.

\subsection{Toxic Effects of Drugs Used By AIDS Patients}

\subsection{Toxidity of Recreational Drugs}

From as early as 1909 (A chard \& al., 1909) evidence has accumulated that long-term consumption of psychoactive drugs leads to immune suppression and dinical abnormalities similar to AIDS, induding lymphopenia, lymphadenopathy, fever, weight loss, septicemia, increased susceptibility to infections and profound neurological disorders (Terry and Pellens, 1928; Briggs \& al., 1967; Dismukes \& al., 1968; Sapira, 1968; Harris and Garret, 1972; Geller and Stimmel, 1973; Brown \& al., 1974; Louria, 1974; M cDonough \& al., 1980; Cox \& al., 1983; Koze and A dams, 1986; Selwyn đal., 1989; Turner \& al., 1989; Kreek, 1991; Pil. lai \&al., 1991; Bryant \& al., 1992). Since the early 1980s, when T-cell ratios became measureable, low $\mathrm{T} 4$ to T8-cell ratios averaging 1 or less were reported in addicts who had injected drugs for an average of 10 years (Layon etal., 1984).

Intravenous drugs can be toxic directly and indirectly. I ndirect toxicity can be due to malnutrition, because of the enormous expense of illicit drugs, or to septicemia because most illicit drugs are not sterile (Cox \&al., 1983; Stoneburner etal., 1988; Lerner 1989; Buehler \&al., 1990; Pillai et al., 1991; Luca-M oretti, 1992). Typically, intravenous drug users develop pneumonia, tuberculosis, endocarditis and wasting disease (Layon \& al., 1984; Stoneburner \& al., 1988; Braun \& al., 1989; Brudney and Dobkin, 1991). Oral consumption of cocaine and other psychoactive drugs has been reported to cause pneumonitis, bronchi- 
tis, edema (Ettinger and Albin, 1989) and tuberculosis Brudney and Dobkin, 1991). Physiological and neurological deficiencies, including mental retardation, are observed in children born to mothers addicted to cocaine and other narcotic drugs (Fricker and Segal, 1978; Lifschitz đal., 1983; Alroomi \& al., 1988; Blanche \& al., 1989; Root-Bernstein, 1990a; Toufexis, 1991; Finnegan \& al., 1992; Luca-M oretti, 1992). According to the National Institute on Drug A buse, "Cocaine is currently the drug of greatest national concern, from a public health point of view ..." (Schuster, 1984).

Because inhalation of alkylnitrites relaxes smooth muscles, it has been prescribed since 1867 against angina pectoris and heart pain at doses of $0.2 \mathrm{~mL}$ Cox \& al., 1983; Newell \& al., 1985b; Shorter, 1987; Seage e al., 1992). No AIDS defining diseases have been reported at these doses in patients with those relatively severe, terminal cardiovascular diseases (Cox $\notin$ al., 1983; Shorter, 1987), possibly because they did not live long enough to develop them. However, immediate and late toxicities have been observed in recreational users who have inhal ed millilitres of nitrite inhalants (Newell \& al., 1985b; Schwart, 1988). Alkylnitrites are directly toxic as they are rapidly hydrolyzed in vivo to yield nitrite ions, which react with all biological macromolecules (Oster. Ioh and Olson, 1986; Maikel, 1988). Addicts with $0.5 \mathrm{mM}$ nitrite derivatives and 70\% methemoglobin in blood have been recorded (Osterloh and Olson, 1986). Toxicity for the immunesystem, the central nervous system, the hematologic system and pulmonary organs has been observed after short exposure to nitrites in humans and in animals (Newell \&al., 1985b, 1988, Wood, 1988). In 1982, Goedert e al. found that the helper to suppressor T-cell ratio was lower in homosexual men who had used volati le nitrite inhalants than among nonusers. Further, alkylnitrites were shown to be both mutagenic and carcinogenic in animals (Jorgensen and Lawesson, 1982; Hersh \& al., 1983; Mirvish \& al., 1988; Newell \&al., 1985b, 1988).

By comparing the AIDS risk factors of 31 homosexual men with AIDS to 29 without, Newell $₫$ al. and others determined a direct "doseresponse gradient": the higher the nitrite usage the greater the risk for AIDS (Marmor \& al., 1982; Newell \& al., 1985a; Haverkos and Dougherty, 1988) and deduced a 7-10 year lag time between chronic 
consumption and Kaposi 's sarcoma (Newell \& al., 1985b). Likewise, a French study of homosexual men with and without AIDS who had inhaled nitrites documents that "cases were significantly older (approximately 10 years) than controls" (Section 4.3.2) (Messiah \& al., 1988). Also, a German study observed Kaposi's sarcoma in an HIV-free man after he had inhaled nitrites for 10 years (Section 4.5.1) (M arquart $\mathrm{A}$ al., 1991). These studies indicate that about 10 years of nitrite inhalation are necessary to convert "controls" to "cases."

In view of this several investigators have proposed that nitrite inhalants cause pulmonary and skin Kaposi's sarcoma and pneumonia by direct toxicity on the skin and oral mucosa (Centers for Disease Control, 1982; Marmor \& al., 1982; Haverkos \&al., 1985; M athur-Wagh \&al., 1985; Newell \& al., 1985a; Lauritsen and Wilson, 1986; Haverkos, 1990). Because of their toxicity a prescription requirement was instated for the sale of nitrite inhalants by the Food and Drug Administration in 1969 (Newell \& al., 1985b) and because of an "A IDS link" (Cox, 1986) the sale of nitrites was banned by the U.S. Congress in 1988 (Public Law 100-690) (Haverkos 1990) and by the "Crime Control Act of 1990" (J anuary 23, 1990).

Although a necessary role of HIV in HIV-positive AIDS patients cannot be excluded, this role would be stoichiometrically insignificant compared to that of the drugs. This is because drug molecules exceed HIV molecules by over 13 orders of magnitude Given about $10^{10}$ leukocytes per human, of which at most 1 in $10^{4}$ are actively infected (Section 3.5.1), and that each actively infected cell makes about 100 viral RNA s per day, there are only $10^{6} \mathrm{~T}$-cells with $10^{2} \mathrm{HIV}$ RNA s in an HIVpositive person. By contrast, $1 \mathrm{~mL}$ (or $0.01 \mathrm{~mol}$ ) of amyl nitrite with a molecular weight of 120 contains $6 \times 10^{21}$ molecules, or $6 \times 10^{7}$ nitrite molecules, for every one of the $10^{14}$ cells in the human body. Thus, based on molecular representation, HIV's role in AIDS, if it existed, would have to be catalytic in comparison with that of drugs.

Pillai, Nair and Watson condude from a recent review on the role of recreational drugs in AIDS: "Circumstantial and direct evidencesuggesting a possible role for drug. . . induced immunosuppression appears overwhelming. What is required now is better and more accurate detection of substance abuse, a direct elucidation of the immune and related 
mechanisms involved, and appropriate techniques to analyze it" (Pillai etal., 1991).

\subsubsection{Toxicity of AZT}

Since 1987 A ZT has been used as an anti-HIV agent (Section 4.3.3) based on two placebo-controlled studies reporting therapeutic and prophylactic benefits (Section 4.4.2). However, AZT was originally developed in the 1960 for cancer chemotherapy to kill human cells via termination of DNA synthesis (Cohen, 1987; Y archoan and Broder, 1987a; Yarchoan \& al., 1991). The primary AZT metabolites are 3'-termini of DNA which arecell-killing, 3'-amino-dT which is more toxic than AZT, and 5'-O-glucuronide which is excreted (Cretton $₫$ al., 1991). As a chain terminator of DNA synthesis, AZT istoxic to all cells engaged in DNA synthesis. AZT toxicity varies a great deal with the subject treated due to differences in its uptake and in its cellular metabolism (Chernov, 1986; Elwell $\notin$ al., 1987; Yarchoan and Broder, 1987b; Smothers, 1991; Yarchoan \&al., 1991).

AZT is prescribed as AIDS prophylaxis or therapy at 500-1500 $\mathrm{mg}$ per day, corresponding to a concentration of $20-60 \mu \mathrm{mol} / \mathrm{L}$ in the patient. Prior to the licensing of $\mathrm{AZT}$, Burroughs Wellcome, the manufacturer of the drug, and the $\mathrm{NIH}$ have jointly claimed selective inhibition of HIV by AZT in vitro because human Iymphoblasts and fibroblasts appeared over 1000-fold more resistant to AZT (inhibited only at 1-3 $\mathrm{mM}$ ) than was replication of HIV (inhibited at 50-500 nM) (Furman eal., 1986). On this basis they calculated an in vitro antiviral therapeutic index of $10^{4}$. This "selective" sensitivity of HIV to AZT was explained in terms of a "selective interaction of AZT with HIV reverse transcriptase" (Furman \&al., 1986). A ccordingly the manufacturer informs AZT recipients: "The cytotoxicity of zidovudine [AZT] for various cell lines was determined using a cell growth assay ... ID 50 values for several human cell lines showed little growth inhibition by zidovudine except at concentrations $>50 \mu \mathrm{g} / \mathrm{mL}(\geq 200 \mu \mathrm{M})$ ) or less." (M edical Economics Data, 1992). Further, it informs them that enterobacteria induding $\mathrm{E}$. coli are inhibited "by low concentrations of zidovudine[AZT]," between 0.02 and $2 \mu \mathrm{M}$ AZT, just like HIV (Medical Economics Data, 1992).

However, an independent study showed in 1989 that AZT is about 
1000-times (!) more toxic for human T-cells in culture, i.e at about 1 $\mu \mathrm{M}$ than thestudy conducted by its manufacturer and the NIH (Avramis \&al., 1989). Other studies have also found that AZT inhibits T-cells and other hemopoietic cells in vitro at 1-8 $\mu \mathrm{M}$ (Balzarini \& al., 1989; Mansuri \& al., 1990; Hitchcock 1991). Since normal deoxynucleotide triphosphates are present in the cell at micromolar concentrations, toxicity of AZT should be expected in the micromolar range Indeed, when AZT is added at a micromolar concentration to the culture medium, it and its phosphorylated derivatives quickly reach an equivalent or higher concentration in the cell, and thus effectively compete with their natural thymi dine counterparts (A vramis $\notin$ al., 1989; Balzarini \& al., 1989; Ho and Hitchcock, 1989; Hitchcock, 1991).

Thus the low cellular toxicity reported by the manufacturer and the $\mathrm{NIH}$ for human cells appears erroneous - possibly because "the clinical development of AZT was exceedingly rapid; it was approved for clinical use in the U.S. about 2 years after the first in vitro observation of its activity against HIV" (Yarchoan $\notin$ al., 1991). It follows that AZT does not selectively inhibit viral DNA synthesis and is prescribed at concentrations that exceed 20- to 60-fold the lethal dosefor human cells in culture

In view of its inevitable toxicity, the rationale of using AZT as an anti-HIV drug must be reconsidered and its potential antiviral effect must be weighed against its toxicity.

4.6.2.1. AZT not a rational anti-HIV drug A rational antiviral therapy depends on proof that the targeted virus is the cause of the disease to be treated and that toxicity for the virus outweighs that for the host cell. Such proof cannot be supplied for AZT for the following reasons:

(1) There is no proof that HIV causes AIDS (Section 3.3).

(2) Even if the hypothesis that HIV causes AIDS by killing T-cells were correct, it would be irrational to kill the same infected cells twice, once presumably with HIV and once more with AZT.

(3) Since many healthy persons with antibodies against HIV have equal or even higher percentages of infected T-cells than AIDS patients (Section 3.3), there is no reverse transcription of HIV during progres- 
sion to AIDS that could be targeted with AZT. Even if some reverse transcription occurred in antibody-positive persons, AZT could not differentially inhibit viral DNA, because HIV DNA comprises only $9 \mathrm{~kb}$ but cell DNA comprises $10^{6} \mathrm{~kb}$. Thus cell DNA is a 100,000-fold bigger target for AZT than HIV. And even if AZT showed a 100-fold preference for reverse transcriptase of HIV over cellular DNA polymerase, as has been claimed by the study conducted by Burroughs Wellcome and theNIH (Furman $\notin$ al., 1986), cell DNA would still bea 1000-fold bigger target for AZT than viral DNA. It follows that cell DNA is the only realistic target of $A Z T$ in antibody-positive persons.

(4) Since AZT cannot distinguish infected from uninfected leukocytes and on average less than 1 in 1000 is infected (Section 3.3), AZT must kill at least 1000 leukocytes in AIDS patients and in asymptomatic HIV-carriers to kill just 1 infected cell - a very high toxicity index, even if HIV were the cause of AIDS.

It follows that there is no rational basis for AZT therapy or prophylaxis for AIDS (Duesberg 1992d).

4.6.2.2. Toxidity of AZT in AIDS Patients and AIDS-freePersons The following AZT-specific diseases have been recorded in AIDS patients, in AIDS-free persons and animals treated with AZT, based on studies listed here (Section 4.4.2) and reviewed el sewhere (Smothers, 1991; Medical Economics Data, 1992):

(1) anemia, neutropenia and leukopenia in $20-80 \%$, with about 30-57\% requiring transfusions within several weeks (Gill \& al., 1987;

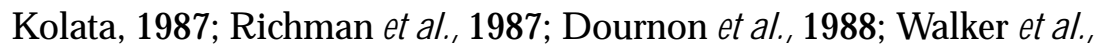
1988; Swanson \& al., 1990; van Leeuwen \& al., 1990; Smothers, 1991; Hamilton \& al., 1992),

(2) severe nausea from intestinal intoxication in up to $45 \%$ Rich. man \& al., 1987; Volberding \& al., 1990; Smothers 1991),

(3) muscle atrophy and polymyositis, due to inhibition of mitochondrial DNA synthesis in 6-8\% Richman \& al., 1987; Bessen \& al., 1988; Gorard and Guilodd, 1988; Helbert \& al., 1988; Dalakas \& al., 1990; Till and M acD onnell, 1990; Yarchoan \& al., 1991; Hitchcock, 1991), 
(4) Iymphomas in about 9\% within 1 year on AZT (Section 4.4.2),

(5) acute (nonviral) hepatitis (D ubin and Braffman, 1989; Smothers, 1991),

(6) nail dyschromia (D on \& al., 1990; Smothers, 1991),

(7) neurological diseases including insomnia, headaches, dementia, mania, Wernicke's encephalopathy, ataxia and seizures (Smothers, 1991), probably due to inhibition of mitochondrial DNA (Hitchcock, 1991),

(8) 12 out of 12 men reported impotence after 1 year on AZT (Callen, 1990),

(9) in addition AZT is carcinogenic in mice, causing vaginal squamous carcinomas (Cohen, 1987; Yarchoan and Broder, 1987a), and it transforms mouse cells in vitro as effectively as methylcholanthrene (Chernov, 1986).

Overall AZT is not a rational prophylaxis or a therapy for AIDS and is capable of causing potentially fatal diseases, such as anemia, leukopenia and muscle atrophy. Yet, despite its predictable toxicity, AZT is thought to have serendipitous therapeutic and prophylactic benefits according to those investigators who have studied its effects together with the manufacturer for licensing of the drug (Section 4.4.2) Fischl \& al., 1987; Richman $\notin$ al., 1987; Vol berding $\notin$ al., 1990). Confronted with the difficulties in rationalizing anti-HIV prophylaxis and therapy with AZT, the Wellcome researcher Freestone cites the Burroughs Wellcome study analyzed above (Section 4.4.2, item 1): “the primary endpoint for the study was death ( 1 in 145 zi dovudine reci pients, 19 in 137 placebo recipients....) - an end-point littlesubject to observer error or bias" (Freestone, 1992).

The popularity of AZT as an anti-HIV drug can only be explained by the widespread acceptance of the virus-AIDS hypothesis, the failure to consider the enormous difference between the viral and cellular DNA targets and a general disregard for the long-term toxicity of drugs (Section 6). In the words of the retrovirologist Temin "but the drug generally becomes less effective after six months to a year ..." Nelson \& al., 1991) - a euphemism for its fatal toxicity by that time. This is a probable reason that AZT was licensed without long-term studies in 
animals compatible with human applications and that the need for such studies is neither mentioned nor called for in reviews of its toxic effects in humans (Chernov, 1986; Yarchoan and Broder, 1987b; Smothers, 1991; Yarchoan \& al., 1991), although AZT must bethe most toxic drug ever approved for indefinite therapy in A merica. Even the manufacturer acknowledges that " . . . the drug has been studied for limited periods of time and long term safety and efficacy are not known" (Shenton, 1992) and recommends that "patients should beinformed ... that the long-term effects of zidovudine are unknown at this time" (M edical Economics Data, 1992). And after prescribing it for five years, even AIDS "experts" have recently expressed doubts about the "survival benefit" of AZT (Kolata, 1992).

\subsection{Drug-AIDS Hypothesis Correctly Predicts the Epidemiology and Heterogeneous Pathology of AIDS}

(1) The long-term consumption of drugs, but not the hosting of a latent virus, predicts drug-specific pathogenicity after "Iong latent periods" These long latent periods of HIV are in reality the lag periods that recreational drugs (Schuster, 1984; Newell \& al., 1985b) and frequent transfusions of foreign proteins take to cause AIDS-defining diseases (Section 3.4.4.5). D rugs are molecularly abundant (Section 4.6.1) and biochemi cally active as long as they are administered and thus cumulatively toxic over time It is for this reason that it typically takes 5-10 years for recreational drugs, and months for AZT, to cause AIDS-defining and other diseases (Sections 3.1 and 5). But HIV, after a brief period of immunogenicity (Clark $\notin$ al., 1991; Daar $\notin$ al., 1991), is chronically dormant and thus molecularly and biochemically irrelevant for the rest of the host's life

(2) Drugs and other noninfectious agents also exactly predict the epidemiology of AIDS. A bout $32 \%$ of A merican AIDS patients are confirmed intravenous drug users, $60 \%$ appear to use recreational drugs orally, and an unknown but large percentage of people in both behavioral and clinical AIDS risk groups use AZT. M oreover, the consumption of recreational drugs by AIDS patients is probably under-reported because the drugs are illicit, and because medical scientists and support for research are currently heavily biased in favor of viral-AIDS 
(Section 6) (Ettinger and A lbin, 1989; Lerner, 1989; Duesberg 1991b). In sum, more than $90 \%$ of A merican AIDS is correlated with drugs. The remainder would reflect the natural background of AIDS-defining diseases in the U.S. (Duesberg, 1992). Indeed, only drug users do not benefit from the ever improving health parameters and increasing life spans of the Western World (Hoffman, 1992; The Software Toolworks World A tlas $^{\mathrm{TM}}$, 1992). The widespread use of AZT in hemophiliacs (Section 4.3.3) unfortunately predicts a new increase in their mortality.

The dramatic increase in A merica in the consumption of all sorts of recreational drugs since the Vietnam War also explains the simultaneous increase of AIDS in intravenous drug users and male homosexuals (Centers for Disease Control, 1992b). AIDS of both risk groups followed closely the above listed drug-use statistics during the last 15 years, with increases in 1987 that corresponded to the expanded AIDS definition (Centers for Disease Control, 1987) and the introduction of AZT treatment. By contrast a sexually transmitted AIDS would have spread much faster among homosexuals than among intravenous drug users (Weyer and Eggers, 1990; Eggers and Weyer, 1991). The apparent exponential spread of AIDS during the period from 1984 to 1987 (Heyward and Curran, 1988; M ann \& al., 1988; Weyer and Eggers, 1990) probably reflected an exponential spread of "AIDS testing" which resulted in an exponential spread of AIDS diagnoses for drug diseases (Section 4.2). AIDS testing had increased from o in 1984 to 20 million tests per year in 1986 in the U.S. alone (Section 3.6).

(3) The drug hypothesis further predicts that the $50-70 \%$ of A merican and $50-80 \%$ of European intravenous drug users who are HIVfree (Stoneburner \& al., 1988; Turner \& al., 1989; Brenner \& al., 1990; U.S. Department of Health and Human Services, 1990; National Commission on AIDS, 1991), and the HIV-free male homosexuals who use sexual stimulants will develop the same diseases as their HIV-positive counterparts- except that their diseases will be diagnosed by their old names. This has been amply confirmed for intravenous drug users (Section 4.5). But since AIDS research became dominated by the virushypothesis, only a few studies have published HIV-free homosexual immunodeficiencies and "AIDS cases" (Section 4.5, N ote added in proof). Yet more such cases must exist because the CDC allows "pre- 
sumptive diagnosis" of HIV disease and only about $50 \%$ of all A merican AIDS cases are confirmed positives (Sections 2.2 and 3.4.1) and because only about 50\% of homosexuals from many different cohorts at risk for AIDS are confirmed HIV-positive (Section 4.5.1).

(4) The drug hypothesis also correctly predicts drug-specific A IDS diseases in distinct risk groups due to distinct drugs (Sections 2. 1.3, 3.4.5 and 5, Table 2).

\subsection{Consequences of the Drug-AIDS Hypothesis: Risk-Specific Preventions and Therapies but Resentment by the Virus-AIDS Establishment}

The drug-AIDS hypothesis predicts that the AIDS diseases of the behavioral AIDS risk groups in the U.S. and Europecan be prevented by stopping the consumption of recreational and anti-HIV drugs, but not by "safe sex" Institute of M edicine, 1988; Weissand Jaffe, 1990; Maddox 1991b) and "clean needles," i.e sterile injection equipment (National Commission on AIDS, 1991) for toxic and unsterilestreet drugs. Indeed AIDS has continued to increase in all countries that have promoted safe sex to prevent AIDS for over 5 years now (Centers for D isease Control, 1992b; World Health Organization, 1992a; A nderson and May, 1992). F urther, the hypothesis raises the hopes for risk-specific therapies

A ccording to the drug-A IDS hypothesis, AZT is AIDS by prescription. Screening of blood for antibodies to HIV is superfluous, if not harmful, in view of the anxiety that a positive test generates among the many believers in the virus-AIDS hypothesis (Grimshaw, 1987) and the toxic AZT prophylaxis prescribed to many who test "positive" Eliminating the test would also reduce the cost of the approximately 12 million annual blood donations in the U.S. (Williams \& al., 1990) and of examining annually 200,000 recruits and 2 million servicemen for the U.S. A rmy (Burke $\notin$ al., 1990) by $\$ 12$ to $\$ 70$ each (Irwin Memorial Blood Bank, San Francisco, personal communication).

F urther, it would lift travel restrictions for antibody-positives to many countries including the U.S. and China, and would lift quarantine for HIV-positive Cubans, and would acquit all those antibody-positive A mericans who are currently imprisoned for having had sex with antibody-negatives, and would grant to HIV "antibody-positives" the same 
chances to be admitted to a health insurance program as to those who have only antibodies to other viruses.

Despite its many potential blessings, the drug hypothesis is currently highly unpopular - not because it would be difficult to verify, but because of its consequences for the virus-AIDS establishment (Section 6). The drug hypothesis is very testable epi demiologically and experimentally by studying the effects of the drugs consumed by AIDS patients in animals. Indeed most tests have al ready been done (Section 4). To disprove this hypothesis it would be necessary to document that an infectious agent exists which - in the absence of AZT (!) causes AIDS diseases above their normal background in the nondrug using population. The medical, ethical and legal consequences of the drug-A IDS hypothesis, should it prevail, have recently been summarized under thetitle "Duesberg: An enemy of the people?" (Ratner, 1992). Ratner points out that, "The loss of confidence of A mericans in their scientists and perhaps, by extension, their physicians, could rival their current disillusionment with politicians" and wonders, "What would happen to the reservoir of good will painstakingly built up for the victims of AIDS?"

\section{Drugs and Other N oncontagious Risk Factors Resolve AII Paradoxes of the Virus-AIDS Hypothesis}

A direct application of the hypothesis that drugs and other noncontagious risk factors cause AIDS proves that it can resolve all paradoxes of the virus-AIDS hypothesis:

(1) It is paradoxical to assume that AIDS is new because HIV is new. HIV is a long-established, perinatally transmitted retrovirus It just appears new because, being a chronically latent virus, it only became detectable with recently developed technology (Section 3.5.1). I nstead drugs are the only new health risks in this era of ever improving health parameters. Thus AIDS is new because the drug epidemic is new.

(2) According to the virus-AIDS hypothesis it is paradoxical that AIDS did not "explode" into the general population as predicted (Institute of M edicine, 1986; Shorter, 1987; Fineberg, 1988; Heyward and Curran, 1988; Blattner, 1991; Mann and the Global AIDS Policy Coali- 
tion, 1992). AIDS has remained restricted for over 10 years to only 15,000 annual cases (0.015\%) of the over 100 million sexually active heterosexual Americans, and to only 25,000 (0.3\%) of the 8 million homosexuals (Centers for Disease Control, 1992b), although venereal diseases (A ral and Holmes, 1991), unwanted pregnancies and births (Hoffman, 1992; The Software Toolworks World Atlas ${ }^{\mathrm{TM}}$, 1992) are on the increase in A merica. (The homosexuals represent about $10 \%$ of the adult male population (Turner \& al., 1989; Lesbian and Gay Substance A buse Planning Group, 1991a).) This is because psychoactive drugs and AZT, not HIV, are the causes of AIDS.

(3) The paradox of a virus causing risk group-specific and countryspecific AIDS diseases is resolved by distinct nonviral AIDS causes including drugs and other noncontagious pathogens like long-term transfusions and malnutrition (Sections 2.1.3 and 3.4.5, Tables 1 and 2).

(4) The paradox of a male-specific A IDS virus (i.e $90 \%$ of all A merican and $86 \%$ of all European AIDS cases are males), although no AIDS disease is male-specific, is resolved by male-specific behavior and by male genetic disorders. In America and Europe males consume over $75 \%$ of all "hard" injected psychoactive drugs (Section 4.3.1), homosexual males are almost exclusive users of oral aphrodisiacs likenitrites (Section 4.3.2) and nearly all hemophiliacs are males.

(5) The paradox of a 10-year-slow AIDS virus, i.e AIDS occurs only after "latent (!) periods" of HIV that average 10 years in adults and 2 years in babies (Section 2.2), is resolved by the cumulative toxicity of long-term drug use According to the CDC the "lifetime use" of drugs determi nes the AIDS risk (J affe $\notin$ al., 1983b). On average 5-10 years elapse in adult drug addicts between the first use of drugs and "acquiring" drug-induced AIDS diseases (Layon \& al., 1984; Schuster, 1984; Savona \& al., 1985; Donahoe \& al., 1987; Espinoza \& al., 1987; Weber \& al., 1990). The time lag from a nitrite habit to Kaposi's sarcoma has been determined to be 7-10 years (Newell \& al., 1985b). Severe T-cell depletion and immunodeficiency is also "acquired" by hemophiliacs on average only after 14-15 years of treatment with blood concentrates (Section 3.4.4.5).

In babies of drug-addicted mothers AIDS appears much sooner than 
in adults because of a much lower threshold of the fetus for drug-pathogenicity. This also resolves the secondary paradox of a discrepancy of 8 years between the "latent periods" of HIV in babies and in adults.

(6) It is paradoxical that A merican teenagers do not get AIDS, although over $70 \%$ are sexually active and about $50 \%$ are promiscuous (Turner \& al., 1989; Burke $\notin$ al., 1990; Congressional Panel, 1992) and $0.03 \%$ to $0.3 \%$ carry HIV (Section 3.5.2). The paradox that a sexually transmitted "AIDS virus" would spare A merican and European teenagers is resolved by the fact that only years of drug consumption, and years of transfusions for hemophilia (Section 3.4.4.5) will cause AIDS-by which time these teenagers are in their twenties

(7) The apparent paradox that the same virus would at the same time cause two entirely different AIDS epidemics, one in Africa and the other in A merica and Europe is an artifact of the AIDS definition. Because of the HIV-based AIDS definition, a new drug epidemic in A merica and Europe and an epidemic of old A frica-specific diseases like fever, diarrhea and tuberculosis (Section 3.4.4.4) were both called AIDS when HIV became detectable Since HIV is endemic in over $10 \%$ of Central A fricans, over $10 \%$ of their AIDS-defining diseases are now called AIDS (Section 2.2).

\section{Why Did AIDS Science Go Wrong?}

\subsection{The Legacy of the Successful Germ Theory: A Bias Against Noninfectious Pathogens}

Unlikeany other scientific hypothesis, the virus-AIDS hypothesis became national A merican dogma before it could be reviewed by the scientific community. It had been announced by the Secretary of Health and Human Services in 1984 before it had been published in the scientific literature U nlike any other medical hypothesis it captured the world without ever bearing any fruits in terms of public health benefits. From the beginning the hypothesis has absorbed the critical potential of its many followers with the question, whether $M$ ontagnier from $F$ rance or Gallo from the U.S. had won the race in isolating the "AIDS virus" and who owned the lucrative patent rights for the "AIDS test." This 
question was so consuming that the presidents of the two countries were called to sign a settlement, and a revisionist paper was published by the opponents describing their fierce controversy as an entente cordiale against the real enemy, the "deadly" AIDS virus Gallo and M ontagnier, 1987). During the 1980 s press accounts consistently called HIV "the deadly virus" (Duesberg, 1989c).

Clearly, the enthusiastic acceptance of the virus-AIDS hypothesis was not based on its scientific rigor or its fruits. It was instead grounded on the universal admiration and respect for the germ theory. The germ theory of the late 19th century ended the era of infectious diseases, which now account for less than $1 \%$ of all mortality in the Western World (Cairns, 1978). It celebrated its last triumph in the 1950 with the elimination of the polio epidemic by antiviral vaccines.

But the germ theory continues to inspire both scientists and the public to believethat a "good" body can be protected against "evil" microbes. Accordingly, even the greatly feared and highly stigmatizing "AIDS test" for a presumably new, sexually transmitted "AIDS virus" was readily sold to all governments, medical associations and even to the AIDS riskgroups (Section 6.2), despite the absence of convincing evidence for transmissibility. In the words of one observer, "The rationale for such programs is often the historical precedent of syphilis screening," which "never proved to be effective" and led to "toxic treatments with arsenical drugs, assuming the tests were correct ..." and "deep stigma and disrupted relationships ...." "Patients required a painful regimen of injections, sometimes for as long as two years" (Brandt, 1988). Even epidemiologists failed to recognize that AIDS and HIV wereonly spreading in newly-established behavioral and clinical risk groups and that HIV was a long-established virus in the general populations of many countries (Section 3.5.1). Instead of considering noni nfectious causes, they simulated “coagents" (Eggers and Weyer, 1991) and "assortative scenarios" Anderson and M ay, 1992) to hide the growing discrepancies between HIV and AIDS and intimidated skeptics with apocalyptic predictions of AIDS pandemics in the general populations of many countries that have rai sed fears and funds to unprecedented levels (Section 1) (Heyward and Curran, 1988; $M$ ann \& al., 1988; $M$ ann and the Global AIDS Policy Coalition, 1992; Anderson and M ay, 1992). 
Even now, in an era free of infectious diseases but full of man-made chemicals, scientists and the public share an unthinking preference for infectious over noninfectious pathogens. Both groups share an obsolete microbophobia but tolerate the use or even indulge in the consumption of numerous recreational and medical drugs. M oreover, progressive scientists and policy makers are not interested in recreational and medical drugs and man-made environmental toxins as causes of diseases, because the mechanisms of pathogenesis are predictable Further, prevention of drug diseases is scientifically trivial and commercially unattractive

By contrast, microbial and particularly viral pathogens are scientifically and commercially attractive to scientists. Beginning with Peyton Rous, at least $10 \mathrm{~N}$ obel prizes have been given to virologists in the last 25 years. And many virologists have become successful biotechnologists. For example, a blood test for a virus is good business if the test becomes mandatory for the 12 million annual blood donations in the U.S., eg. the "AIDS test." The same is true for a vaccineor an antiviral drug that is approved by the Food and Drug A dministration.

Thousands of lives have been sacrificed to this bias for infectious theories of disease, even before AIDS appeared. For example, the U.S. Public Health Service insisted for over 10 years in the 1920 s that pellagra was infectious, rather than a vitamin B deficiency as had been proposed by J oseph Goldberger (Bailey, 1968). Tertiary syphillis is commonly blamed on treponemes, but is probably dueto a combination of treponemes and long-term mercury and arsenic treatments used prior to penicillin, or merely to these treatments alone (Brandt 1988; Fry, 1989). "Unconventional" viruses were blamed for neurological diseases like K reutzfeld-J acob's disease, A Izheimer's disease and kuru Gajdusek, 1977). The now extinct kuru was probably a genetic disorder that affected just one tribe of natives from N ew Guinea (Duesberg and Schwartz, 1992). Although a Nobel Prize was given for this theory, the viruses never materialized and an unconventional protein, termed "prion," is now blamed for some of these diseases Evans 1989c; Duesberg and Schwart, 1992). Shortly after this incident, a virus was also blamed for a fatal epidemic of neuropathy, including blinding, that started in the 1960 in Japan, but it turned out later to becaused by the 
prescription drug clioquinol (Enterovioform, Ciba-Geigy) (Kono, 1975; Shigematsu \& al., 1975). In 1976 the CDC blamed an outbreak of pneumonia at a convention of Legionnaires on a "new" microbe, without giving consideration to toxins. Since the "Legionnaire's disease" did not spread after the convention and the "Legionnaires bacillus" proved to be ubiquitous, it was later concluded that "CDC epidemiologists must in the future take toxins into account from the start" Culliton, 1976). The Legionnaire's disease fiasco is in fact the probable reason that the CDC initially took toxins into account as the cause of AIDS (Oppenheimer, 1992).

The pursuit of harmless viruses as causes of human cancer, supported since 1971 by the Virus-Cancer Program of the National Cancer Institute's War On Cancer, was also inspired by indiscouragable faith in the germ theory (Greenberg, 1986; Duesberg, 1987; Shorter, 1987; A nderson, 1991; Editorial, 1991; Duesberg and Schwartz, 1992). For example, it was claimed in the 1960s that the rare Burkitt's lymphoma was caused by the ubiquitous E pstein-Barr virus, 15 years after infection (Evans 1989c). But the lymphoma is now accepted to be nonviral and attributed to a chromosome rearrangement (Duesberg and Schwartz, 1992). F urther, it was claimed that noncontagious cervical cancer is caused by the widespread herpes virus in the 1970s, and by the widespread papilloma virus in the 1980s-but in each case cancer would occur only 30 to 40 years after infection (Evans 1989c). Noninfectious causes like chromosome abnormalities, possibly induced by smoking, have since been consi dered or reconsidered (Duesberg and Schwartz, 1992). Further, ubiquitous hepatitis virus was proposed in the 19605 to cause regional adult hepatomas 50 years (!) after infection (Evans, 1989C). In the 1980s the rare, but widely distributed, human retrovirus HTLV-I was claimed to cause regional adult T-cell leukemias (Blattner, 1990). Yet the leukemias would only appear at advanced age, after "latent periods" of up to 55 years, the age when these "adult" leukemias appear spontaneously (Evans 1989C; Blattner, 1990; Duesberg and Schwart, 1992). Although the Virus-Cancer program has generated such academic triumphs as retroviral oncogenes (Duesberg and Vogt, 1970) and reverse transcriptase (Temin and M itzutani, 1970), it has been a total failure in terms of dinical relevance I ndeed, the pride 
of retrovirologists in retrovirus-specific reverse transcription is the probable reason that inhibition of DNA synthesis with AZT is perceived, even now, as a "specific" antiretroviral therapy (Section 4.3.3).

The wishful thinking that viruses cause "slow" diseases and cancers faces four common problems: (1) the diseases or tumors occur on average only decades after infection; (2) the viruses are all inactive, if not defective, during fatal disease or cancer; (3) the "viral" tumors are all donal, derived from a singlecell (with a tumor-specific dhromosome abnormality) that had emerged out of billions of identically infected cells of a given carrier; and (4) above all, no human cancers and none of the "slow viral diseases" are contagious (Rowe, 1973; Duesberg and Schwart, 1992).

Therefore these viruses all fail Koch's postulates, the acid test of the germ theory. And therefore these viruses are all assumed to be very "slow," causing diseases only after long "Iatent periods" that exceed by decades the short periods of days or weeks that these viruses need to replicate and to become immunogenic. Because of their consistent scarcity, defectiveness and even complete absence from some tumors and slow diseases (Duesberg and Schwartz, 1992), the search for the presumably pathogenic latent viruses has been directed either at antiviral antibodies, i.e "seroepidemiological evidence" (Blattner \& al., 1988), or at artificially amplified viral DNA and RNA (Section 3.3) or at the "activation" of latent viruses, euphemistically called "virus isolation" (Section 2.2).

A ccordingly cancer-, AIDS- and other slow-virologists try to discredit Koch's postulates in favor of "modern concepts of causation." For example, Evans states that, “... K och's postulates, great as they were for years, should be replaced with criteria reflecting modern concepts of causation, epidemi ology, and pathogenesis and technical advances" (Evans, 1992). A nd Blattner, Gallo and Temin point out that Koch's postulates are just a "useful historical reference point" Blattner et al., 1988), and Weiss and J affe find it "bizarre that anyone should demand strict adherence to these unreconstructed postulates 100 years after their proposition" (Weiss and J affe, 1990) - but they all fail to identify a statute of limitation for adherence to the virus-AIDS hypothesis. In addition, "cofactors" are assumed (a) to make up for the typi- 
cal inertia of the viral pathogens or carcinogens, (b) to account for the clonality of the cancers via a clonal cellular cofactor, and (c) to help to close the enormous gaps between the very common infections and the very rare incidences of "slow" disease or cancer, that even the long "latent periods" could not close (D uesberg and Schwart, 1992). The tumor virologist Rowe "recognized that the latent period may cover much of the life span of theanimal and that the virus did not act alone but that the tumor response might require ... treatment with a chemical carcinogen" (Rowe, 1973).

Despite the total lack of public health benefits and even negative consequences of these theories, such as the psychologically toxic prognoses that antibodies against HTLV-I or agai nst papilloma virus signal future cancers (Duesberg and Schwartz, 1992), or that antibodies against HIV signal future AIDS and the need for AZT prophylaxis, the public and the majority of scientists have held on to them much longer than was justified in terms of scientific evidence The irresistible appeal of the germ theory was the basis for each of these unproductive theories of the past, as it is the basis now for the universal and enthusiastic approval of the virus-AIDS hypothesis.

But unlike the mistaken germ theories of the past, the virus-AIDS hypothesis was a windfall not only for (1) the virologists and epidemiologists, but also for (2) the biotechnology companies who could develop virus-tests and antiviral drugs, (3) theAIDS patients who were relieved that a God-given, egalitarian virus rather than behavioral factors were to blame for their diseases, and (4) the politicians who had to confront the public and the gay (homosexual) lobby requesting action against AIDS. Indeed, a thoroughly intimidated public was happy, once more, to be offered protection by its scientists against another "deadly" virus, al beit for the highest price-tag ever.

\subsection{Big Funding and Limited Expertise Paralyze AIDS Reseanch}

I ronically, AIDS research suffers not only from being tied to an unproductive hypothesis, it also suffers from the staggering funds it receives from governments (Section 1 ) and from conceptual ly matched private sources I ntended to buy a fast solution for AIDS, thesefunds have instead paralyzed AIDS research by creating an instant orthodoxy of retrovirol- 
ogists that fiercely protects its narrowly focused scientific expertise and global commercial interests (Booth, 1988; Rappoport, 1988; Nussbaum, 1990; Duesberg, 1991b 1992b; Savit, 1991; Connor, 1991, 1992).

The leaders of the AIDS orthodoxy are all veterans from the wars on "slow" and cancer viruses N aturally they were highly qualified to fill the growing gaps in the virus-AIDS hypothesis with their "modern concepts of causation" (Evans, 1992), including long "Iatent periods," "cofactors" and "seroepidemi ological" arguments of causation (Sections 3.3, 3.4 and 3.5). When it became apparent that the first order mechanism of viral pathogenesis, postulating direct killing of T-cells, failed to explain immunodeficiency, the bewildering diversity of AIDS diseases, the many asymptomatic HIV infections, and HIV-free AIDS cases, the scientific method would have called for a new hypothesis. Instead the virus hunters have shifted the virus-A IDS hypothesis from a failed first order mechanism to a multiplicity of hypothetical second order mechanisms, including cofactors and latent periods, to fill the ever growing discrepancies between HIV and AIDS. By conjugating these second order mechanisms with a multiplicity of unrelated diseases, the virus-AIDS hypothesis has become by far the most mercurial hypothesis in biology. It predicts either diarrhea or dementia or Kaposi's sarcoma or no di sease, 1, 5, 10 or 20 years after 1 or 2000 sexual contacts with an antibody-HIV-positive person with or without an AIDS disease

But the coup to rename dozens of unrelated diseases with the common nameAIDS, proved to bethe most effective weapon of the AIDS establishment in winning unsuspecting followers from all constituencies. By making AIDS a synonym for K aposi's sarcoma and candidiasis and dementia and diarrhea and lymphoma and lymphadenopathy, the road was paved for a common cause Who would have accepted, prior to AIDS, that a dental patient caught candidiasis from her doctor's K aposi's sarcoma? Or which scientist would accept it even now knowing the original data rather than just the corresponding press release? A ccording to the sociologist D avid Phillips "researchers use newspapers as a 'filter' to help them decide which scientific article is worth reading" (Briefings, 1991) or more often which article is worth knowing about. 
The control of AIDS research by the nationally and internationally funded AIDS orthodoxy via the popular and scientific press is almost total. It instructs science writers that faithfully report every "breakthrough" in HIV research and every "explosion" of the epidemic. It feeds scientific journals with over 10,000 HIV-AIDS papers annually and with advertisements for HIV tests and antiviral drugs Schwitzer. 1992). The AIDS doctors are controlled by the companies created, consulted or owned by the AIDS establishment (Barinaga, 1992; Schwitzer 1992). For example, the Physician's Desk Reference 1992 instructs AIDS doctors about AZT with an exact copy of Burroughs Welcome's instructions Sciencewriters are warned against reporting minority views. For example, Fauci states: "J ournalists who make too many mistakes, or who are sloppy, are going to find that their access to scientists may diminish" (Fauci, 1989). And Ludlam points out, "Whilst I support, and encourage the reporting of, minority views ... If the belief that AIDS is not due to HIV becomes prevalent ... (it) could lead directly to the deaths of countless misinformed individuals" (L udlam, 1992). A ny chal lengers are automatically outnumbered and readily marginalized by the sheer volume of the AIDS establishment. For example, the 12,000 scientists attending the annual international AIDS conference held in San Francisco in 1990 were only a fraction of the many who study the information encoded in the 9000 nucleotides of HIV. Says the HIV virologist Gallo when asked about a dissenter: "W hy does the Institute of M edicine, WHO, CDC, National Academy of Sciences, NIH, Pasteur I nstitute and the whole body of world science 100 percent agree that HIV is the cause of AIDS?" (Liversidge, 1989).

Consequently there is no "peer-reviewed" funding for researchers who challenge the virus-A IDS hypothesis (Duesberd, 1991b; Maddox, 1991a; Bethell, 1992; Farber, 1992; Hodgkinson, 1992). Since HIV became the domi nant focus of the billion-dollar AIDS-research (Coffin $₫$ al., 1986; Institute of M edicine, 1988), there has not been even one follow-up of themany previous studies blaming sexual stimulants and psychoactive drugs for homosexual AIDS (Sections 4.4 and 4.5). N one of theformer "lifestyle" advocates (Section 2.2) have investigated whether drugs might cause AIDS without HIV. Instead drugs, if mentioned at all, were since described as risk factors for infection by HIV (Darrow 
Æal., 1987; M oss \& al., 1987; van G riensven \& al., 1987; Chaisson \& al., 1989; Weiss, S.H., 1989; Goudsmit 1992; Seage \& al., 1992) — as if HIV could discriminate between hosts on the basis of their drug habits Duesberg, 1992a). For example, Friedman-K ien concluded in 1982 and 1983 with M armor \& al. (1982) and Jaffe $\&$ al. (1983b) that the "lifetime exposure to nitrites..." was responsi ble for AIDS (Section 4.3.2). In 1990 he and his collaborators just mentioned nitrite use in HIV-free Kaposi's sarcoma cases (Friedman-Kien \& al., 1990) and in 1992 they blamed viruses other than HIV for HIV-free AIDS cases and drug use was no longer mentioned (Huang \& al., 1992).

Likewise all studies investigating transfusion-mediated immunodeficiency in hemophiliacs were frozen around 1987 (Table 3), oncethe virus-AIDS hypothesis had monopolized AIDS research. The question whether immunodeficient (!) HIV-free hemophiliacs would ever develop AIDS defining diseases was left unanswered and even became unaskable

Fascinated by the past triumphs of the germ theory, the public, science journalists and even scientists from other fields never question the authority of their medical experts, even if they fail to produce useful results (Adams, 1989; Schwitzer, 1992). M edical scientists are typically credited for the virtual elimination of infectious diseases with vaccines and antibiotics, although most of the credit for eliminating infectious diseases is actually owed to vastly improved nutrition and sanitation Stewart, 1968; M cKeown, 1979; M oberg and Cohn, 1991; Oppenheimer, 1992). Indeed, the belief in the infallibility of modern science is the only ideology that unifies the zoth century. For example, in the name of the virus-AIDS hypothesis of the American Government and the A merican researcher Gallo, antibody-positive A mericans have been convicted for "assault with a deadly weapon" because they had sex with antibody-negatives, Central A frica dedicates its limited resources to "AIDS testing," the former U.S.S.R. conducted 20.2 million AIDS tests in 1990 and 29.4 million in 1991 to identify a total of 178 antibodypositive Soviets and communist Cuba even quarantines its own citizens if they are antibody-positive (Section 3.6).

Predictably the AIDS virus hunters, on their last crusade for the germ theory, have no regard for the current drug-use epidemic and its 
many overlaps with A merican and European AIDS. Even direct evidence for the role of drugs in AIDS is fiercely rejected by the virusAIDS orthodoxy (Booth, 1988; M oss \& al., 1988; Kaslow \& al., 1989; Baltimore and Feinberg, 1990; Ostrow \& al., 1990). M erely questioning the therapeutic or prophylactic benefits of AZT is protested by the AIDS establishment (Baltimore and Feinberg, 1990; Weiss and J affe, 1990; A nonymous, 1992; Freestone, 1992; Tedder \&al., 1992). The prejudice against noninfectious pathogens is so popular, that the virusAIDS establishment uses it regularly to intimi date those who propose noninfectious alternatives, to censor their papers (Duesberg, 1992e) and even to question their integrity.

For example, an editorial in Sciencecalled mea "rebel without a cause for AIDS," because denying HIV was to deny a cause al together. The editorial quoted Baltimore as saying I was "irresponsi ble and pernicious" (Booth, 1988). An article in Naturecalled my drug hypothesis a "perilous message" that would "belittle 'safe sex,' would have us abandon AIDS screening. .. and curtail research into anti-HIV drugs" "Arguments that AIDS (is) the result of evil vapors (poppers (!)), mal'aria ... (are from) the last century." "We... regard the critics as 'flat-earthers' bogged down in molecular minutiae and miasmal theories of disease, while HIV continues to spread" (Weiss and J affe, 1990). This is said even though the article agrees that, "D uesberg is right to draw attention to our ignorance of how HIV causes disease ..." Weiss and J affe, 1990). Others declare "All attempts by epidemiologists to link AIDS to the use of amyl nitrite or other drugs as a direct cause of disease have failed ... Duesberg's continued attempts to persuade the public to doubt the role of HIV in AIDS are not based on facts" (Baltimore and Feinberg, 1990). Gallo called the author of the article, "Experts mount startling challenge to AIDS orthodoxy" in TheSunday Times(London) (Hodgkinson, 1992), "irresponsible both to myself (Gallo) and to HIV as the cause of AIDS" (Gallo, 1992). Further, Vandenbroukeand Pardoel argue, "If one is allowed to compare the evolution of scientific theories with the evolution of biologic nature in general, the poppers (nitrite inhalants) episode is the N eanderthal of modern epidemiology" (Vandenbroucke and Pardoel, 1989).

As a consequence there are no studies that investigate the long-term 
effects of psychoactive drugs Lerner, 1989; Pillai \& al., 1991; Bryant et al., 1992). The toxicologist Lerner points out that "fewer than 60 arecurrently enrolled in fellowship programs on alcoholism and drug abuse in the entire country" (Lerner 1989), although about 8 million A mericans alone are estimated to use cocaine Weiss, S.H., 1989; Finnegan \& al., 1992) and many more use other psychoactive drugs regularly (Section 4). This stands in contrast to the 40,000 annual AIDS cases that are studied by at least 40,000 AIDS researchers of which just 12,000 attended the annual International AIDS Conference in San Francisco in 1990.

Instead of warning against drugs, the AIDS establishment "educates" the public with its "clean needle" campaigns that drugs (albeit illegal) are safe, but bugs are not. For example, AIDS researcher M oss, citing Napoleon's line “On s'engage et puis on voit," recommends “clean needles" for "harm reduction" (M oss, 1987). Mindful of its educators, the public is unaware and even disinformed about the health risks of recreational drugs. A popular joke in point is the response of two "junkies" (drug addicts) sharing a syringe filled with an intravenous drug to a concerned colleague: "We are safe, because we use a clean needle and condoms." The long "latent periods" between the gratification from recreational drugs, such as tobacco, alcohol, cocaine and nitrite inhal ants, to their irreversi ble health effects unfortunately give credence to the "perilous message" that drugs are safe but bugs are not.

Particularly the victims of drug consumption prefer egalitarian infectious causes over noninfectious behavioral ones that imply personal responsibility (Shilts, 1985; Lauritsen and Wilson, 1986; Rappoport, 1988; Callen, 1990). For example, the executive director of the San Francisco based national "Project I nform," an organization operated mainly for and by male homosexuals, M artin Delaney, informs its dients about a study documenting a "level of sexual contact and drug use which was shocking to the general public" as follows: "It (thestudy) might just as well have noted that most wore Levi's (jeans) for all this told us about the cause of AIDS" (Project I nform, 1992). The organization collaborates with the $\mathrm{NIH}$ and is supported by grants from pharmaceutical companies including Burroughs Wellcome, the manufacturer of AZT (Project I nform, 1992).

In 1987, before AZT, Delaney advised gay men in his book Strate 
giesfor Sunvival: A Gay Men's Health Manual for theAgeof AIDS about the health effects of nitrite inhalants: "Possi ble heart damage; fibrillation (compulsive, erratic heart rhythms); possible stroke and resulting brain damage Conducive to high-risk sexual behavior; distortion of judgement and senses. Statistical link to Kaposi's sarcoma (KS, an AIDSrelated cancer); suspected immuno-suppression" (Delaney and Goldblum, 1987). Delaney's advice about amphetamines reads as follows: “Liver and heart damage; neuropathy (nerve damage); possible brain damage; weight loss; nutritional and vitamin depletion; adrenal depletion (uses up the body's energy reserves). Distorted judgment, values, senses, delusions of strength, anxiety, paranoia, rebound depression, financial strain, powerful addiction, conducive to high-risk sexual activity. Likely immunosuppression (not currently measured), potential for unknown and risky drug interactions, complication in treatment of brain disorders." Delaney also warns about the effects of cocaine: “Heart and lung damage, stroke, cardiovascular irregularities, possible physical addiction. Distortion of judgment, values, and senses, dangerous delusions of grandeur and strength, intense anxiety, paranoia, financial strain, leads to poor judgment about high-risk sexual activity. Likely immunosuppression (not currently measured); increased stress, if smoked, complicates treatment of pneumonia." The book also gives the basis for Delaney's intimate knowledge of drug toxicity: "He . . . has done work for the National Institute on Drug Abuse" (Delaney and Goldblum, 1987).

Clearly big science is not always good science, particularly if it is conceptually paralyzed by an unproductive hypothesis. I hope that the scientific evidence collected for this article will focus attention on the noninfectious causes of AIDS and prove that it is not "too late to correct" (Red Queen) the spell of the virus-AIDS hypothesis by the scientific method. Considering noninfectious causes may prove to be as beneficial to the challenge of AIDS as it was, for example, to the challenge of pellagra. Indeed, a few investigators have recently smuggled recreational drugs as "cofactors" of HIV Haverkos and Dougherty, 1988; Haverkos, 1990) or even more cautiously as cofactors of cofactors of HIV (Archibald $\notin$ al., 1992) into the highly fundable virus-AIDS hypothesis. One investigator even dared to document that drugs are 
sufficient for pediatric AIDS, if only in preliminary reports Koch, 1990; Koch $\notin$ al., 1990). A complete report of the data (Section 4.5) was not published for political reasons (Thomas Koch, personal communication). And the " 100 percent" consensus on HIV claimed by Gallo in 1989 (Liversidge, 1989) is eroding just a bit in the face of a growing group of dissenters, some of which united in the "Group for the Scientific Reappraisal of the HIV/ AIDS Hypothesis" (Deloughry, 1991; Bethell, 1992; Bialy and Farber, 1992; Farber, 1992; Hodgkinson, 1992; Project Inform, 1992; Nicholson, 1992; Ratner, 1992; Schoch, 1992).

\section{NoteAdded in Proof}

Sparked by an article in Newsweek (Cowley, 1992), numerous HIV-free AIDS cases were unexpectedly reported by many independent (!) inves tigators at the VIII I nternational Conference on AIDS/ III STD World Congress in A msterdam in J uly 1992 (now a joint meeting with sexually transmitted diseases, STDs). Surprisingly, some of the recently announced HIV-free AIDS cases had been studied for years (Altman, 1992a; Cohen, 1992a b; L Lurence $₫$ al., 1992), even by the CDC (Spira and J ones, 1992). As a result the CDC had to alter its long-held position that HIV causes all AIDS to "HIV causes the vast majority of AIDS cases ..." (Nicholson, 1992). In its monthly HIV/ AIDS Surveillance Reports the CDC still states that "AIDS is a specific group of diseases which are indicative of severe immunosuppression related to infection with the human immunodeficiency virus (HIV)" (Centers for Disease Control, 1992b). TheAIDS risk factors of most of these HIV-free "AIDS patients" were reported to be "intravenous drugs, unprotected sex and transfusions" and the corresponding diseases were Kaposi's sarcoma and pneumonia (Cowley, 1992).

AIDS-virus matchmakers soon reached the consensus that an as yet undiscovered "new AIDS virus," that "doesn't appear any more contagious than HIV" (Cowley, 1992), was to beblamed for HIV-negative AIDS (Bowden \& al., 1991; Castro \& al., 1992; Huang \& al., 1992; Altman, 1992a, b; Cohen, 1992a, b; L Laurence $\notin$ al., 1992). A nd the director for AIDS research at the $\mathrm{NIH}$ reassured the public, "I $\mathrm{f}$ there is something, scientists will find it" (N ews Report, 1992). States TheNev York Times "A rguably, the greatest thrills for a scientist are in discov- 
ering a new microbe, a new disease, cure and prevention ... M any ... know how quickly the exhilaration that comes from believing they are on the verge of making such a discovery vanishes when the initial findings cannot be confirmed" (Altman 1992b).

However, the new HIV-free AIDS cases are entirely consistent with those listed above that were caused by drug consumption and other noncontagious risk factors (Section 4.5). Although public recognition of HIV-freeAIDS cases is new, the new cases just complement the over 1200 cases of "acquired" immunodeficiency and AIDS-defining diseases described above including 334 hemophiliacs (Section 3.4.4.5, Table 3), 265 male homosexuals (Sections 3.4.4.3 and 4.5), 444 intravenous drug users (Section 4.5) and 183 mostly male tuberculosis patients from F lorida (Pitchenik \& al., 1987, 1990). If the 2466 HIV-free AIDS cases from A frica were included (Section 3.4.4.8), the number of documented HIV-free AIDS cases would exceed 3000 !

M oreover healthy HIV carriers who have been infected for over 10 years and have transmitted their HIV to at least 5 healthy persons via blood transfusions over 7-10 years ago have now received public recognition (Altman, 1992C; L earmont \& al., 1992). These cases supplement the 1 million A mericans, 0.5 million Europeans, 0.3 million Thais and 6 million A fricans who are healthy, although most had been infected by 1985 (Section 3.5.1).

Thus both predictions of the hypothesis that AIDS is noncontagious are now generally accepted: (1) HIV-free AIDS and (2) AIDS-freetrans mission of HIV. Asks J ohn M addox, editor of Nature, "Does that mean Duesberg has been right all along, and that HIV plays no part in the causation of AIDS?" (M addox, 1992b). Indeed, it would be an evolutionary miracle if the last decade had generated three different AIDS viruses, HIV-1, HIV-2 and the "new AIDS virus," when no such virus has ever emerged before in the history of medicine

\section{Adknowledgements}

Dedicated to: (1) all intravenous drug users, oral users of recreational drugs and AZT recipients who were never told that drugs cause AIDS diseases; (2) all "antibody-positives" who were never told that the virusAIDS hypothesis is unproven. 
I thank J anieStone (Berkeley) for numerous corrections of the manuscript, David Shugar (AssociateEditor of Pharmacology and Theraper tics Warsaw, Poland) for his courage to take up the AIDS controversy and for playing the devil's advocate of HIV, A nnette Gwardyak (M anaging Editor) for accommodating many "final" revisions, Hansueli Albonico (Langrau, Switzerland), Harvey Bialy (New York), Julie Cas tiglia (San Diego), Robert Cramer (M ontlhery/ Paris), Bryan Ellison (Berkeley), Celia Farber (New York), Harry Haverkos (Rockville, Maryland), Robert Hoffman (San Diego), Geoff Hoffmann (Vancouver, Canada), Phillip E. J ohnson (Berkeley), Bill J ordan (Los A ngeles), J ohn Lauritsen (New York), Nathaniel Lehrman (New York), A nthony Liversidge (New York), Claus Pierach (Minneapolis), Paul Rabinow (Berkeley), Robert Root-Bernstein (East Lansing, Michigan), Harry Rubin (Berkeley), Frank Rothschild (Berkeley), Russell Schoch (Berkeley), Craig Schoonmaker (New York), J ody Schwart (Berkeley), J oan Shenton (London), Gordon Stewart (Bristol, U.K.), Richard Strohman (Berkeley), Charles Thomas, J r (San Diego), Fritz UImer (Wuppertal, Germany), Michael Verney-Elliott (London), Warren Winkelstein (Berkeley) and Y ue Wu (Berkeley) for critical and catalytic information, Gedge Rosson (Berkeley) for Fig. 1, Brian Davis for fact-checking and typing, Osias Stutman for suggesting the Lewis Carroll quotation, Ted Gardner (Santa Barbara) for a generous donation and encouragement, and the librarians of UC-Berkeley, particularly Chris Campbell, Ingrid Radkey, Pat Stewart and N orma Kobzina, for AIDS references that were not even cited in the daily A merican newspapers. I am still supported by Outstanding Investigator Grant 5-R 35CA 39915-07 from the $N$ ational Cancer Institute.

\section{References}

Achard, C., Bernard, H. and Gagneux, C. (1909) Action de la morphinesur les proprietes leucocytaires; leuco-diagnostic du morphinisme Bull. Memoires SocieeMed. Hopitaux Paris 28: 958-966.

Adams, J. (1989) AIDS: TheHIV Myth. St Martin's Press, New York.

A frasiabi, R., M itsuyasu, R.T., Schwart, K. and Fahey, J.L. (1986) Characterization of a distinct subgroup of high-risk persons with Kaposi's sarcoma and good prognosis who present with normal T4 cell number and T 4:T 8 ratio and negative HTLV-III/ LAV serologic results. Am J. Med. 81: 969-973. 
AIDS-Hemophilia French Study Group (1985) I mmunologic and virologic status of multitransfused patients: role of type and origin of blood products. Blood 66: 896-901.

Albonico, H. (1991a) Lichtblicke zum zweiten J ahrzehnt in der AIDS-Forschung. Schweizerische/Erztezeitung 72: 379-380.

Albonico, H. (1991b) Relativierung des HIV-Dogmas-Ein Beitragzur Enweiterten Sicht von AIDS. Pädagogische A rbeitsstelle, Dortmund.

Aledort, L.M . (1988) Blood products and immune changes: impacts without HIV infection. Sem Hematol. 25: 14-19.

Alroomi, L.G., Davidson, J., Evans, T.J., Galea, P. and Howat, R. (1988) Maternal narcotic abuse and the newborn. Arch. Dis Child. 63: 81-83.

Altman, L.K. (1992a) N ew virus said to cause a condition like AIDS. TheNew York Times J uly 23.

Altman, L.K. (1992b) Working in public to explain AIDS-like ills. TheNew York Times, August 18.

Altman, L.K. (1992C) Group with HIV has no symptoms. TheNew York Times, October 9.

A maro, H., Zuckerman, B. and Cabral, H. (1989) Drug use among adolescent mothers: profile of risk. Pediatrics 84: 144-151.

A nand, R., Reed, C., Forlenza, S., Siegal F., Cheung, T. and M oore, J. (1987) Non-natural variants of human immunodeficiency virus isolated from AIDS patients with neurological disorders. Lance ii: 234-238.

Anderson, D.J., O'Brien, T.R., Politich, J.A., M artinex, A., Seage, G.R., III, Padian, N., Horsburgh, R., J r and Mayer, K.H. (1992) Effects of disease stage and zidovudine therapy on the detection of human immunodeficiency virus type 1 in semen. J.Am Med. Ass 267: 2769-2774.

A nderson, J. (1990) AIDS in Thailand. Br. Med. J. 300: 415-416.

A nderson, L.F. (1991) Cancer Act anniversary encourages reflections, new visions. J. natn. Cancer Inst. 83: 1795-1796.

Anderson, R.M. and May, R.M . (1988) Epidemiological parameters of HIV trans mission. Nature(Lond.) 333: 514-519.

Anderson, R.M. and M ay, R.M. (1992) Understanding the AIDS pandemic. Sci. Am 266: 20-26.

Anderson, W. (1987) DrugSmugging U.S. General Accounting Office, Washington, DC.

A nnell, A., Fugelstad, A. and A gren, G. (1991) HIV-prevalence and mortality in relation to type of drug abuse among drug addicts in Stockholm 1981-1988. In: DrugAddiction and AIDS, pp. 16-22, Loimer, N., Schmid, R. and Springer, A. (ed.) Springer-Verlag, New York.

A nonymous (1984) The cause of AIDS? Lancet i: 1053-1054. 
A nonymous (1990) Senate approves measures on transit and AIDS. TheNew York Times, August 6.

Anonymous (1991) Dentist-infected AIDS patient dies. Dallas Morning News, December 9.

A nonymous (1992) Doubts about zidovudine Lance 339: 421.

Antonaci, S., Jirillo, E., Stasi, D., De Mitrio, V., La Via, M .F. and Bonomo, L. (1988) I mmunoresponsiveness in hemophilia: lymphocyte- and phagocytemediated functions. Diagn. din. I mmun. 5: 318-325.

A oun, H. (1989) When a house officer gets AIDS. New Eng. J. Med. 321: 693496.

Aoun, H. (1992) From the eye of the storm, with the eyes of a physician. Ann. intern. Med. 116: 335-338.

A ral, S.O. and Holmes, K.K. (1991) Sexually transmitted diseases in the AIDS era. Sai. Am 264: 62-69.

Archer, C.B., Spittle, M.F. and Smith, N.P. (1989) Kaposi's sarcoma in a homosexual-10 years on. Clin. exp. Derm 14: 233-236.

Archibald, C.P., Schecter, M.T., Le, T.N., Craib, K.J .P., M ontaner, J.S.G. and O'Shaughnessy, M.V. (1992) Evidence for a sexually transmitted cofactor for AIDS-related Kaposi's sarcoma in a cohort of homosexual men. Epidemiology 3: 203-209.

A ronson, D.L. (1983) Pneumonia deaths in haemophiliacs. Lancetii: 1023.

A ronson, D.L. (1988) Cause of death in hemophilia patients in the U nited States from 1968 1979. Am J. Hematol. 27: 7-12.

Avramis, V.I., M arkson, W., J ackson, R.L. and Gomperts, E. (1989) Biochemical pharmacology of zidovudine in human T-lymphoblastoid cells (CEM). AIDS 3: 417-422.

Aylward, E.H., Butz, A.M., Hutton, N., Joyner, M.L. and Vogel hut, J.W. (1992) Cognitive and motor development in infants at risk for human immunode ficiency virus. Am J. Dis Children 146: 218-222.

Bagasra, O., Hauptman, S.P., Lischner, H.W., Sachs, M. and Pomerantz, R.J. (1992) Detection of human immunodeficiency virus type 1 provirus in mononuclear cells by in situ polymerase chain reaction. New Eng. J. Med. 326: 1385-1391.

Bailey, H. (1968) TheVitamin Pioneers Rodale, Emmaus, PA.

Balter, M. (1991) M ontagnier pursues the mycoplasma-A IDS link. Science251: 271.

Baltimore, D. and Feinberg, M.B. (1989) HIV revealed, toward a natural history of the infection. New Eng. J. Med. 321: 1673-1675.

Baltimore, D. and Feinberg, M.B. (1990) Quantification of human immunodeficiency virus in the blood. New Eng. J. Med. 322: 1468-1469. 
Balzarini, J., Herdewijn, P. and DeClercq, E. (1989) Differential patterns of intracellular metabolism of 2', 3'-didehydro-2', 3'-dideoxythymidine and 3'-azido2', 3'-dideoxythymidine, two potent anti-human immunodeficiency virus compounds J. biol. Chem 264: 6127-6133.

Bardach, A.L. (1992) The heretic. Buzz, J anuary/ February: 68-73, 90, 92. Barinaga, M. (1992) Confusion on the cutting edge Science257: 616-619.

Bartholomew, C., Saxinger, W.C., Clark, J.W., Gail, M., Dudgeon, A., M ahabir, B., Hull-Drysdale, B., Cleghorn, F., Gallo, R.C. and Blattner, W.A. (1987) Transmission of HTLV-I and HIV among homosexual men in Trinidad. J. Am Med. Ass 257: 2604-2608.

Beardsley, T. (1986) French virus in the picture Nature(Lond.) 320: 563.

Becherer, P.R., Smiley, M.L., M atthews, T.J., Weinhold, K.J., McM illan, C.W. and White, G.C., II (1990) Human immunodeficiency virus-1 disease progression in hemophiliacs. AmJ. Hematol. 34: 204-209.

Beemon, K., Duesberg, P. and Vogt, P. (1974) Evidence for crossing-over between avian tumor viruses based on analysis of viral RNAS. Proc Natt. Acad. Sa. U.S.A. 71: 4254-4258.

Belman, A.L., Diamond, G., Dickson, D., Horoupian, D., Llena, J., Lantos, G. and Rubenstein, A . (1988) Pediatric acquired immunodeficiency syndrome Am J. Dis Child. 142:29-35.

Beral, V., Peterman, T.A., Berkelman, R.L. and J affe, H. W. (1990) Kaposi's sarcoma among persons with AIDS: a sexually transmitted infection? Lancet 335: 123-128.

Bergeron, L. and Sodroski, J. (1992) Dissociation of unintegrated viral DNA accumulation from single-cell lysis induced by human immunodeficiency virus type 1. J. Virol. 66: 5777-5787.

Berkley, S., Okware, S. and Naamara, W. (1989) Surveillance for AIDS in U ganda. AIDS 3: 79-85.

Bessen, L.J ., Greene, J.B., Louie, E., Seitzman, L.E. and Weinberg, H. (1988) Severe polymyositis-like syndrome associated with zidovudine therapy of AIDS and ARC. New Eng. J. Med. 318: 708.

Bethell, T. (1992) Heretic. TheAmerican Spectator, M ay: 18-19.

Bialy, H. and Farber, C. (1992) It's timeto reevaluate the HIV AIDS hypothesis. Rethinking AIDS, 1: 1-2.

Biggar, R.J. and The International Registry of Seroconverters (1990) AIDS incubation in $1891 \mathrm{HIV}$ seroconverters from different exposure groups. AIDS 4: 1059-1066.

Blanche, S., Rouzioux, C., M oscato, M.L., Veber, F., M ayaux, M.J., Jacomet, C., Tricoire, J., Deville, A., Vial, M., Firton, G. and HIV Infection in Newborns 
French Collaborative Study Group (1989) A prospectivestudy of infants born to women seropositive for human immunodeficiency virus type 1. New Eng. J. Med. 320: 1643-1648.

Blattner, W.A. (ed.) (1990) Human Rerovirology: HTLV. Raven Press, New York. Blattner, W.A. (1991) HIV epidemiology: past, present, and future FASEB J . 5: 2340-2348.

Blattner, W.A., Biggar, R.J., Weiss, S.H., Clark, J.W. and Goedert, J.J. (1985) E pidemiology of human lymphotropic retroviruses: an overview. Cancer Res 45 (Suppl.): 4598-4601.

Blattner, W.A., Gallo, R.C. and Temin, H.M. (1988) HIV causes AIDS. Science 241: 514-515.

Bolling, D.R. and Voeller, B. (1987) AIDS and heterosexual anal intercourse J. Am Med. Ass 258: 474.

Booth, W. (1988) A rebel without a cause for AIDS. Science239: 1485-1488.

Bove, J.R., Rigney, P.R. Kehoe, P.M . and Campbell, J. (1987) Lookback: preliminary experience of AABB members. Transfusion 27: 201-202.

Bowden, F.J., M cPhee, D.A., Deacon, N.J., Cumming, S.A., Doherty, R.R., Sonza, S., Lucas, C.R. and Crowe, S.M . (1991) A ntibodies to gp41 and nef in otherwise HIV-negative homosexual man with Kaposi's sarcoma. Lance 337 : $1313-1314$.

Brandt, A.M . (1988) AIDS in historical perspective: four lessons from the history of sexually transmitted diseases. Am J. Pub Health 78: 367-371.

Braun, M.M., Truman, B.I., Maguire, B., Di Ferdinando, G.T., J r., Wormser, G., Broaddus, R. and M orse, D.L. (1989) Increasing incidence of tuberculosis in a prison inmate population, associated with HIV-infection. J. Am Med. Ass 261: 393-397.

Bregman, D.J. and Langmuir, A.D. (1990) Farr's law applied to AIDS projections. J. Am Med. Ass 263: 50-57.

Brenner, H., Hernando-Briongos, P. and Goos, C. (1990) AIDS among drug users in Europe DrugAlcohol Depend. 29: 171-181.

Breo, D.L. and Bergalis, K. (1990) Meet Kimberly Bergalis-the patient in the “dental AIDS case" J. Am Med. Ass 264: 2018-2019.

Briefings (1991) All the [Science] that's fit to print. Science254: 649.

Briggs, J.H., McKerron, C.G., Souhami, R.L., Taylor, D.J.E. and Andrews, H. (1967) Severesystemic infections complicating "mainline" heroin addiction. Lancet ii: 1227-1231.

Brown, S.M., Stimmel, B., Taub, R.N., Kochwa, S. and Rosenfield, R.E. (1974) Immunologic dysfunction in heroin addicts. Arch. intern. Med. 134: 1001-1006. Brudney, K. and Dobkin, J. (1991) Resurgent tuberculosis in New York City. Am Rev. Respir. Dis 144: 744-749. 
Bryant, H.U., Cunningham, K.A . and J errells, T.R. (1992) Effects of cocaineand other drugs of abuse on immune responses In: Cocaine Pharmacology, Phys iology and Clinical Strategies pp. 353-369, Lalkoski, J.M., Galloway, M.P. and White, F.J. (eds) CRC Press, Boca Raton, FL.

Bschor, F., Bornemann, R., Borowski, C. and Schneider, V. (1991) M onitoring of HIV-spread in regional populations of injecting drug users - the Berlin expe rience In: DrugAddidion and AIDS, pp. 102-109, Loimer, N, Schmid, R. and Springer, A . (eds) Springer-Verlag, New York.

Buehler, J.W., Devine, O.J., Berkelman, R.L. and Chevarley, F.M . (1990) I mpact of the human immunodeficiency virus epidemic on mortality trends in young men, U nited States. Am J. Puld. Health 80: 1080-1086.

Buimovici-Klein, E., Lange, M., Ong, K. R, Grieco, M.H. and Cooper, L.Z. (1988) Virus isolation and immunestudies in a cohort of homosexual men. J. Med. Virol. 25: 371-385.

Bundesgesundheitsamt (Germany) (1991) Bericht des AIDS-Zentrums des Bundesgesundheitsamtes über A ktuelle Epidemiologische Daten (bis zum 31.7.1991). AIDS -Forschung 6:509-512.

Bureau of J ustice Statistics (1988) Special Report-Drug Law Violators, 1980-1986. U.S. Department of J ustice, Washinton, D.C.

Bureau of Justice Statistics (1991) Catalog of Federal Publications on I llegal Drug and Alcohol Abuse U.S. Department of J ustice, Washington, D.C.

Burke, D.S., Brundage, J.F., Goldenbaum, M., Gardner, M., Peterson, M., Visintine, R., Redfield, R. and Walter Reed Retrovirus Research Group (1990) Human immunodeficiency virus infections in teenagers; seroprevalenceamong applicants for the U.S. military service J. Am Med. Ass 263: 2074-2077.

Burns, D.P.W. and Desrosiers, R.C. (1991) Selection of genetic variants of simian immunodeficiency virus in persistently infected rhesus monkeys. J. Virol. 65: $1843-1854$.

Cairns, J. (1978) Cancer Scienceand Sociey. W.H. Freeman and Company, San Francisco.

Callen, M . (1990) Sunviving AIDS. Harper Perennial, New York.

Castro, A., Pedreira, J, Soriano, V., Hewlett, I., J hosi, B., Epstein, J. and Gonza lez-Lahoz, J. (1992) Kaposi's sarcoma and disseminated tuberculosis in HIVnegative individual. Lance 339: 868.

Centers for Disease Control (1981) Kaposi's sarcoma and Pneumocystis pneumonia among homosexual men-N ew York City and California. Morb Mort. Wedkly Rep. 30: 305-308.

Centers for Disease Control (1982) Epidemiologic aspects of the current outbreak of Kaposi's sarcoma and opportunistic infections. New Engl. J. Med. 306: 248-252. 
Centers for Disease Control (1986) Reports on AIDS published in the Morbidity and Mortality Wedky Report, J une 1981 through M ay 1986. U.S. Dept. of Health and Human Services, National Technical Information Service, Springfield, VA.

Centers for Disease Control (1987) Revision of the CDC surveillance case definition for acquired immunodeficiency syndrome J. Am Med. Ass 258: 1143-1154.

Centers for Disease Control (1988) U pdate: acquired immunodeficiency syndrome and human immunodeficiency virus infection among health-care workers. Morb Mort. Weekly Rep. 37: 229-239.

Centers for Disease Control(1990) Possible transmission of human immunodeficiency virus to a patient during an invasive dental procedure Morb. Mort. Wedkly Rep. 39: 489 492.

Centers for Disease Control (1991 ) Opportunistic non-H odgkin's lymphomas among severely immunocompromised HIV-infected patients surviving for prolonged periods on antiretroviral therapy - U nited States. Morb. Mort. Wedkly Rep. 40: 591401.

Centers for Disease Control (1992a) The second 100,000 cases of A cquired I mmunodeficiency Syndrome-U nited States, J une 1981-December 1991. Morb. Mort. Weekly Rep. 41: 28-29.

Centers for Disease Control (1992b) HIV/ AIDS Survellance, Year -end Edition. U.S. Department of Health and Human Services, Atlanta, GA.

Centers for Disease Control (1992C) Surveillance for occupationally acquired HIV infection-U nited States, 1981-1992. Morb Mort. Wedkly Rep. 41: 823-825.

Chaisson, R.E., Bacchetti, P., Osmond, D., Brodie, B., Sande, M.A. and M oss, A.R. (1989) Cocaine useand HIV infection in intravenous drug users in San Francisco. J. Am Med. Ass 261: 561-565.

Chernov, H.I . (1986) Document on New Drug A pplication 19-655. Food and Drug Administration, Washington, DC.

Christensen, A.C. (1991) Novel reading. Nature(Lond.) 351: 600.

Clark, S.J., Saag, M.S., Decker, W.D., Campbell-Hill, S., Roberson, J.L., Veldkamp, P.J., Knappes, J.C., Hahn, B.H. and Shaw, G.M. ( 1991 ) High titers of cytopathic virus in plasma of patients with symptomatic primary HIVinfection. New Eng. J. Med. 324: 954-960.

Clifford, D. B, Jacoby, R. G, Miller, J. P, Seyfried, W.R. and Glicksman, M. (1990) Neuropsychometric performance of asymptomatic HIV-infected subjects. AIDS 4: 767-774.

Coffin, J., Haase, A., Levy, J.A., M ontagnierR, L., Oroszlan, S., Teich, N., Temin, H., Varmus, H., Vogt, P. and Weiss, R. (1986) Human immunodeficiency viruses Soience232: 697. 
Cohen, J. (1992a) Mystery virus meets the sceptics. Science257: 1032-1034.

Cohen, J. (1992b) N ew virus reports roil AIDS meeting. Science257: 604-605.

Cohen, S.S. (1987) A ntiretroviral therapy for AIDS. New Eng. J. Med. 317: 629.

Colebunders, R., Mann, J., Francis, H., Bila, K., Izaley, L., Kakonde, N., Kabasele,

K., I foto, L., Nzilamba, N., Quinn, T., van der Groen, G., Curran, J., Vercauten, B. and Piot, P. (1987) Evaluation of a clinical case definition of Acquired I mmunodeficiency Syndrome in A frica. Lance i: 492-494.

Collier, A.C., M eyers, J.D., Corey, L, M unphy, V. L, Roberts, P.L. and Hansfield, H.H. (1987) Cytomegalovirus infection in homosexual men. Am J. Med. 82: 593-601.

Congressional Panel (1992) Federal response to teen AIDS called "N ational Disgrace" AIDS Weekly, A pril 20: 12-13.

Connor, S. (1987) Oneyear in pursuit of the wrong virus. New Scientist 113: 49-58.

Connor, S. (1991) M illion pound row over AIDS test. Thel ndependent on Sunday, J anuary 20.

Connor, S. (1992) Scientists dispute royalties on HIV blood-test patent. TheI nde pendent, August 14.

Coombs, R.W., Collier, A.C., Allain, J.-P, Nikora, B., Leuther, M, Gjerset, G.F. and Corey, L. (1989) Plasma viremia in human immunodeficiency virus infection. New Eng. J. Med. 321: 1626-1631.

Cotton, P. (1990) Cofactor question divides codiscoverers of HIV. J. Am Med. Ass 264:3111-3112.

Cowley, G. (1992) Is a new AIDS virus emerging? Newsweek, J uly 27, 4: 41.

Cox, G.D. (1986) County Health Panel urges "poppers" ban, cites AIDS link. The Los Angdes Daily J ournal, M arch 24.

Cox, T. C, J acobs, M.R., Leblanc, A.E. and Marshman, J .A. (1983) Drugs and Drug Abuse Addiction Research Foundation, Toronto, Canada.

Craib, K.J .P., Schechter, M.T., Le, T.N., O'Shaughnessy, M.V. and M ontaner, J.S.G. (1992) HIV causes AIDS: a controlled study. VIII I nternational Conferenceon AIDS/ III STD World Congress, A msterdam.

Cramer, R. (1992) AIDS-Forschung-eine Besinnung. NeueZürcher Zeitung J anuary 3.

Cretton, E.M., Xie, M.Y., Bevan, R.J., Goudgaon, N.M., Schinazi, R.F. and Sommadossi, J.P. (1991) Catabolism of 3'- azido-3'-deoxythymidine in hepatocytes and liver microsomes, with evidence of formation of 3'-amino-3'-deoxythymidine, a highly toxic catabolite for human bone marrow cells. Molec Pharmac 39: 258-266.

Crewdson, J. (1989) The great AIDS quest. Chicago Tribune, N ovember 19.

Crewdson, J . (1992) House critique triggers another Gallo inquiry. Chicago Tribune, J une 14. 
Culliton, B.J . (1976) Legion fever: postmortem on an investigation that failed. Soience194:1025 1027.

Culliton, B.J. (1990) Inside the Gallo probe Sience248: 1494-1498.

Culver, K.W., Ammann, A.J., Partridge J.C., Wong, D.F., Wara, D.W. and Cowan, M.J. (1987) Lymphocyte abnormalities in infants born to drug abusing mothers. J. Pediat. 111: 230-235.

Curran, J., Lawrence, D.N., J affe, H., K aplan, J .E., Zyla, L.D., Chamberland, M., Weinstein, R., Lui, K.-J, Schonberger, L. B., Spura, T.J., A lexander, W. J., Swinger, G., A mmann, A., Solomon, S., Auerbach, D., Mildvan, D., Stoneburner, R., Jason, J.M., Haverkos, H.W. and Evatt, B.L. (1984) Acquired immunodeficiency syndrome (AIDS) associated with transfusions. New Eng. J. Med. 310: 69-75.

Curran, J.W., Morgan, M.W., Hardy, A.M., Jaffe, H.W., Darrow, W.W. and Dowdle, W.R. (1985) The epidemiology of AIDS: current status and future prospects Science229: 1352-1357.

Daar, E.S., M oudgil, T., M eyer, R.D. and Ho, D.D. (1991) Transient high levels of viremia in patients with primary human immunodeficiency virus type 1 infection. New Eng. J. Med. 324: 961-964.

Dalakas, M .C., Illa, I., Pezeshkpour R, G.H., Laukaitas, J.P., Cohen, B. and Griffin, J.L. (1990) Mitochondrial myopathy caused by long-term zidovudine therapy. New Eng. J. Med. 322:1098-1105.

Darby, S.C., Rizza, C.R., Doll, R., Spooner, R.J.D., Stratton, I.M. and Thakrar, B. (1989) Incidence of AIDS and excess mortality associated with HIV in haemophiliacs in the U nited Kingdom: report on behalf of the directors of haemophilia centers in the U nited Kingdom. Br. Med. J. 298: 1064-1068.

Darrow, W. W, Echenberg, D.F., Jaffe, H.W., O'M alley, P.M., Byers, R.H., Getchell, J.P. and Curran, J.W. (1987) Risk factors for human immunodeficiency virus (HIV) infections in homosexual men. Am J. Publ. Health 77: 479-483.

de Biasi, R., Rocino, A., Miraglia, E., Mastrullo, L. and Quirino, A.A. (1991) The impact of a very high purity of factor VIII concentrate on the immune system of human immunodeficiency virus-infected hemophiliacs: a randomized, prospective, two-year comparison with an intermediate purity concentrate Blood 78: 1919-1922.

DeCock, K.M., Selik, R.M., Soro, B., Gayle, H. and Colebunders, R.L. (1991) AIDS surveillance in A frica: a reappraisal of case definitions. $\mathrm{Br}$. Med. J. 303 : 1185-1188.

Deininger, S., M üller, R., Guggenmoos-Holzmann, I., Laukamm-J osten, U. and Bienzle, U. (1990) Behavioral characteristics and laboratory parameters in homo- and bisexual men in West Berlin: an evaluation of five years of testing and counselling on AIDS. Klin. Wochenschr. 68: 906-913. 
Delaney, M. and Goldblum, P. (1987) Strategies for Survival: A Gay Men's Health Manual for theAge of AIDS. St. Martin's Press, N ew York.

DeLoughry, T.J. (1991) 40 scientists call on colleagues to re-evaluate AIDS the ory. TheChronide of Higher Education, December 4.

Des Jarlais, D., Friedman, S., Marmor, M., Cohne, H., Mildvan, D., Yancovitz, S., M athur, U., Et-Sadr, W, Spira, T.J. and Garber, J. (1987) Development of AIDS, HIV seroconversion, and potential cofactors for T 4 cell loss in a cohort of intravenous drug users. AIDS 1:105-111.

DesJ arlais, D., Friedman, S.R. and Hopkins, W. (1988) Risk reduction of the acquired immunodeficiency syndrome among intravenous drug users. In: AIDS and IV DrugAbusers Current Perspectives pp. 97-109, Galea, R.P., Lewis, B.F. and Baker, L. (eds) National Health Publishing, Owings Mills, MD.

Dismukes, W.E., Karchmer, A.W., J ohnson, R.F. and Dougherty, W.J . (1968) Viral hepatitis associated with illicit parenteral use of drugs J. Am Med. Ass 206: 1048-1052.

Don, P. C, Fusco, F., Fried, P., Baterman, A, Duncanson, F.P., Lenox, T.H. and Klein, N.C. (1990) Nail dyschromia associated with zidovudine Ann. intern. Med. 112: 145-146.

Donahoe, R.M., Bueso-Ramos, C., Donahoe, F., M adden, J.J., Falek, A., Nicholson, J.K.A. and Boxos, P. (1987) Mechanistic implications of the findings that opiates and other drugs of abuse moderate $T$-cell surface receptors and antigenic markers. Ann. N.Y. Acad. Sa. 496: 711-721.

Dournon, E., M atheron, S., Rozenbaum, W., Gharakanian, S., Michon, C., Girard, P.M., Perrone, C., Salmon, D., Detruchis, P., Leport, C. and Claude Bernard Hospital AZT Study Group (1988) Effects of zidovudine in 365 consecutive patients with AIDS or AIDS-related complex. Lancet ii: 1297-1302.

Doyle, A.C., Sir (1928) TheBoscombeValley Mystery. John M urray, London.

Drew, W.L., Mills, J., Levy, J., Dylewski, J., Casavant, C., Amann, A.J., Brodie, $\mathrm{H}$. and Merigan, T. (1985) Cytomegalovirus infection and abnormal T-lymphocyte subset ratios in homosexual men. Ann. intern. Med. 103: 61 53.

Dubin, G. and Braffmann, M.N. (1989) Zidovudine-induced hepatotoxicity. Ann. intern. Med. 110: 85-86.

Duckett, M. and Orkin, A.J . (1989) AIDS-related migration and travel policies and restrictions: a global survey. AIDS 3 (Suppl. 1): \$231-\$252.

Duesberg, P.H. (1968) The RNA s of influenza virus. Proc natn. Acad. Si. U.S.A. 59: 930-937.

Duesberg, P.H.. (1987) Retroviruses as carcinogens and pathogens: expectations and reality. Cancer Res 47: 1199-1220.

Duesberg, P.H. (1989a) Defective viruses and AIDS. Nature(Lond.) 340: 515.

Duesberg, P.H. (1989b) Does HIV cause AIDS? J. AIDS 2: 514-515. 
Duesberg, P.H. (1989C) Human immunodeficiency virus and acquired immunodeficiency syndrome: correlation but not causation. Proc natn. Acad. Sa. U.S.A. 86: 755-764.

Duesberg, P.H. (1990a) AIDS: non-infectious deficiencies acquired by drug consumption and other risk factors. Res I mmun. 141:5-11.

Duesberg, P.H. (1990b) Responding to the AIDS debate Naturwissenschaften 77: 97-102.

Duesberg, P.H. (1990c) Quantitation of human immunodeficiency virus in the blood. New Eng. J. Med. 322: 1466.

Duesberg, P.H. (1991a) AIDS epidemiology: inconsistencies with human immunodeficiency virus and with infectious disease. Proc natn. Acad. Sd. U.S.A. 88: 1575-1579.

Duesberg, P.H. (1991b) Can alternative hypotheses survive in this era of megaprojects? TheSientist, J uly 8.

Duesberg, P.H. (1991C) Defense says only AIDS not infectious (letter). San Franisco Examine, August 30.

Duesberg, P.H. (1992a) AIDS: the alternative view (letter). Lancet 339: 1547.

Duesberg, P.H. (1992b) A giant hole in the HIV-AIDS hypothesis. TheSunday Times May 31.

Duesberg, P.H. (1992C) HIV as target for zidovudine Lance 339: 551.

Duesberg, P.H. (1992d) HIV, AIDS, and zidovudine Lancet 339: 805-806.

Duesberg, P.H. (1992e) Questions about AIDS (letter). Nature(Lond.) 358: 10.

Duesberg, P.H. (1992f) The role of drugs in the origin of AIDS. Biomed. Pharmacother. 46: 3-15.

Duesberg. P.H. and Ellison, B.J . (1990) Is the AIDS virus a sciencefiction? Policy Rev. 53: 40-51.

Duesberg. P.H. and Schwart, J.R. (1992) L atent viruses and mutated oncogenes: no evidence for pathogenicity. Prog Nudeic Adid Res Molec Bid. 43: 135-204.

Duesberg, P.H. and Vogt, P.K. (1970) Differences between the ribonucleic acids of transforming and non-transforming avian tumor viruses Proc natn. Acad. Sa. U.S.A. 67: 1673-1680.

Editorial (1987) AIDS in A frica. Lancet ii: 192-194.

Editorial (1990) Zidovudine for symptomless HIV infection. Lance 335: 821-822. Editorial (1991) The impact of the N ational Cancer Act. J. natn. Cancer Inst. 83: S1-S16.

Eggers, H.J. and Weyer, J.J. (1991) Linkage and independence of AIDS Kaposi disease: the interaction of human immunodeficiency virus and some coagents. Infection 19: 115-122.

Eigen, M. (1989) The AIDS debate Naturwissenschaften 76: 341-350. 
Elwell, L.P., Ferone, R., Freeman, G.A., Fyfe, J.A., Hill, J.A., Ray, P. II., Richards, C.A., Singer, S. C., Knidk, C. B, Rideout, J.L. and Zimmerman, T.P. (1987) A ntibacterial activity and mechanism of action of 3'-azido-3'-deoxythymidine (BW A509U). Antimicrob. Agents Chemother. 31: 274-280.

Ensoli, B., Barillari, G., Salahuddin, S.Z., Gallo, R.C. and Wong-Staal, F. (1990) Tat protein of HIV-I stimulates growth of cells derived from Kaposi's sarcoma lesions of AIDS patients. Nature(Lond.) 345: 84-86.

Espinoza, P., Bouchard, I., Buffet, C., Thiers, V., Pillot, J. and Etienne, J.P. (1987) High prevalence of infection by hepatitis B virus and HIV in incarcerated French drug addicts Gastroenterol. din. Bid. 11: 288-292.

Ettinger, N.A. and Albin, R.J. (1989) A review of the respiratory effects of smoking cocaine Am J. Med. 87: 664-668.

European Collaborative Study (1991) Children born to women with HIV-I infection: natural history and risk of transmission. Lancet 337: 253-260.

Evans, A.S. (1989a) Author's reply. J. AIDS 2: 515-517.

Evans, A.S. (1989b) Does HIV cause AIDS? An historical perspective J. AIDS2: 107-113.

Evans, A.S. (1989C) Viral I nfetions of Humans, Epidemiology and Control. Plenum Publishing Corporation, New York.

Evans, A.S. (1992) AIDS: the alternative view (letter). Lancet 339: 1547.

Evatt, B.L., Ramsey, R.B. Lawrence, D.N., Zyla, L.D. and Curran, J.W. (1984) The acquired immunodeficiency syndrome in patients with hemophilia. Ann. intern. Med. 100:499505.

Evatt, B.L., Gomperts, E.D., M cDougal, J.S. and Ramsey, R.B. (1985) Coincidental appearance of LAV/ HTLV-III antibodies in hemophiliacs and the onset of the AIDS epidemic. New Eng. J. Med. 312: 483-486.

Eyster, M.E., Whitehurst, D.A., Catalano, P.M., M cM illan, C.W., Goodnight, S.H., Kasper, C.K., Gill, J.C., A ledort, L.M., Hilgartner, M.W., Levine, P.H., Edson, J.R., Hathaway, W.E., Lusher, J.M., Gill, F.M., Poole, W.K. and Shapiro, S.S. (1985) Long-term follow-up of hemophiliacs with lymphocytopenia or thrombocytopenia. Blood 66: 1317-1320.

Farber, C. (1992) Fatal distraction. Spin 3: 36-45, 84, 90-91.

Fauci, A. (1989) Writing for my sister Denise The AAAS Observer, Supplement to Science, September 1: 4.

Fauci, A.S. (1991) The role of the endogenous cytokines in the regulation of HIV expression. HIV Adv. Res Ther. 1: 3-7.

Fenner, F., M cAuslan, B.R., M ims, C.A., Sambrook, J. and White, D.O. (1974)

TheBiology of Animal Viruses A cademic Press, Inc., N ew York.

Fineberg, H.V. (1988) The social dimensions of AIDS. Si. Am 259: 128-134. 
Finnegan, L.P., M ellot, J.M., Williams, L.R. and Wapner, R.J. (1992) Perinatal exposure to cocaine: human studies. In: Cocaine Pharmacology, Physiology and Clinical Strategies pp. 391-409, Lakoski, J.M., Galloway, M.P. and White, F.J. (eds) CRC Press, Boca Raton, FL.

Fischl, M.A., Richman, D.D., Grieco, M.H., Gottlieb, M.S., Volberding, P.A., Laskin, O.L., Leedon, J.M. Groopman, J.E., Mildvan, D., Schooley, R.T., Jackson, G.G., Durack, D.T., King, D. and AZT Collaborative Working Group (1987) The efficacy of azidothymidine (AZT) in the treatment of patients with AIDS and AIDS-related complex. New Engl. J. Med. 317: 185-191.

Fischl, M.A., Richman, D.D., Causey, D.M., Grieco, M.H., Bryson, Y., M ildvan, D., Laskin, O.L., Groopman, J.E., Volberding, P.A., Schooley, R.T., J ackson, G.G., Durack, D.T., A ndrews, J.C., Nusinoff-Lehrman, S., Barry, D.W. and AZT Collaborative Working Group (1989) Prolonged zidovudine therapy in patients with AIDS and advanced AIDS-related complex. J. Am Med. Ass 262: 2405-2410.

Flanagan, T.J . and Maguire K. (1989) Sourcebook of Criminal J ustice Statistics (1989) - Bureau of J ustice Statistics NCJ -124224. U.S. Department of J ustice, U.S. Government Printing Office, Washington, DC.

Folkart, B.A . (1989) Paul Gann dies; Tax-crusading Prop. 13 author. Los Angdes Times September 12.

Francis, D.P. (1983) The search for the cause In: TheAIDS Epideric, pp. 137-148, Cahill, K.M. (ed.) St. Martin's Press, New York.

Francis, D.P., Curran, J.W. and Essex, M. (1983) Epidemic acquired immune deficiency syndrome: epidemiologic evidence for a transmissible agent. J . natn. Cancer Inst. 71: 1-4.

Freeman, B.A. (1979) Burrows Textbook of Midrobidogy. W.B. Saunders Co., Philadelphia.

Freestone, D.S. (1992) Zidovudine Lance 339: 626.

Fricker, H.S. and Segal, S. (1978) Narcotic addiction, pregnancy, and the newborn. Am J. Dis Child. 132: 360-366.

Friedland, G.H., Satzman, B.R., Rogers, M.F., Kahl, P.A., Lesser, M.L., Mayers, M.M. and Klein, R.S. (1986) Ladk of transmission of HTLV-III/ LAV infection to household contacts of patients with AIDS or AIDS-related complex with oral candidiasis. New Eng. J. Med. 314: 344-349.

Friedman-Kien, A.E., Saltzman, B.R., Cao, Y., Nestor, M.S., Mirabile, M., Li, J.J . and Peterman, T.A. (1990) Kaposi's sarcoma in HIV-negative homosexual men. Lance 335: 168-169.

Froesner, G. ( 1991 ) Congress report: VII Internationale AIDS-Konferenz in Florenz, 1991. AIDS -Forschung 9: 477-486. 
Fry, T.C. (1989) TheGreat AIDS Hoax. Life Science Inst., Austin, TX.

Fultz, P.N., Stricker, R.B., M cClure H.M., Anderson, D.C., Switzer,W. M. and Horaist, C. (1990) Humoral response to SIV/ SM M infection in macaque and mangabey monkeys. J. AIDS 3: 319-329.

Furman, P.A., Fyfe, J.A., St Clair, M., Weinhold, K., Rideout, J L., F reeman, G.A., N usinoff-Lehrman, S., Bolognesi, D.P., Broder, S., Mitsuya, H. and Barry, D.W. (1986) Phosphorylation of 3'-azido-3' deoxythymidine and selective interaction of the 5 '-triphosphate with human immunodeficiency virus reverse transcriptase Proc natn. Acad. Sc. U.S.A. 83: 8333-8337.

Gajdusek, D.C. (1977) U nconventional viruses and the origin and disappearance of kuru. Science197: 943-960.

Gallo, R.C. (1987) The AIDS virus. Sci. Am 256: 45-46.

Gallo, R.C. (1990) Mechanism of disease induction by HIV. J. AIDS 3: 380-389.

Gallo, R.C. ( 1991) VirusHunting-AIDS, Cance, and theHuman Retrovinus A Story of Sientific Discovery. Basic Books, New York.

Gallo, R.C. (1992) Self-deluding (letter). TheSunday Times M ay 24.

Gallo, R.C. and M ontagnier, L. (1987) The chronology of AIDS research. Nature (Lond.) 326: 435-436.

Gallo, R.C. and Montagnier, L. (1988) AIDS in 1988. Sd. Am 259: 41-48.

Gallo, R.C., Sarin, P.S., Gelmann, E.P., Robert-Guroff, M. and Richardson, E. (1983) I solation of human T-cell leukemia virus in acquired immune deficiency syndrome (AIDS). Sience220: 865-867.

Gallo, R.C., Salahuddin, S.Z., Popovic, M., Shearer, G.M., Kaplan, M., Haynes, B.F., Palker, T.J., Redfield, R., Oleske, J., Safai, B., White, G., Foster, P. and Markham, P.D. (1984) Frequent detection and isolation of cytopathic retrovirus (HTLV-III) from patients with AIDS and at risk for AIDS. Science224: 500-503.

Garry, R.F. and Koch, G. (1992) Tat contains a sequence related to snake neurotoxins [letter]. AIDS, 6: 1541-1542.

Garry, R. F, Witte, M.H., Gottlieb, A. A, Elvin-Lewis, M., Gottlieb, M. S, Witte, C. L, A lexander, S. S., Cole, W.R. and Drake, W.L. (1988) Documentation of an AIDS virus infection in the United States in 1968. J. Am Med. Ass 260: 2085-2087.

Garry, R.F., Kort, J.J., Koch-N olte, F. and Koch, G. (1991) Similarities of viral proteins to toxins that interact with monovalent cation channels. AIDS 5: 1381-1384.

Geller, S.A. and Simmel, B. (1973) Diagnostic confusion from lymphatic lesions in heroin addicts. Ann. intern. Med. 78: 703-705.

Gilks, C. (1991) What use is a clinical case definition for AIDS in A frica? Br. Med. J. 303: 1189-1190. 
Gill, J.C., Menitove, M.D., A nderson, P.R., Casper, J.T., Devare, S.G., Wood, C., Adair, S., Casey, J., Scheffel, C. and M ontgomery, M.D. (1986) HTLV-III serology in hemophilia: relationship with immunologic abnormalities. J. Pediat. 108: 511-516.

Gill, P.S., Rarick, M., Byrnes, R.K., Causey, D, Loureiro, C. and Levine, A.M. (1987) Azidothymidine associated with bonemarrow failure in the acquired immunodeficiency syndrome (AIDS). Ann. intern. Med. 107: 502-505.

Ginzburg, H.M. (1988) A cquired immune deficiency syndrome (AIDS) and drug abuse In: AIDS and I.V. Drug Abusers Current Perspedtives, pp. 61-73, Galea, R.P., Lewis, B.F. and Baker, L. (eds) National Health Publishing, Owings Mills, MD.

Goedert, J.J., Neuland, C.Y., Wallen, W.C., Greene, M.H., Mann, D.L., M urray, C., Strong, D. M., Fraumeni, J.F., J r and Blattner, W.A. (1982) A myl nitrite may alter $T$ lymphocytes in homosexual men. Lancet i: 412-416.

Goedert, J.J., Kessler, C.M., Aledort, L.M., Biggar, R.J ., Andes, W.A., W hite, G.C., II, Drummond, J.E., Vaidya, K., Mann, D.L., Eyster, M.E., Ragni, M.V., Lederman, M.M., Cohen, A.R., Bray, G.L. Rosenberg, P.S., Friedman, R.M., Hilgartner, M.W., Blattner, W.A., Kroner, B. and Gail, M.H. (1989) A prospective study of human immunodeficiency virus type 1 infection and the development of AIDS in subjects with hemophilia. New Eng. J. Med. 321: 1141-1148.

Goldsmith, M.S. (1990) Science ponders whether HIV acts alone or has another microbe's aid. J. Am Med. Ass 264: 265-266.

Goodgame, R.W. (1990) AIDS in U ganda-clinical and social features New Eng. J. Med. 323: 383-389.

Gorard, D.A. and Guilodd, R.J . (1988) Necrotising myopathy and zidovudine Lancet 1: 1050.

Gottlieb, M.S., Schanker, H.M., Fan, P.T., Saxon, A., Weisman, J.D. and Pozalski, J . (1981) Pneumocystis pneumonia-Los Angeles. Morb. Mort. Wedky Rep. 230: 250-252.

Goudsmit, J. (1992) Alternative view on AIDS. Lancet 339: 1289-1290.

Graham, N.M.H., Zeger, S.L., Park, L.P., Phair, J.P., Detels, R., Vermund, S.H., Ho, M., Saah, A.J . and Multicenter AIDS Cohort Study (1991) Effect of zidovudine and Pneumocystiscarinii pneumonia prophylaxis on progression of HIV-1 infection to AIDS. Lance 338: 265-269.

Greenberg, D.S. (1986) What ever happened to the war on cancer? Discover, M arch, 47-66.

Grimshaw, J. (1987) Being HIV antibody-positive Br. Med. J. 295: 256-257.

Guinan, M.E. and Hardy, A. (1987) Epidemiology of AIDS in women in the United States, 1981 through 1986. J. Am Med. Ass 257: 2039-2042. 
Guyton A.C. (1987) Textbook of Medical Physiology. W.B. Saunders, New York. Haas, M . (1989) The need for a search for a proximal principle of human AIDS. Cancer Res 49: 2184-2187.

Hahn, B.H., Shaw, G.M., Taylor, M.E., Redfield, R.R., Markham, P.D., Salahuddin, S.Z., Wong-Staal, F., Gallo, R.C., Parks, E.S. and Parks, W.P. (1986) Genetic variation in HTLV-III/ LAV over time in patients with AIDS or at risk for AIDS. Science232: 1548-1553.

Hamilton, D.P. (1991) What next in the Gallo case? Science254: 941-945.

Hamilton, J.D., Hartigan, P.M., Simberkoff, M.S., Day, P.L., Diamond, G.R., Dickinson, G.M., Drusano, G.L., Egorin, M.J., George, W.L., Gordin, F.M . and Veterans Affairs Cooperative Study Group on AIDS Treatment (1992) A controlled trial of early versus late treatment with zidovudine in symptomatic human immunodeficiency virus infection. New Eng. J. Med. 326: 437-443.

Hardy, A.M., Allen, J.R., M organ, W.M. and Curran, J.W. (1985) The incidence rate of acquired immunodeficiency syndrome in selected populations. J. Am Med. Ass 253: 215-220.

Harris, P.D. and Garret, R. (1972) Susceptibility of addicts to infection and neoplasia. New Eng. J. Med. 287: 310.

Haseltine, W.A. and Wong-Staal, F. (1988) The molecular biology of the AIDS virus. Sa. Am 259: 52-62.

Haverkos, H.W. (1988a) Epidemiologic studies-Kaposi's sarcoma vs opportunistic infections among homosexual men with AIDS. In: Health Hazards of Nitritel nhalants, pp. 96-105, Haverkos, H.W. and Dougherty, J.A. (eds) NIDA Research Monograph 83, National Institute on Drug A buse, Washington, DC.

Haverkos, H.W. (1988b) Kaposi's sarcoma and nitriteinhalants. In: Psychological, Neuropsychiatric and SubstanceAbuseAspets of AIDS, pp. 165-172, Bridge, T.P., Mirsky, A.F. and Goodwin, F.K. (eds) Raven Press, New York.

Haverkos, H.W. (1990) Nitrite inhalant abuse and AIDS-related K aposi's sarcoma. J. AIDS 3 (Suppl. 1): 547-550.

Haverkos, H.W. and Dougherty, J.A. (eds) (1988) Health Hazards of Nitritel nhalants NIDA Research M onograph 83, National Institute on Drug A buse, Washington, DC.

Haverkos, H.W., Pinsky, P.F., Drotman, D.P. and Bregman, D.J. (1985) Disease manifestation among homosexual men with acquired immunodeficiency syndrome: a possible role of nitrites in Kaposi's sarcoma. J. Sexually Trans mitted Dis 12: 203-208.

Hearst, N. and Hulley, S. (1988) Preventing the heterosexual spread of AIDS: are we giving our patients the best advice? J. Am Med. Ass 259: 2428-2432.

Helbert, M., F letcher, T., Peddle, B., Harris, J.R.W. and Pinching, A.J . (1988) 
Zidovudine-associated myopathy. Lance ii: 689-690.

Hersh, E.M., Reuben, J. M., Bogerd, H., Rosenblum, M., Bielski, M., Mansell, P.W.A., RIos, A., Newell, G.R. and Sonnenfeld, G. (1983) Effect of the recre ational agent isobutyl nitrite on human peripheral blood leukocytes and on in vitro interferon production. Cancer Res 43: 1365-1371.

Heyward, W.L. and Curran, J.W. (1988) The epidemiology of AIDS in the U.S. Si. Am 259: 72-81.

Hilts, P.J. (1992) M onkey's HIV vulnerability portends AIDS breakthrough. The New York Times J une 12.

Hishida, O., Ido, E., Igarashi, T., Hayami, M., Miyazaki, M., A yisi, N.K. and Osei-Kwasi, M. (1992) Clinically diagnosed AIDS cases without evident association with HIV type 1 and 2 infection in Ghana. Lance 340: 971-972. Hitchcock, M.J.M . (1991) Review: antiviral portrait series Number 1; 2',3'-didehydro-2', 3' dideoxythymidine (D 4T), and anti-HIV agent. Antiviral Chem Chemother. 2: 125-132.

Ho, D.D, M oudgil, T. and Alam, M. (1989a) Quantification of human immunodeficiency virus type 1 in the blood of infected persons. New Eng. J. Med. 321: 1621-1625.

Ho, D.D., Moudgil, T., Robin, H.S., Alam, M., Wallace, B.J. and Mizrachi, Y. (1989b) Human immunodeficiency virus type 1 in a seronegative patient with visceral Kaposi's sarcoma and hypogamma globulinemia. Am J. Med. 86: 349-351.

Ho, H.-T. and Hitchcock, M .J.M . (1989) Cellular pharmacology of 2', 3'-dideoxy2, 3'-didehydrothymidine, a nucleotide analog active against human immunodeficiency virus. Antimicrob. Agents Chemother. 33: 844-849.

Hodgkinson, N. (1992) Experts mount startling challenge to AIDS orthodoxy. TheSunday Times(Focus), April 26.

Hoffman, M.S. (ed.) (1992) World Almanacand Book of Facts Scripps Howard Co., New York.

Hoffmann, G.W. (1990) A response to P.H. Duesberg with reference to an idiotypic network model of AIDS immunopathogenesis. Res. I mmun. 141: 701-709.

Holmberg, S.D., Conley, L.J., Buchbinder, S.P., J udson, F.N., Bush, T.J., K atz, M.H., Penley, K.A., and Hershow, R.C. (1992) Use of therapeutic and prophylactic drugs for AIDS by homosexual and bisexual men in threeU.S. cities AIDS, 7:699-704.

Holub, W.R. (1988) AIDS: a new disease? Am Clin. Prod. Rev. 7: 28-37.

Hoxie, J.A., Haggarty, B.S., Rakowski, J.L., Pillsbury, N. and Levy, J.A. (1985) Persistent noncytopathic infection of normal human T Iymphocytes with AIDS-associated retrovirus. Science229: 1400-1402. 
Huang, Y.Q., Li, J J., Rush, M.G., Poiesz, B.J., Nicolaides, A., J acobson, M., Zhang, W.G., Coutavas, E, A bbott, M.A. and Friedman-Kien, A.E. (1992) HPV-16-related DNA sequences in Kaposi's sarcoma. Lance 339: 515-518. Institute of M edicine (1986) Confronting AIDS. N ational A cademy Press, Washington, DC.

Institute of M edicine (1988) Confronting AIDS-Update1988. N ational A cademy Press, Washington, DC.

Jaffe, H.W., Bregman, D.J . and Selik, R.M. (1983a) A cquired immune deficiency syndrome in the U nited States: the first 1,000 cases J. I nfeet Dis 148: 339-345. Jaffe, H.W., Choi, K., Thomas, P.A., Haverkos, H.W., Auerbach, D.M., Guinan, M.E., Rogers, M.F., Spira, T.J., Darrow, W.W., Kramer, M.A., Friedman, S.M., M onroe, J.M., Friedman-Kien, A.E., Lubenstein, L.J., M armor, M., Safai, B., Dritz, S.K., Crispi, S.J., Fannin, S.L., Orkwis, J.P., Kelter, A., Rushing W.R., Thacker, S.B. and Curran, J.W. (1983b) National case-control study of Kaposi's sarcoma and Pneumocystiscarinii pneumonia in homosexual men: Part 1, epidemiologic results. Ann. intern. Med. 99: 145-151.

Jason J., Holman, R.C., Evatt, B.L. and Hemophilia-AIDS Collaborative Study Group (1990) Relationship of partially purified factor concentrates to immune tests and AIDS. Am J. Hematol. 34: 262-269.

J in, Z., Cleveland, R.P. and Kaufman, D.B. (1989) I mmunodeficiency in patients with hemophilia: an underlying deficiency and lack of correlation with factor replacement therapy or exposure to human immunodeficiency virus. Allergy din. Immun. 83: 165-170.

J ohnson, R.E., Lawrence, D.N., Evatt, B.L., Bregman, D.J., Zyal, L.D., Curran, J.W., Aledort, L.M., Eyster, M .E., Brownstein, A.P. and Carman, C.J. (1985) Acquired immunodeficiency syndrome among patients attending hemophilia treatment centers and mortality experience of hemophiliacs in the United States. Am J. Epidemiol. 121: 797-810.

Jorgenson, K.A. and Lawesson, S.-O. (1982) A mylnitrite and K aposi's sarcoma in homosexual men. New Eng. J. Med. 307: 893-894.

J udson, 1:7. N., Penley, K.A., Robinson, M.E. and Smith, J.K. (1980) Comparative prevalence rates of sexually transmitted diseases in heterosexual and homosexual men. Am J. Epidemiol. 112: 836-843.

Kaslow, R.A., Blackwelder, W.C., Ostrow, D.G., Yerg, D., Palenneck, J., Goulson, A.H. and Valdiserri, R.O. (1989) No evidence for a role of alcohol or other psychoactive drugs in accelerating immunodeficiency in HIV-I positive individuals. J. Am Med. Ass 261: 3424-3429.

Kestler, H., Kodoma, T., Ringler, R, D., M arthas, M., Pederson, N., Ladkner, A., Regier, D., Sehgal, P., Danie, M., King, N. and Desrosiers, R. (1990) Induction of AIDS in rhesus monkeys by molecularly cloned simian immunode 
ficiency virus. Science248:1109-1112.

Kestler, H.W., Ringler, D.J., M ori, M.D., Panicalli, D.L., Sehgal, P.K., Daniel, M.D. and Desrosiers, R.C. (1991) I mportance of the nef gene for maintenance of high virus loads and for development of AIDS. Cell 65: 651462.

Klein, G. (1988) The role of science J. AIDS 1: 611415.

Koch, T. (1990) U ninfected dhildren of HIV-infected mothers may still suffer nervous problems. CDC AIDS Wedky, July 30: 9.

Koch, T.K., Jeremy, R, Lewis, E, Weintraub, P. and Cowan, M. (1990) Developmental abnormalities in uninfected infants born to human immunodeficiency virus-infected mothers. Ann. Neurd. 28: 456-457.

Koerper, M.A. (1989) AIDS and hemophilia. In: AIDS: Pathogenesis and T reatment, pp. 79-95, Levy, J.A. (ed.) Marcel Dekker, Inc., New York.

Kolata, G. (1987) I mminent marketing of AZT raises problems; marrow suppression hampers AZT use in AIDS victims. Sience235: 1462-1463.

Kolata, G. (1992) After 5 years of use, doubt still douds leading AIDS drug. The New York Times J une 2.

Kono, R. (1975) Introductory review of subacutemyelo-optico-neuropathy (SMON) and its studies done by the SM ON research commission. J ap. J. Med. Sa. Bid. 28 (Suppl.): 1-21.

Konotey-A hulu, F.I.D. (1987) AIDS in A frica: misinformation and disinformation. Lancetii: 206-207.

Konotey-A hulu, F.I.D. (1989) What is AIDS? Tetteh-A'Domenco Co., Watford, England.

Kozel, N.J . and A dams, E.H. (1986) Epidemiology of drug abuse: an overview. Science234: 970-974.

Kreek, M.J. (1991) M ethadonemaintenancetreatment for harm reduction approach to heroin addiction. In: Drug Addiction and AIDS, pp. 153-178, Loimer, N., Schmid, R. and Springer, A. (eds) Springer-Verlag, New York.

Kreiss, J.K., Kasper, C.K., Fahey, J.L., Weaver, M., Visscher, B.R., Stewart, J.A. and Lawrence, D.N. (1984) N ontransmission of T-cell subset abnormalities from hemophiliacs to their spouses. J. Am Med. Ass 251: 1450-1454.

Kreiss, J.K., Kitchen, L.W., Prince, H.E., Kasper, C.K., Goldstein, A.L., Naylor, P.H., Preble, O., Stewart, J.A. and Essex, M. (1986) Human T cell leukemia virus typellI antibody, lymphadenopathy, and acquired immune deficiency syndrome in hemophiliac subjects. Am J. Med. 80: 345-350.

Lambert, B. (1991) Kimberly Bergalis is dead of AIDS at 23 (contracted from a health care worker) (Obituary). TheNew York Times December 9.

Landesmann, S., Minkoff, H., Holman, S., McCalla, S. and Sijin, O. (1987) Serosurvey of human immunodeficiency virus infection in parturients. J. Am Med. Ass 258: 2701-2703. 
Lang, D.J., Kovacs, A.A.S., Zaia, J .A., Doelkin, G., Niland, J.C., Aledort, L., Azen, S.P., Fletcher, M. A., Gauderman, J., Gjerst, G.J., Lusher, J., Operskalski, E.A., Parker, J.W., Pegelow, C., Vyas, G.N., M osley, J.W. and The Transfusion Safety Group (1989) Seroepidemiologic studies of cytomegalovirus and Epstein-Barr virus infections in relation to human immunodeficiency virus type 1 infection in selected recipient populations. J. AIDS 2: 540-549.

Lang, W., Perkins, H., A nderson, R.E., Royce, R., J ewell, N. and Winkelstein, W., J R (1989) Patterns of T lymphocyte changes with human immunodeficiency virus infection: from seroconversion to the development of AIDS. J. AIDS 2: 63-69.

Lang, W., Osmond, D., Samuel, M., M oss A., Schrager, L. and Winkelstein, W., J R (1991 ) Population-based estimates of zidovudine and aerosol pentamidine use in San Francisco: 1987-1989. J. AIDS 4: 713-716.

Lange, W.R., Dax, E.M., Haerten, C.A., Snyder, F.R. and J affe, J.H. (1988) Nitrite inhalants: contemporary patterns of abuse In: Health Hazards of Nitrite Inhalants, pp. 86-94, Haverkos, H.W. and Dougherty, J.A. (eds) National Institute on Drug A buse, Washington, DC.

Langhoff, E., M cElrath, J., Bos, H.J., Pruett, J., Granelli-Piperno, A., Cohn, Z.A. and Steinman, R.M . (1989) M ost CD4 + T cells from human immunodeficiency virus-1 infected patients can undergo prolonged clonal expansion. J. Clin. Invest. 84: 1637-1643.

Laurence, J., Siegal, F.P., Schattner, E., Gelman, I.H. and M orse, S. (1992) Acquired immunodeficiency without evidence of infection with human immunodeficiency virus types 1 and 2. Lance 340: 273-274.

Laurent-Crawford, A. G., Krust, B., Muller, S., Riviere, Y., Rey-Cuille, M.-A., Bechet, J.-M ., M ontagnier, L. and Hovanessian, A.G. (1991) The cytopathic effect of HIV is associated with apoptosis Virology 185: 829-839.

Lauritsen, J. (1990) Poison by Prescription-TheAZT Story. A sklepios Press, New York.

Lauritsen, J. (1991) The "AIDS" war: censorship and propaganda dominate media coverage of the epidemic. New York Native, August 12.

Lauritsen, J. (1992) FDA documents show fraud in AZT trials. New York Native, March 30.

Lauritsen, J. and Wilson, H. (1986) Death Rush, Poppers and AIDS. Pagan Press, New York.

Lawrence, D.N., Jason, J.M., Holman, R.C. and M urphy, J.J. (1990) HIV transmission from hemophilic men to their heterosexual partners. In: Heterosexual Transmission of AIDS, pp. 35 53, Alexander, N.J., Gabelnick, H.L. and Spieler, J.M. (eds) Wiley-Liss, New York. 
Layon, J., Idris, A., Warsynski, M., Sherer, R., Brauner, D., Patch, O., McCulley, D. and Orris, P. (1984) Altered T-lymphocyte subsets in hospitalized intravenous drug abusers. Arch. intem. Med. 144: 1376-1380.

Learmont, J., Tindall, B., Evans, L., Cunningham, A., Cunningham, P., Wells, J., Penny, R., Kaldor, J. and Cooper, D.A. (1992) Long-term symptomless HIV-I infection in recipients of blood products from a single donor. Lancet 340: 863-867.

Lemaître, M., Guetard, D., Henin, Y., M ontagnier, L. and Zerial, A. (1990) Protective activity of tetracycline analogs against the cytopathic effect of the human immunodeficiency viruses in CEM cells. Res Virol. 141: 5-16.

Lemp, G.F., Payne, S.F., Rutherford, G.W., Hessol, N.A., Winkelstein, W., J r., Wiley, J.A., M oss, A.R., Chaisson, R.E., Chen, R.T., Feigel, D.W., Thomas, P.A . and Werdegar, D. (1990) Projections of AIDS morbidity and mortality in San Francisco. J. Am Med. Ass 263: 1497-1501.

Leonhard, H.-W. (1992) Alles nur ein I rrtum? neuepraxis Zeitschrift für Sozjalarbeit, Sozial padagogik und Sozial politik 22: 1429.

Lepage, P., Dabis, F., Hitimana, D.-G., M sellati, P., van Goethem, C., Stevens, A.-M ., N sengumuremyi, F., Bazubargira, A., Serufilira, A., De Clercq, A. and van de Perre P. (1991) Perinatal transmission of HIV-I: lack of impact of maternal HIV infection on characteristics of livebirths and on neonatal mortality in Kigali, Rwanda. AIDS 5: 295-300.

Lerner, W.D. (1989) Cocaine abuse and acquired immunodeficiency syndrome: tale of two epidemics Am J. Med. 87: 661-663.

Lesbian and Gay Substance A buse Planning Group ( 1991a) Gay Men, Lesbians and their Alcohol and Other Drug Use A Review of theLiterature San Francisco Department of Public Health, San Francisco, CA.

Lesbian and Gay Substance A buse Planning Group (1991b) San Francisco Lesbian, Gay and Bisexual SubstanceAbuseNeedsAssessment. San Francisco Department of Public Health, San Francisco, CA.

Levy, J. (1988) Mysteries of HIV: challenges for therapy and prevention. Nature (Lond.) 333: 519-522.

Lifschitz, M.H., Wilson, G.S., Smith, E.O. and Desmond, M.M. (1983) Fetal and postnatal growth of children born to narcotic-dependent women. J. Pediat. 102: 686-691.

Liversidge, A. (1989) AIDS: words from the front. Spin, 12: 54-56, 60-61, 81.

Lo, S.-C., Tsai, S., Benish, J.R., Shih, J.W.-K., Wear, D.J. and Wong, D.M . (1991) Enhancement of HIV-I cytocidal effects in CD4+ lymphocytes by the AIDSassociated mycoplasma. Science251: 1074-1076.

Louria, D.B. (1974) I nfectious complications of nonalcoholic drug abuse A. Rev. Med. 25: 219-231. 
Lowell, C.P. and Glaser, M.G. (1989) Long term survival of male homosexual patients with Kaposi's sarcoma. J. R. Soc Med. 82: 226-227.

Lu, W. and A ndrieu, J.-M . (1992) Similar replication capacities of primary human immunodeficiency virus type 1 isolates derived from a wide range of clinical sources. J. Virol. 66: 334-340.

Luca-M oretti, M . (1992) Specific behavioral factors among intravenous drug users have been shown to influence HIV seroconversion. J. intern. Med. Health Ass 1: 1-9.

Ludlam, C.A . (1992) AIDS: the alternative view (letter). Lancet 339: 1547-1548. Ludlam, C.A., Tucker, J., Steel, C.M., Tedder, R.S., Cheinsong-Popov, R., Weiss, R., McClelland, D.B.L., Phillip, I. and Prescott, R.J. (1985) Human T-lymphotropic virus type III (HTLV-III) infection in seronegative hemophiliacs after transfusion of factor VIII. Lancetii: 233-236.

Lui, K.-J, Darrow, W.W. and Rutherford, G. W, III (1988) A model-based estimate of the mean incubation period for AIDS in homosexual men. Science 240: 1333-1335.

Lusso, P, De Maria, A., Mainati, M., Lori, F., DeRocco, S.E., Baseler, M. and Gallo, R.C. (1991) Induction of CD4 and susceptibility to HIV-1 infection in human CD $8+T$ lymphocytes by human herpes virus 6 . Nature(Lond.) 349: 533-535.

Maddox, J. (1991a) AIDS research turned upside down. Nature(Lond.) 353: 297. Maddox, J. (1991b) Basketball, AIDS and education. Nature(Lond.) 354: 103.

Maddox, J. (1992a) Rage and confusion hide role of HIV. Nature(Lond.) 357: 188. Maddox, J. (1992b) Humbling of world's AIDS researchers. Nature(Lond.) 358: 367.

Madhok, R., Gracie, A., Lowe, G.D.O., Burnett, A., Froebel, K., Follet, E. and Forbes, C.D. (1986) I mpaired cell mediated immunity in haemophilia in the absence of infection with human immunodeficiency virus. Br. Med. J. 293: 978-980.

Mahir, W.S., Millard, R.E., Booth, J.C. and Flute, P.T. (1988) Functional studies of cell-mediated immunity in haemophilia and other bleeding disorders. Br. J. Haemat. 69: 367-370.

Maike, R.P. (1988) The fateand toxicity of butyl nitrites In: Health Hazards of Nitrite Inhalants pp. 15-27, Haverkos, H.W. and Dougherty, J.A. (eds) NIDA Research M onograph 83, N ational Institute on Drug A buse, Washington, DC.

Mann, J., Chin, J., Piot, P. and Quinn, T. (1988) The international epidemiology of AIDS. Sa. Am 259:82 89.

Mann, J. and Global AIDS Policy Coalition (1992) AIDS in theWorld. Harvard International AIDS Center.

Mansuri, M.M., Hitchcock, M.J.M., Buroker, R.A., Bregman, C.L.,Ghazzouli, 
I., Desiderio, J.V., Starrett, J.E., Stercycki, R.Z. and M artin, J.C. (1990) Comparison of in vitro biological properties and mouse toxicities of three thymidine analogs active against human immunodeficiency virus. Antimicrob. Agents Chemother. 34: 637-641.

Marion, S.A., Schechter, M.T., Weaver, M.S., M cLeod, W.A., Boyko, W.J ., Willoughby, B., Douglas, B., Craib, K.J.P. and O'Shaughnessy, M. (1989) Evidence that prior immune dysfunction predisposes to human immunodeficiency virus infection in homosexual men. J. AIDS 2: 178-186.

Marmor, M., Friedman-Kien, A.E., Laubenstein, L., Byrum, R.D., William, D.C., D'Onofrio, S. and Dublin, N. (1982) Risk factors for Kaposi's sarcoma in homosexual men. Lanceti: 1083-1087.

Marquart, K.-H, Engst, R. and Oehlschlaegel, G. (1991) An 8-year history of Kaposi's sarcoma in an HIV-negative bisexual man. AIDS 5: 346-348.

Martin, M.A., Byran, T., Rasheed, S. and Khan, A.S. (1981) Identification and cloning of endogenous retroviral sequences present in human DNA. Proc natn. Acad. Sci. U.S.A. 78: 4892-4896.

Marx, J . (1989) Circumcision may protect against the AIDS virus. Science 245: 470-471.

Mathé, G. (1992) Is the AIDS virus responsi ble for the disease? Biomed. Pharmacother. 46: 1-2.

Matheson, D.S., Green, B.J., Fritzler, M.J., Poon, M.-C., Bowen, T.J. and Hoar, D.I. (1987) Humoral immune response in patients with hemophilia. Clin. Immun. Immunopath. 4:41 50.

Mathur-Wagh, U., Enlow, R.W., Spigland, I., Winchester, R.J., Sacks, H.S., Rorat, E., Yancovitz, S. R., Klein, M.J., William, D.C. and Mildvan, D. (1984) Longitudinal study of persistent generalized lymphadenopathy in homosexual men: relation to acquired immunodeficiency syndrome Lance i: 1033-1038.

Mathur-Wagh, U., Mildvan, D. and Senie R.T. (1985) Follow-up of 41/2years on homosexual men with generalized lymphadenopathy. New Eng. J. Med. 313: $1542-1543$.

McDonough, R.J., Madden, J.J., Falek, A., Shafer, D.A., Pline M., Gordon, D., Bokof, P., Kuehnle, J.C. and M andelson, J. (1980) Alteration of T and null lymphocyte frequencies in the peripheral blood of human opiate addicts: in vivo evidence of opiate receptor sites on T Iymphocytes. J I mmun. 125: 2539-2543.

McDunn, S.H., Winter, J.N., Variakojis, D., Rademaker, A.W., von Roenn, J.H., Tallman, M.S., Gordon, L.I . and Bauer, K.D. (1991) Human immunodeficiency virus-related lymphomas: a possible association between tumor proliferation, lack of ploidy anomalies and immune deficiency. J. clin. Oncol. 9: 1334-1340. 
M cGrady, G.A., Jason, J.M . and Evatt, B.L. (1987) The course of the epidemic of acquired immunodeficiency syndrome in the U nited States hemophilia population. Am J. Epidemiol. 126: 25-30.

McKee, M. (1992) Defense puts AIDS virus on trial. The Recorder, J anuary 17.

McKegney, F.P., O'Dowd, M.A., Feiner, C., Selwyn, P., Drucker, E. and Friedland, G.H. (1990) A prospective comparison of neuropsychologic function in HIV-seropositive and seronegative methadone maintained patients. AIDS 4: 565-569.

McKeown, T. (1979) TheRoleof Medicine Dream, Mirage, or Nemesis? Princeton University Press, Princeton, NJ.

Medical Economics Data (1992) Physician's Desk Reference 1992. Medical Economics Co., M ontvale, NJ.

Menitove, J.E., Aster, R.H., Casper, J.T., Lauer, S.J., Gottschall, J.L., Williams, J.E., Gill, J.C., Wheeler, D.V., Piaskowski, V., Kirchner, P. and M ontgomery, R.R. (1983) T-lymphocyte subpopulations in patients with classic hemophilia treated with cryoprecipitate and lyophilized concentrates. New Eng. J. Med. 308: 83-86.

Merriam-Webster (eds) (1965) Webster's Third I nternational Didionary. G. and C. Merriam Co., Springfield, MA.

Messiah, A., Mary, J.Y., Brunet, J.B., Rozenbaum, W., Gentilini, M. and Valleron, A.J. (1988) Risk factors for AIDS among homosexual men in France Eur. J. Epidemid. 4: 68-74.

Mienties, G.H., Miedema, F., van A meijden, E.J., van den Hoek, A.A., Schellekens, P.T.A., Roos, M.T. and Coutinho, R.A. (1991) Frequent injecting impairs lymphocyte reactivity in HIV-positive and HIV-negative drug users. AIDS 5: 3541.

Mientjes, G.H., van Ameijden, E.J., van den Hoek, A.J.A.R. and Coutinho, R.A. (1992) I ncreasing morbi dity without rise in non-A IDS mortality among HIVinfected intravenous drug users in A msterdam. AIDS 6: 207-212.

Mills, J. and Masur, H. (1990) AIDS-related infections Sa. Am 263: 50-57.

Mims, C. and White, D.O. (1984) Viral Pathogenesisand I mmundogy. Blackwell Scientific Publications, Oxford.

Minvish, S.S. and Haverkos, H.W. (1987) Butylnitrite in theinduction of Kaposi's sarcoma in AIDS. New Eng. J. Med. 317: 1603.

Mirvish, S.S., Ramu, M.D. and Babcock, D.M . (1988) Indications from animal and chemical experiments of a carcinogenic role for isobutyl nitrite In: Health Hazards of Nitritel nhalants pp. 39-49, Haverkos, H.W. and Dougherrty, J.A. (eds) NIDA Research Monograph 83, National Institute on Drug A buse, Washington, DC.

Moberg, C.L. and Cohn, Z.A. (1991) RenéJules Dubos Sai. Am 264: 66-74. 
Mok, J.Q., DeRossi, A., A des, A.E., Giaquinto, C., Grosch-Woerner, I. and Peckham, C.S. (1987) Infants born to mothers seropositive for human immunodeficiency virus. Lance i: 1164-1168.

M ontagnier, L., Chermann, J.C., Barré-Sinoussi, F., Chameret, S., Gruest, J., Nugeyre, M.T., Rey, F., Dauguet, C., Axler-Blin, C., Vezinet-Brun, F., Rouzioux, C., Saimot, G.-A, Rozenbaum, W., Gluckman, J: C., Klatzmann, D., Vilmer, E., Griscelli, C., Foyer-Gazengel, C. and Brunet, J.B. (1984) A new human T-lymphotropic retrovirus: characterization and possible role in lymphadenopathy and acquired immune deficiency syndromes. In: Human T-Cel Leukemia/ Lymphona Virus, TheFamily of Human T-Lymphotropic Retroviruses: Their Rolein Malignandies and Assodiation with AIDS, pp. 363-379, Gallo, R. C, Essex, M.E. and Gross, L. (eds) Cold Spring Harbor Laboratory, Cold Spring Harbor, NY.

Moore, J.D.M., Cone, E.J. and Alexander, S.S. (1986) HTLV-III seropositivity in 1971-1972 parental drug abusers-a case of false positives or evidence of viral exposure? New Eng. J. Med. 314: 1387-1388.

M organ, M., Curran, J.W. and Berkelman, R.L. (1990) The future course of AIDS in the United States J. Am Med. Ass 263: 1539-1540.

M oss, A.R. (1987) AIDS and intravenous drug use: the real heterosexual epidemic. Br. Med. J. 294: 389-390.

M oss, A.R., Osmond, D., Bacchetti, P., Chermann, J., BarréSinoussi, F. and Carlson, J. (1987) Risk factors for AIDS and HIV seropositivity in homosexual men. Am J. Epidemiol. 125: 1035-1047.

M oss, A.R., Osmond, D. and Bacchetti, P. (1988) The cause of AIDS. Sience242: 997.

Muñoz, A., Vlahov, D., Solomon, L., Margolick, J.B., Bareta, J.C., Cohn, S., Astemborski, J. and Nelson, K.E. (1992) Prognostic indicators for development of AIDS among intravenous drug users. J. AIDS 5: 694-700.

Murray, H.W., Scavuzzo, D.A., Kelly, C.D., Rubin, B.Y. and Roberts, R.B. (1988) $\mathrm{T} 4+$ cell production of interferon gamma and the dinical spectrum of patients at risk for and with acquired immunodeficiency syndrome Arch. intem. Med. 148: 1613-1616.

Nakamura, N., Sugino, H., Takahara, K., J in, C., Fukushige S. and M atsubara, K. (1991) Endogenous retroviral LTR DNA sequences as markers for individual human chromosomes Cytogene. Cell Gene. 57: 18-22.

National Center for Health Statistics (1989) Monthly Vital Statistics Report. Department of Health and Human Services-Public Health Service-Publication No. (PMS) 89-1120, Hyattsville, MD.

National Center for Health Statistics (1992) Health, United States, 1991. Public Health Service, Hyattsville, MD. 
National Comission on AIDS (1991) TheTwin Epiderics of SubstanceUseand HIV. National Commission on AIDS, Washington, D.C.

National Institute on Drug A buse (1987) Trends in Drug AbuseR dated Hospital Emergency Room Episodes and Medical Examiner Casesfor Seleted Drugs DAWN 1976-1985. National Institute on Drug A buse, Bethesda, MD.

N ational Institute on Drug A buse (1990a) Annual Emergency Room Data 1990. U.S. Deparment of Health and Human Services.

National Institute on Drug A buse (1990b) Annual Medical Examiner Data 1990.

U.S. Department of Health and Human Services.

Nelson, J., Rodack, J., Fitz, R. and Smith, A.B. (1991) Magic reeling as worst nightmare comes true- he's getting sicker. National Enquire, December 10. Newell, G.R., Mansell, P.W.A., Wilson, M.B., Lynch, H.K., Spitz, M.R. and Hersh, E.M . (1985a) Risk factor analysis among men referred for possible acquired immune deficiency syndrome Prevent. Med. 14: 81-91.

Newell, G.R., Mansell, P.W.A., Spitz, M.R., Reuben, J.M. and Hersh, E.M. (1985b) Volatile nitrites: use and adverse effects related to the current epidemic of the acquired immune deficiency syndrome Am J. Med. 78:811-816.

Newell, G. R, Spit, M.R. and Wilson, M.B. (1988) Nitrite inhalants: historical perspective In: Health Hazards of Nitritel nhalants pp. 1-14, Haverkos, H.W. and Dougherty, J.A. (eds) NIDA Research Monograph 83, National Institute on Drug A buse, Washington, DC.

News Report (1992) HHS Secretary Sullivan: no cause for alarm over HIV-negative immune deficiency. AIDS Wedky, August 3: 2-5.

Nicholson, J. (1992) Rebel scientists: HIV doesn't cause AIDS. New York Post, J uly 23.

Novice, D. M, Brown, D.J.C., Log, A.S. F, Lloyd, J.C. and Thomas, H.C. (1986) Influence of sexual preference and chronic hepatitis $B$ virus infection on $T$ lymphocyte subsets, natural killer activity, and suppressor cell activity. J. Hepatol. 3: 363-370.

Nussbaum, B. (1990) Good Intentions How Big Business, Politics, and Medicineare Corrupting theFight Against AIDS. Atlantic M onthly Press, New York.

O'Brien, T. R, George J. R and Holmberg, S.D. (1992) Human immunodeficiency virus type 2 infection in the United States. J. Am Med. Ass 267: 2775-2779.

Office of National Drug Control Policy (1988) TheNational Narcotics Inteligence Consumers CormitteeReports Executive Office of the President, Washington, DC.

Oppenheimer, G.M . (1992) Causes, cases, and cohorts: the role of epidemiology in the historical construction of AIDS. In: AIDS: TheMaking of a ChronicDis ease, pp. 49-83, Fee, E. and Fox, D.M. (eds) University of California Press, Berkeley. 
Osterloh, J. and OIson, K. (1986) Toxicities of alkylnitrites. Ann. intern. Med. 104: 727.

Ostrow, D.G., van Raden, M.J., Fox, R., Kingsley, L.A., Dudley, J., Kaslow, R.A. and M ulticenter AIDS Cohort Study (M ACS) (1990) Recreational drug use and sexual behavior change in a cohort of homosexual men. AIDS 4: 759-765.

Ou, C.Y., Ciesielski, C.A., M yers, G., Bandea, C.I ., Luo, C.-C., Korber, B.T.M., Mullins, J.I., Schochetman, G., Berkelman, R. L., Economou, A. N., Witte, J.J., Furman, L. J., Satten, G.A., Macinnes, K.A., Curran, J.W., Jaffe, H.W., Laboratory I nvestigation Group and Epidemiologic I nvestigation Group (1992) M olecular epidemiology of HIV transmission in a dental practice Science256: 1165-1171.

Palca, J. (1990) A reliable animal model for AIDS. Sience248: 1078.

Palca, J. (1991a) Hints emerge from the Gallo probe Sience253: 728-731.

Palca, J. (1991b) The sobering geography of AIDS. Science252: 372-373.

Palca, J. (1992a) The case of the F lorida dentist. Science255: 392-394.

Palca, J. (1992b) CDC doses the case of the Florida dentist. Sience256:1130-1131.

Pallangyo, K.J., M baga, I.M., M ugusi, F., M bena, E., M halu, F.S., Bredberg, U. and Biberfeld, G. (1987) Clinical case definition of AIDS in A frican adults. Lancetii: 972.

Papadopolous-Eleopulos, E. (1988) Reappraisal of AIDS-Is the oxidation induced by the risk factors the primary cause? Med. Hypotheses 25: 151-162.

Peterman, T.A., Stoneburner, R.L., Allen, J.R., J affe, H.W. and Curran, J.W. (1988) Risk of human immunodeficiency virus transmission from heterosexual adults with transfusion-associated infections. J. Am Med. Ass. 259: 55-58.

Peters, B.S, Beck. J, Coleman, D.G., Wadsworth, M.J.H., M cGuiness, O., Harris, J.R.W. and Pinching, A.J. (1991) Changing disease patterns in patients with AIDS in a referral centre in the United Kingdom: the changing face of AIDS. Br. Med. J. 302: 203-207.

Pifer, L.L. (1984) Pneumocystis carinii: a misunderstood opportunist. Eur. J. din. Miorobiol. 3: 169-173.

Pillai, R., Nair, B.S. and Watson, R.R. (1991) AIDS, drugs of abuse and the immunesystem: a complex immunotoxicological network. Arch. Toxicol. 65: 609-617.

Piot, P., Plummer, F.A., M halu, F.S., Lamboray, J.-L, Chin, J. and M ann, J.M. (1988) AIDS: an international perspective Science239: 573-579.

Pitchenik, A.E., Burr, J., Suarez, M., Fertel, D., Gonzalez, G. and M oas, C. (1987) Human T-cell lymphotropic virus-III (HTLV-III) seropositivity and related disease among 71 consecutive patients in whom tuberculosis was diagnosed: a retrospective study. Am Rev. Resp. Dis 135: 875-879. 
Pitchenik, A.E., Burr, P., Laufer, M., Miller, G., Cacciatore, R., Bigler, W.J., Witte, J.J. and Cleary, T. (1990) Outbreaks of drug-resistant tuberculosis at AIDS centre Lance 336: 440-441.

Pluda, J.M., Yarchoan, R., Jaffe, E.S., Feuerstein, I.M., Solomon, D., Steinberg, S., Wyvill, K.M., Raubitschek, A., K atz, D. and Broder, S. (1990) Development of non-H odgkin lymphoma in a cohort of patients with severe human immunodeficiency virus (HIV) infection on long-term antiretroviral therapy. Ann. intern. Med. 113: 276-282.

Pollack, S., A tais, D., Y offe, G., K atz, R., Shechter, Y. and Tatarsky, I. (1985) Impaired immune function in hemophilia patients treated exclusively with cryoprecipitate: relation to duration of treatment. Am J. Hematol. 20: 1-6.

Ponce, H. (1992) Thesignificance of T lymphocytes in transfusion medicine Trans fusion Med. Rev. 16: 32-43.

Project I nform (1992) Is HIV the cause of AIDS? Project Disaussion Paper \# 5, San Francisco, May 27.

Puschel, K. and M ohsenian, F. (1991) HIV-I-prevalence among drug deaths in Germany. In: Drug Addidion and AIDS, pp. 89-96, Loimer, N., Schmid, R. and Springer, A. (eds) Springer-Verlag, N ew York.

Quinn, T.C., Mann, J .M., Curran, J.W. and Piot, P. (1986) AIDS in A frica: an epidemiological paradigm. Science234: 955-963.

Quinn, T.C., Piot, P., McCormick, J.B., Feinsod, F.M., Taelman, H., Kapita, B., Stevens, W. and Fauci, A.S. (1987) Serologic and immunologic studies in patients with AIDS in North A merica and A frica: the potential role of infectious agents as cofactors in human immunodeficiency virus infection. J. Am Med. Ass 257: 2617-2621.

Rappoport, J. (1988) AIDS INC. Human Energy Press, San Bruno, CA.

Ratner, R.A. (1992) Editor's N otes; Duesberg: An enemy of the people? MSDC Physician, J une/ J uly 6: 4-5.

Raymond, C.A. (1988) Combating a deadly combination: intravenous drug abuse, acquired immuno deficiency syndrome New Eng. J. Med. 259: 329-332.

Rezza, G., Lazzarin, A., Angarano, G., Zerboni, R., Sinicco, A., Salassa, B., Pristera, R., Barbanera, M., Ortona, L. and Aiuti, F. (1990) Risk of AIDS in HIV seroconverters: a comparison between intravenous drug users and homosexual males Eur. J. Epidemiol. 6: 99-101.

Richman, D.D., Fischl, M.A., Grieco, M.H., Gottlieb, M.S., Volberding, P.A., Laskin, O.L., Leedom, J.M., Groopman, J.E., Mildvan, D., Hirsch, M.S., Jackson, G.G., Durack, D.T., N usinoff-Lehrman, S. and the AZT Collaborative Working Group (1987) The toxicity of azidothymidine (AZT) in the treatment of patients with AIDS and AIDS-related complex. New Eng. J . Med. 317: 192-197. 
Rogers, M .F., Ou, C.-Y., Rayfield, M., Thomas, P.A., Schoenbaum, E.E., A brams, E., Krasinski, K., Selwyn, P.A., Moore J., Kaul, A., Grimm, K.T., Bamji, M., Schochetman, G., The New York City Collaborative Study of M aternal HIV Transmission and M ontefiori Medical Center HIV Perinatal Trans mission Study Group (1989) U se of the polymerase chain reaction for early detection of the proviral sequences of human immunodeficiency virus in infants born to seropositive mothers. New Eng. J. Med. 320: 1649-1654.

Root-Bernstein, R.S. (1990a) Do we know the cause(s) of AIDS? Perspect. Biol. Med. 33: 480-500.

Root-Bernstein, R.S. (1990b) Multiple-antigen-mediated autoimmunity (M AMA) in AIDS: a possible model for postinfectious autoimmune complications. Res Immun. 141: 321-339.

Root-Bernstein, R.S. (1990C) Non-HIV immunosuppressive factors in AIDS: a multifactorial, synergistic theory of AIDS etiology. Res Immun. 141: 815-838.

Rosenberg, M.J. and Weiner, J.M . (1988) Prostitutes and AIDS: a health department priority? Am J. Pub Health 78: 418-423.

Rowe, W.P. (1973) Genetic factors in the natural history of murine leukemia virus infection: G.H.A. Clowes Memorial Lecture Cancer Res 33: 3061-3068.

Rubin, H. and Temin, H. (1958) A radiological study of cell-virus interaction in the Rous sarcoma. Virology 7: 75-91.

Rubinstein, E. (1990) II: The untold story of HUT78. Saience248: 1499-1507.

Safai, B., Peralta, H., Menzies, K., Tizon, H., Roy, P., Flomberg, N. and Wolinsky, S. (1991) Kaposi's sarcoma among HIV-negative high risk population. VII I nternational Conferenceon AIDS, Florence, I taly.

Salahuddin, S.K., Nakamura, S., Biberfeld, P., Kaplan, M.H., M arkham, P.D., Larsson, L. and Gallo, R.C. (1988) Angiogenic properties of Kaposi's sarcoma-derived cells after long-term culture in vitro. Science242: 430-433.

Sande, M .A . (1986) Transmissions of AIDS. The case against casual contagion. New Eng. J. Med. 314: 380-382.

Sapura, J.D. (1968) The narcotic addict as a medical patient. Am J . Med. 45: 555-588.

Sarngadharan, M.G., Popovic, M., Bruch, L., Schupach, J. and Gallo, R. (1984) Antibodies reactive with Human T-lymphotropic retroviruses (HTLV-III) in the serum of patients with AIDS. Science224: 506-508.

Savitz, E.J . (1991) No magic cure, the war on AIDS produces few gains except on Wall Street. Barron's December 16: 10-29.

Savona, S., Nardi, M.A., Lenette, E.T. and Karpatkin, S. (1985) Thrombocytopenic purpura in narcotics addicts. Ann. intern. Med. 102: 737-741.

Scheper-Hughes, N. and Herrick, R. (1992) Ethical tangles: Cuba's highly controversial AIDS and HIV program raises thomy ethical issues New I ntema- 
tionalist (Oxford, U.K.), May: 35.

Schnittman, S.M., Psallidopoulos, M.C., Lane H.C., Thompson, L., Baseler, R, M., Massari, F., Fox, C.H., Salzman, N.P. and Fauci, A. (1989) The reservoir for HIV-I in human peripheral blood is a $\mathrm{T}$ cell that maintains expression of CD4. Science245: 305-308.

Schoch, R. (1992) Dad, I'm HIV positive Newswedk, August 17: 9.

Schüpach, J. (1986) First isolation of HTLV-III. Nature(Lond.) 321:119-120.

Schuster, C.R. (1984) Foreword. In: Cocaine Pharmacology, Effects and Treatment of Abuse, pp. 7-8, Grabowski, J. (ed.) NIDA Research M onograph 50, National Institute on Drug A buse, Washington, DC.

Schwartz, R.H. (1988) Deliberate inhalation of isobutyl nitrite during adolescence: a descriptive study. In: Health Hazards of Nitritel nhalants pp. 81-85, Haverkos, H.W. and Dougherty, J.A. (eds) NIDA Research Monograph 83, National Institute on Drug A buse, Washington, DC.

Schwitzer, G. (1992) The magical medical media tour. J. Am Med. Ass. 267: 1969-1971.

Scolaro, M., Durham, R. and Pieczenik, G. (1991) Potential molecular competitor for HIV. Lance 337: 731-732.

Seage, G.R., M ayer, K.H., Horsburgh, C.R., Holmberg, S.D., M oon, M.W. and Lamb, G.A. (1992) The relation between nitrite inhalants, unprotected receptive anal intercourse, and the risk of human immunodeficiency virus infection. J. Am Epideriol. 135:1-11.

Seligmann, M., Chess, L., Fahey, J.L., Fauci, A.S., Ladhmann, P.J ., L'age-Stehr, J., Ngu, J., Pinching, A.J ., Rosen, F.S., Spira, T.J. and Wybran, J. (1984) AIDS-an immunologic reevaluation. New Eng. J. Med. 311: 1286-1292.

Selik, R.M., Starcher, E.T. and Curran, J.W. (1987) Opportunistic diseases reported in AIDS patients: frequencies, associations, and trends. AIDS 1: 175-182.

Selik, R.M., Buehler, J.W., Karon, J.M., Chamberland, M.E. and Berkelman, R.L. (1990) Impact of the 1987 revision of the case definition of acquired immune deficiency syndrome in the U nited States. J. AIDS 3: 73-82.

Selwyn, P.A., Feingold, A.R., Hartel, D., Schoenbaum, E.E., Adderman, M.H., Klein, R.S. and Freidland, S.H. (1988) Increased risk of bacterial pneumonia in HIV-infected intravenous drug users without AIDS. AIDS 2: 267-272.

Selwyn, P.A., Hartel, D, Wasserman, W. and Drucker, E. (1989) I mpact of the AIDS epidemic on morbidity and mortality among intravenous drug users in a N ew York City methadone maintenance program. Am J. Publ. Health 79: 1358-1362.

Semple, M., Loveday, C., Weller, I. and Tedder, R. (1991) Direct measurement of viraemia in patients infected with HIV-I and its relationship to disease progression and zidovudine therapy. J. Med. Virol. 35: 38-45. 
Shannon, E., Booth, C., Fowler, D. and McBride, M. (1990) A loosing battle Time, December 3, 24: 4448.

Sharp, R.A., M orley, S.M., Beck, J.S. and U rquhart, G.E.D. (1987) Unresponsive to skin testing with bacterial antigens in patients with haemophilia A not apparently infected with human immunodeficiency virus (HIV) J. din. Path. 40: 849-852.

Shaw, G.M., Hahn, B.H., Arya, S.K., Groopman, J.E., Gallo, R.C. and WongStaal, F. (1984) M olecular characterization of human T-cell leukemia (lymphotropic) virustypellI in the acquired immune deficiency syndrome Sience 226:1165-1171.

Shenton, J. (1992) HIV, AIDS, and zidovudine Lance 339: 806.

Shigematsu, I., Yanagawa, H., Yamamoto, S.-I. and Nakae, K. (1975) Epidemiological approach to SM ON (Subacute M yelo-optico-neuropathy). J ap. J . Med. Sa. Bid. 28 (Suppl.): 23-33.

Shilts, R. (1987) And theBand Played On. St Martin's Press, N ew York.

Shilts, R. (1991) Gay troops in the Gulf War can't come out. San Francisco Chronide, February 2.

Shorter, E. (1987) TheHealth Century. Doubleday, N ew York.

Simmonds, P., Balfe, P., Peutherer, J. F, Ludlam, C.A., Bishop, J .O. and LeighBrown, A.J . (1990) Human immunodeficiency virus-infected individuals contain provirus in small numbers of peripheral mononuclear cells and at low copy numbers. J. Virol. 64: 864-872.

Smith, D.G. (1990) Thailand: AIDS crisis looms. Lance 335: 781-782.

Smith, G.D. and Phillips, A.N. (1992) Confounding in epidemiological studies: why “independent" effects may not beall they seem. Br. Med. J. 305: 757-759.

Smothers, K. (1991) Pharmacology and toxicology of AIDS therapies. TheAIDS Reader 1: 29-35.

Sonnabend, J.A. Witkin, S.S. and Purtillo, D.T. (1983) A multifactorial model for the development of AIDS in homosexual men. Ann. NY Acad. Sa. 437: 177-183.

Spira, T.J. and J ones, B.M . (1992) Is there another agent that causes low CD 4 counts and AIDS? J. Cell. Biochem (Suppl.) 16E: 56.

Sprent, J. (1977) Migration and Lifespan of Lymphocytes, in B and T cellsin Immune Recognition. J ohn Wiley and Sons, New York.

Spornraft, P., Froschl, M., Ring J., Meurer, M., Goebel, F.D., Ziegler-Heitbrock, H.W., Riethmüller, G. and Braun-Falco, O. (1988) T4/ T8 ratio and absolute T4 cell numbers in different clinical stages of K aposi's sarcoma in AIDS. Br. J. Derm 119: 1-9.

Stark, K., M uller, R., Gugenmoos-Holzmann, I., Deininger, S., M eyer, E. and Bienzle, U. (1990) HIV infection in intravenous drug abusers in Berlin: risk 
factors and time trends. Klin. Wochenschr. 68: 415-420.

Stehr-Green, J.K., Holman, R.C., Jason, J.M . and Evatt, B.L. (1988) Hemophiliaassociated AIDS in the U nited States, 1981 to September 1987. Am J. Pub Health 78: 439442.

Stehr-Green, J.K., J ason, J.M., Evatt, B.L. and Hemophilia-A ssociated AIDS Study Group (1989) Geographic variability of hemophilia-associated AIDS in the U nited States: effect of population characteristics. Am J. Hematol. 32: 178-183.

Steinbrook, R. (1992) Scientists infect monkeys with human AIDS virus. LosAnge lesTimes J une 12.

Stewart, G.T. (1968) Limitations of the germ theory. Lanceti: 1077-1081.

Stewart, G.T. (1989) Uncertainties about AIDS and HIV. Lance i: 1325.

St Louis, M.E., Conway, G.A., Hayman, C.R., Miller, C., Peterson, L.R. and Dondero, T.J . (1991) Human immunodeficiency virus infection in disadvantaged adolescents. J. Am Med. Ass 266: 2387-2391.

Stoneburner, R. L., Des Jarlais, D.C., Benezra, D., Gorelkin, L., Sotheran, J. L., Friedman, S. R., Schultz, S., M armor, M., Mildvan, D. and M aslansky, R. (1988) A larger spectrum of severe HIV-I-related disease in intravenous drug users in N ew York City. Science242: 916-919.

Stutman, O. (1975) I mmunodepression and malignancy. Adv. Cancer Res. 22: 261-422.

Sullivan, J.L., Brewster, F.E., Brettler, D.B., Forsberg, A.D., Cheeseman, S.H., Byron, K.S., Baker, S.M., Willitts, D.L., Lew, R.A. and Levine, P.H. (1986) Hemophiliac immunodeficiency: influence of exposure to factor VIII concentrate, LAV/ HTLV-III, and herpes viruses J. Pediat. 108: 504-510.

Swanson, C. E, Cooper, D.A. and A ustralian Zidovudine Study Group (1990) Factors influencing outcome of treatment with zidovudine of patients with AIDS in Australia. AIDS 4: 749-757.

Taelman, H., Kagame, A., Batungwanayo, J., Booaerts, J., Clerinx, J., Allen, S. and van de Perre, P. (1991) Tuberculosis and HIV infection (letter). Br. Med. J . 302: 1206.

Tedder, R.S., Semple, M.G., Tenant-F lowers, M. and Loveday, C. (1992) HIV, AIDS, and zidovudine Lance 339: 805.

Temin, H.M. (1990) Proof in the pudding. Policy Review 54: 71-72.

Temin, H. and Mitzutani, S. (1970) RNA-dependent DNA polymerase in virions of Rous sarcoma virus. Nature(Lond.) 226:1211-1213.

Terry, C.E. and Pellens, M. (1928) TheOpium Problem Bureau of Social Hygiene of New York.

The Software Toolworks World Atlas ${ }^{T M}$ (1992) Population Growth Rate Chatsworth, CA. 
Thompson, D. (1990) A long battle with AIDS. Time, J uly 2: 42-43.

Till, M. and M acDonnell, K.B. (1990) M yopathy with human immunodeficiency virus type 1 (HIV-I) infection: HIV-I or zidovudine? Ann. intern. Med. 113: 492-494.

Toufexis, A. (1991) Innocent victims. Time, May 13, 19: 56-60.

Treichler, P.A. (1992) The country and the city: dreams of Third World AIDS. In: AIDS: TheMaking of a Chronic Disese pp. 386-412, Fee, E. and Fox, D.M. (eds) University of California Press, Berkeley.

Tsoukas, C., Gervais, F., Shuster, J., Gold, P., O'Shaughnessy, M. and RobertGuroff, M. (1984) Association of HTLV-III antibodies and cellular immune status of hemophiliacs. New Eng. J. Med. 311: 1514-1515.

Turner, C.F., Miller, H.G. and M oses L.E. (1989) AIDS, Sexual Behavior and Intravenous Drug Use National A cademy Press, Washington, DC.

U.S. Department of Health and Human Services (1990) National HIV SerosurvillanceSummary. Centers for Disease Control, Atlanta.

Valentine, C.B., Weston, R., Kitchen, V., Main, J., M oncrieff, K.C. and A ber, V.R. (1992) A nonymous questionnaire to assess consumption of prescribed and alternative medication and patterns of recreational drug use in a HIV population. AIDS Wedky, August 10: 18.

Vandenbroucke, J.P. and Pardoel, V.P.A.M . (1989) An autopsy of epidemiologic methods: the case of "poppers" in the early epidemic of the acquired immunodeficiency syndrome (AIDS). J. Epideriol. 129: 455-457.

van Griensven, G.J.P., Tielman, R.A.P., Goudsmit, J., van der Noorda, J., de Wolf, F., de Vroome, E.M.M. and Coutinho, R.A. (1987) Risk factors and prevalence of HIV antibodies in homosexual men in The $\mathrm{N}$ etherlands. Am J. Epidemid. 125: 1048-1057.

van Griensven, G.J.P., Vroome, E.M.M., de Wolf, H., Goudsmit, J., Roos, M. and Coutinho, R.A. (1990) Risk factors for progression of human immunodeficiency virus (HIV) infection among seroconverted and seropositive homosexual men. Am J. Epideriol. 132: 203-210.

van Leeuwen, R., van den Hurk, P.J., J obis, G.J., van der Wouw, P.A., Reiss, P., Eeftinck Schattenkerk, J.K.M., Danner, S.A. and Lange, J.M.A. (1990) Failure to maintain high-dose treatment regimens during long-term use of zidovudine in patients with symptomatic human immunodeficiency virus type 1 infection. Genitourin Med. 66: 418-422.

van Voorhis, B.J., M artinez, A., M ayer, K. and Anderson, D.J. (1991) Detection of human immunodeficiency virus type 1 in semen from seropositive men using culture and polymerase chain reaction deoxyribonucleic acid amplification techniques Fertil. Steril. 55: 588-594.

Varmus, H. (1988) Regulation of HIV and HTLV gene expression. GenesDev. 2: 
1055-1062.

Vermund, S. (1991) Changing estimates of HIV-I seroprevalence in the U nited States. J. NIH Res 3: 77-81.

Villinger, F., Powell, J. D, J ehuda-Cohen, T., Neckelmann, N., Vuchetich, M., De, B., Folks, T.M., M cClure, H.M. and Ansari, A.A. (1991) Detection of occult simian immunodeficiency virus SIV smm infection in asymptomatic seronegative nonhuman primates and evidence for variation in SIV gag sequence between in vivo- and in vitro-propagated virus J. Vird. 65: 1855-1862.

Voevodin, A. (1992) HIV screening in Russia (letter). Lance 339: 1548.

Volberding, P.A., Lagakos, S.W., Koch, M .A., Petinelli, C., M yers, M. W, Booth, D.K., Balfour, H. H., J R, Reichman, R.C., Bartlett, J.A., Hirsch, M.S., M urphy, R.L., Hardy, W.D., Soeiro, R., Fischl, M.A., Bartlett, J.G., Merigan, T.C., Hyslop, N.E., Richman, D.D., Valentine, F.T., Corey, L. and AIDS Clinical Trial Group (1990) Zidovudine in asymptomatic human immunodeficiency virus infection: a controlled trial in persons with fewer than 500 CD4-positive cells per cubic millimeter. New Eng. J. Med. 322: 941-949.

Waldholz, M. (1992) Stymied Science: New Discoveries Dim Drug M akers' Hopes for Quick AIDS Cure Wall Stree J ournal, May 26.

Walker, R.E., Parker R.I., Kovacs J.A., M asur, H., Lane, H.C., Carleton, S., Kirk, L.E., Gralnick H.R. and Fauci, A.S. (1988) A naemia and erythropoiesis in patients with the acquired immunodeficiency syndrome (AIDS) and Kaposi sarcoma treated with zidovudine Ann. intern. Med. 108: 372-376.

Walton, J., Beeson, P.B. and Scott, R.B. (eds) (1986) TheOxford Companion to Mediane Oxford University Press, Oxford, New York.

Wang, L.-H, Galehouse, D., M ellon, P., Duesberg, P., M ason, W. and Vogt, P.K. (1976) M apping oligonucleotides of R ous sarcoma virus RNA that segregate with polymerase and group-specific antigen markers in recombinants. Proc nat. Acad. So. U.S.A. 73: 3952-3956.

Ward, J.W., Bush, T.J., Perkins, H.A., Lieb, L.E., Allen, J.R., Goldfinger, D., Samson, S.M., Pepkowitz, S.H., Fernando, L.P., Holland, P.V. and Study Group from the AIDS Program (1989) The natural history of transfusion-associated infection with human immunodeficiency virus, New Eng. J. Med. 321: 947-952.

Weber, J.N., Rogers, L.A., Scott, K., Berrie, E., Harris, J.R.W., Wadsworth, J., M oshtael, O., M cM anus, T., J effries, D.J. and Pinching, A.J. (1986) Threeyear prospective study of HTLV-III/ LAV infection in homosexual men. Lanceti: 1179-1182.

Weber, R., Ledergerber, W., Opravil, M., Siegenthaler, W. and Lüthy, R. (1990) Progression of HIV infection in misusers of injected drugs who stop injecting or follow a programme of maintenance treatment with methadone $\mathrm{Br}$. Med. J. 301: 1361-1365. 
Weiss, R.A. (1988) A virus in search of a disease Nature(Lond.) 333: 497-498. Weiss, R.A. (1989) AIDS: defective viruses to blame? Nature(Lond.) 338: 458. Weiss, R. (1991) Provenance of HIV strains. Nature(Lond.) 349: 374.

Weiss, R. and J affe, H. (1990) D uesberg, HIV and AIDS. Nature(Lond.) 345: 659-660.

Weiss, R, Teich, N., Varmus, H. and Coffin, J. (1985) Moleaular Biology of RNA Tumor Viruses Cold Spring Harbor Press, Cold Spring Harbor, N.Y.

Weiss, S.H. (1989) Links between cocaine and retroviral infection. J. Am Med. Ass 261: 607-609.

Weiss, S.H., Goedert, J.J., Gartner, S., Popovic, M., Waters, D., M arkam, P., Di M arzo Veronesi, F., Gall, M.H., Gallo, R.C. and Blattner, W.A. (1988) Risk of human immunodeficiency virus (HIV-I) infection among laboratory workers. Science239: 68-71.

Weller, R. (1955) Zur Erzeugung von Pneumocystosen im Tierversuch. Zeitschrift fur Kinderheilkunde 76: 366-378.

Weniger, B.G., Limpakarnjanarat, K., U ungchusak, K., Thanprasertsuk, S., Choopanya, K., Vanichseni, S., Uneklabh, T., Thongcharoen, P. and Wasi, C. (1991) The epidemiology of HIV infection and AIDS in Thailand. AIDS 5 (Suppl. 2): S71-s85.

Weyer, J. and Eggers, H.J. (1990) On the structure of the epidemic spread of AIDS: the influence of an infectious coagent. Zentral bl. Bakterid. 273: 52-67.

Widy-Wirski, R., Berkley, S., Downing, R., Okware, S., Recine, U., Mugerwas, R., Lwegaba, A. and Sempala, S. (1988) Evaluation of the WHO clinical case definition for AIDS in U ganda. J. Am Med. Ass 260: 3286-3289.

Williams, A.E., Fang, C.T. and Sandler, G. (1990) HTLV-I/II and blood transfusion in the U nited States. In: Human Retrovirology: HTLV, pp. 349-362, Blattner, W.A. (ed.) Raven Press, New York.

Williford Pifer, L.L., Woods, D.R., Edwards, C.C., J oyner, R.E., A nderson, F.J. and A rheart, K. (1988) Pneumocytiscarinii serologic study in pediatric acquired immunodeficiency syndrome Am J. Dis Child. 142: 36-39.

Winkelstein, W., J r., Lyman, D.H., Padian, N., Grant, R., Samuel, M., Wiley, J.A., A nderson, R.E., Lang, W, Riggs, J. and Levy, J.A. (1987) Sexual practices and risk of infection by the human immunodeficiency virus: the San Francisco men's health study. J. Am Med. Ass 257: 321-325.

Witte, J.J. and Wilcox, K.R. (1991) U pdate: transmission of HIV infection during invasive dental procedures_Florida. Marb Mart Wedly Rep. 40: 377-381.

Wood, R.W. (1988) The acute toxicity of butyl nitrites In: Hellth Hazards of Nitrite I nhalants, pp. 28-38, Haverkos, H.W. and Dougherty, J.A. (eds) NIDA Research M onograph 83, National Institute on Drug A buse, Washington, DC. 
World Health Organization (1992a) WHO-Report No. 32: AIDS Sunvillancein Europe (Situation by 31st December 1991). World Health Organization, Geneva.

World Health Organization (1992b) Acquired I mmunodeficiency Syndrome(AIDS) Data as of I J anuary 1992. World Health Organization, Geneva.

Yarchoan, R. and Broder, S. (1987a) A ntiretroviral therapy for AIDS. New Eng. J. Med. 317: 630.

Yarchoan, R. and Broder, S. (1987b) Development of antiretroviral therapy for the acquired immunodeficiency syndrome and related disorders. New Eng. J. Med. 316: 557-564.

Yarchoan, R., Pluda, J.M., Perno, C.-F., M itsuya, H. and Broder, S. (1991) A ntiretroviral therapy of human immunodeficiency virus infection: current strate gies and challenges for the future Blood 78: 859-884.

\section{Note added in proof:}

Ten years after designating AIDS infectious based on clusters of cases, the CDC published in 1995: "Such clusters may be difficult to identify because most persons with AIDS have had contact with many different people In particular, drug users and homosexual and bisexual men may have had contact with hundreds of partners that they did not know very well." (Drotman, Peterman and Friedman-Kien, 1995).

Drotman, D.P., T.A. Peterman and A.E. Friedman-Kien, 1995. Kaposi's sarcoma. How can epidemiology help find the cause? Dermatoepidemiology 13: 575-582 
INFECTIOUS AIDS: HAVE WE BEEN MISLED? 